: : : : : : : : : : : : : : : : : : : : : :

$\left.\begin{array}{l}0 \\ \vdots \\ \vdots\end{array}\right)$

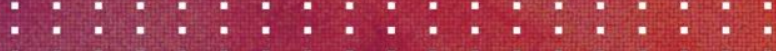

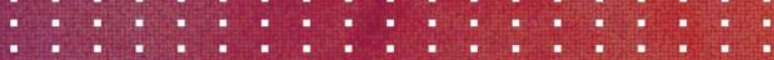

\title{
IDENTIFICAÇÃO DOS ASPECTOS ANTROPOTECNOLÓGICOS NO PLANO DE AUXILIO MÚTUO (PAM)
}

ROSÂNGELA DE FRANÇA BAIL JOÃO LUIZ KOVALESKI REGINA NEGRI PAGANI
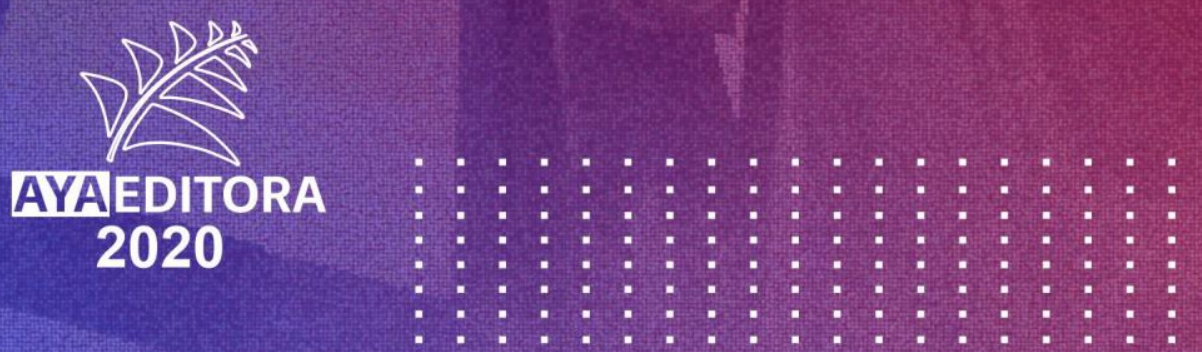


\title{
ROSÂNGELA DE FRANÇA BAIL \\ JOÃO LUIZ KOVALESKI \\ REGINA NEGRI PAGANI
}

\author{
Editor Chefe: \\ Bibliotecária: \\ Capa: \\ Diagramação: \\ Revisão:
}

\author{
Prof $^{\circ}$ Dr. Adriano Mesquita Soares \\ Bruna Cristina Bonini - CRB 9/1347 \\ Designed by jcomp - br.freepik.com \\ Ana Lucia Ribeiro Soares \\ Os Autores
}

\section{Conselho Editorial}

Prof. ${ }^{\text {a }}$ Dr. ${ }^{-a}$ Andreia Antunes da Luz - Faculdade Sagrada Família

Prof. - Dr. ㅁ Daiane Maria De Genaro Chiroli - Universidade Tecnológica Federal do Paraná

Prof. ${ }^{\circ}$ Dr. Gilberto Zammar - Universidade Tecnológica Federal do Paraná

Prof. ${ }^{a}$ Ma. Jaqueline Fonseca Rodrigues - Faculdade Sagrada Família

Prof. ${ }^{\circ}$ Dr. João Luiz Kovaleski - Universidade Tecnológica Federal do Paraná

Prof. ${ }^{\circ}$ Me. Jorge Soistak - Faculdade Sagrada Família

Prof. ${ }^{\circ}$ Me. Luiz Henrique Domingues - Universidade Norte do Paraná

Prof. ${ }^{\circ}$ Me. Myller Augusto Santos Gomes - Universidade Estadual do Centro-Oeste

Prof. ${ }^{\text {a }}$ Dr. ${ }^{\text {a }}$ Pauline Balabuch - Faculdade Sagrada Família

Prof. ${ }^{\circ}$ Me. Pedro Fauth Manhães Miranda - Centro Universitário Santa Amélia

Prof. - Dr. ${ }^{\text {a }}$ Regina Negri Pagani - Universidade Tecnológica Federal do Paraná

Prof. ${ }^{\circ}$ Me. Rudy de Barros Ahrens - Faculdade Sagrada Família

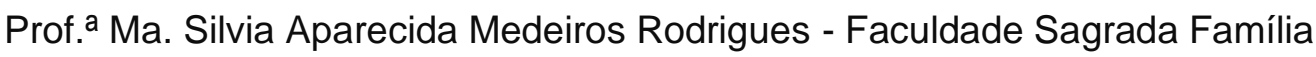

Prof. ${ }^{\text {a }}$ Dr. ${ }^{\text {a }}$ Silvia Gaia - Universidade Tecnológica Federal do Paraná

Prof. ${ }^{\text {a }}$ Dr. ${ }^{\text {a }}$ Sueli de Fátima de Oliveira Miranda Santos - Universidade Tecnológica Federal do Paraná

Prof. ${ }^{\text {a }}$ Dr. ${ }^{\text {a }}$ Thaisa Rodrigues - Instituto Federal de Santa Catarina

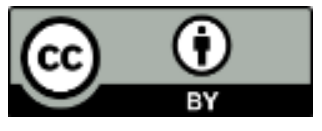




\section{IDENTIFICAÇÃO DOS ASPECTOS ANTROPOTECNOLÓGICOS NO PLANO DE AUXÍLIO MÚTUO (PAM)}

\begin{tabular}{|c|c|}
\hline Editor Chefe: & Prof $^{\circ}$ Dr. Adriano Mesquita Soares \\
\hline Bibliotecária: & Bruna Cristina Bonini - CRB 9/1347 \\
\hline Capa: & Designed by jcomp - br.freepik.com \\
\hline Diagramação: & Ana Lucia Ribeiro Soares \\
\hline Revisão: & Os Autores \\
\hline
\end{tabular}

B153 Bail, Rosângela de França

Identificação dos aspectos antropotecnológicos no Plano de Auxílio Mútuo (PAM)./ Rosângela de França Bail; João Luiz Kovaleski; Regina Negri Pagani. -- Ponta Grossa: Aya, 2020. 99 p.. -- ISBN: 978-65-88580-06-6

Formato: PDF

Requisitos de sistema: Adobe Acrobat Reader.

Modo de acesso: World Wide Web.

DOI 10.47573/aya.88580.1.4

1. Atropologia. 2. Antropologia empresarial. 3. Transferência de tecnologia. 4. Serviços médicos de emergência. 5. Ergonomia. I.

Kovaleski, João Luiz. II. Pagani, Regina Negri. III. Título

\section{AYA Editora $\odot$}

+55 (42) 3086-3131

国 contato@ayaeditora.com.br

回 https://ayaeditora.com.br

Rua: João Rabello Coutinho, 557

Ponta Grossa - Paraná - Brasil

84.071-150 


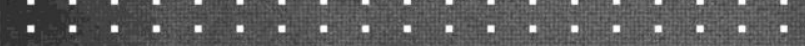

: : : : : : : : : : : : : : : :

$\vdots: \vdots: \vdots: \vdots: \vdots \vdots: \vdots: \vdots \vdots: \vdots \vdots \vdots$

$\div: \vdots: \vdots: \vdots: \vdots: \vdots: \vdots \vdots \vdots: \vdots$

\section{IDENTIFICAÇĀO DOS ASPECTOS ANTROPOTECNOLÓGICOS NO PLANO DE AUXILIO MÚTUO (PAM)}

ROSÂNGELA DE FRANÇA BAIL JOÃO LUIZ KOVALESKI REGINA NEGRI PAGANI

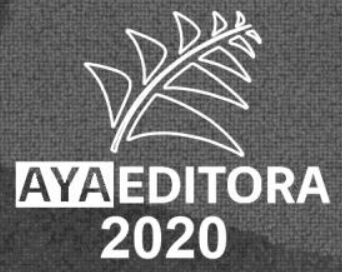




\section{SUMÁRIO}

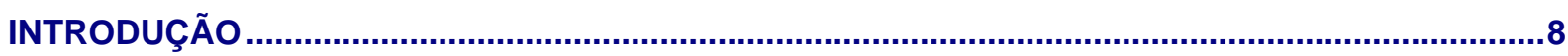

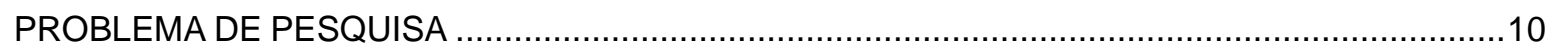

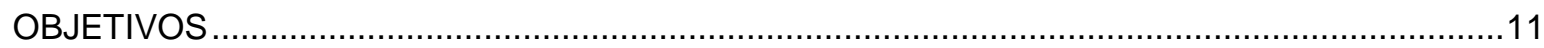

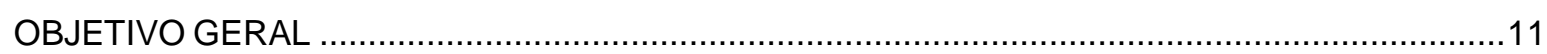

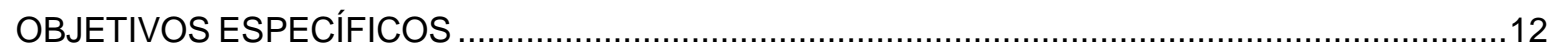

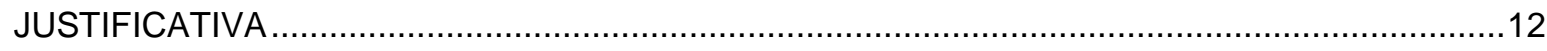

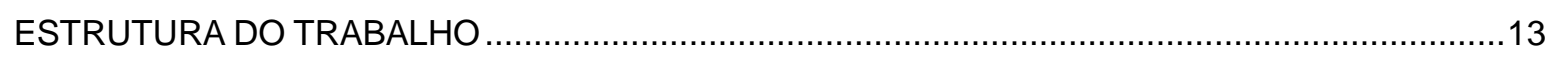

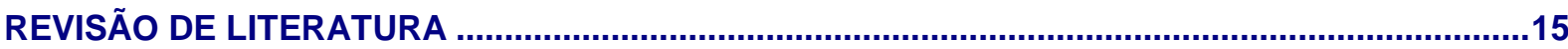

TRANSFERÊNCIA DE CONHECIMENTO E TECNOLOGIA …................................................ 15

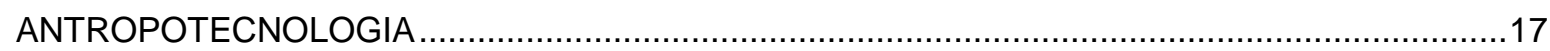

SERVIÇOS DE EMERGÊNCIA DE ATENDIMENTO PRÉ-HOSPITALAR ....................................22

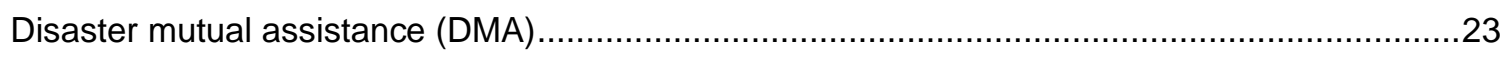

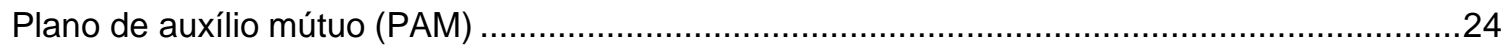

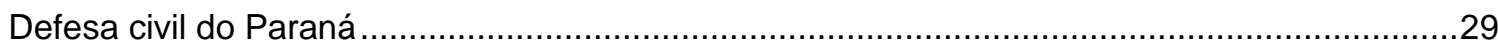

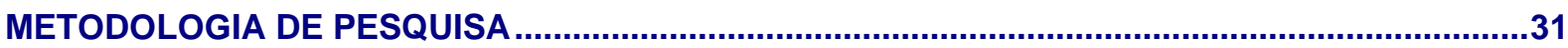

PROCEDIMENTO DE ELABORAÇÃO DA REVISÃO DE LITERATURA …....................................32

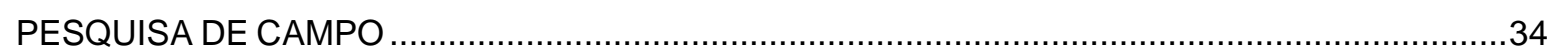

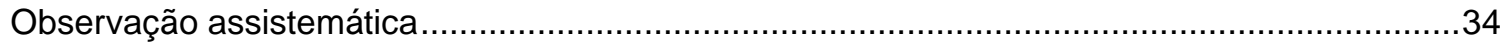

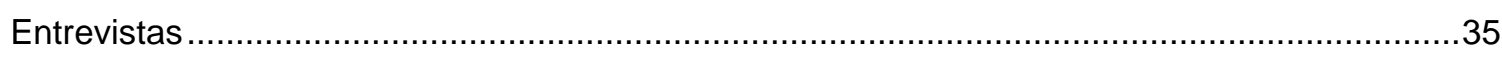

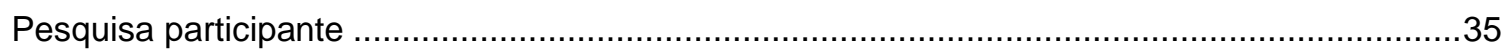

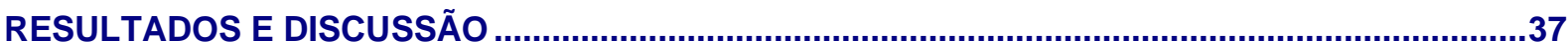

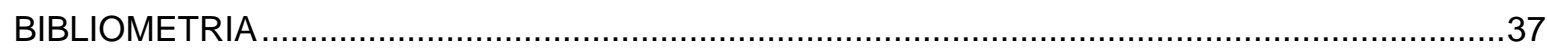

PLANO DE AUXÍLIO MÚTUO (PAM) NO BRASIL E NO ESTADO DO PARANÁ .............................43

Plano de auxílio mútuo (PAM) em Ponta Grossa, no Paraná ……..............................................47

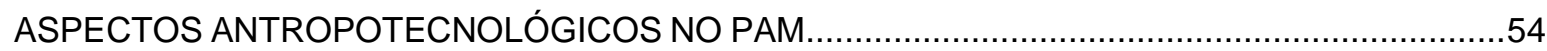

Pontos fortes e fracos apontados pelas empresas participantes .............................................58

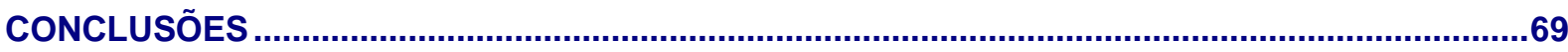

REFERÊNCIAS

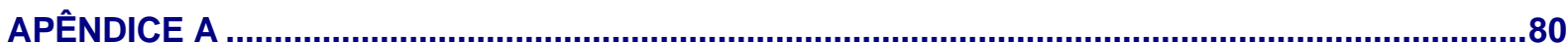

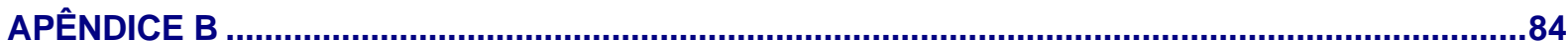

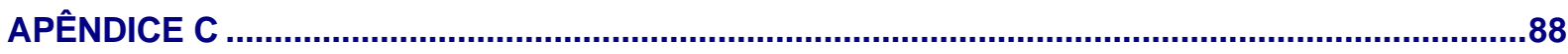

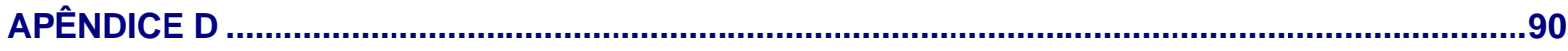

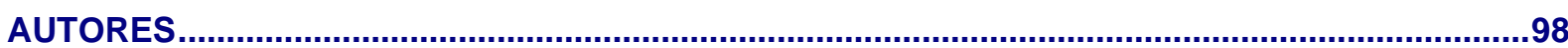




\section{RESUMO}

\section{Como citar:}

BAIL, Rosângela de França; KOVALESKI, João Luiz; PAGANI, Regina Negri. Identificação dos aspectos antropotecnológicos no plano de auxílio mútuo (PAM). Ponta Grossa: AYA Editora, 2020.

A antropotecnologia estuda a adaptação do indivíduo ao processo de produção, enfatizando a complexidade da relação entre homem, máquina e tecnologia, relacionando-a com o bem-estar do ser humano. Este trabalho objetiva estudar como os aspectos antropotecnológicos estão inseridos no Plano de Auxílio Mútuo (PAM), comparado a atuação do Disaster Mutual Assistance (DMA), norte americano, que desenvolve trabalhos similares ao projeto brasileiro. O PAM é uma instituição sem fins lucrativos, que visa, o estabelecimento e a manutenção dos relacionamentos interpessoais, e interação dos integrantes, com as autoridades federais, estaduais e municipais responsáveis pela resposta às emergências. O presente estudo, tem como objetivos específicos: identificar as características da antropotecnologia e a transferência de conhecimento e tecnologia (TCT), descrever a origem do PAM, estabelecer uma comparação entre o DMA e o PAM e buscar as evidências antropotecnológicas no PAM. Para alcançar tais objetivos, foi realizada uma pesquisa bibliográfica exploratória, que adotou a estratégia de revisão sistemática de literatura. Para a pesquisa de campo, foi realizada coletas de dados junto ao PAM do Brasil e no Estado do Paraná, visando observar sua origem, seu processo evolutivo e seus principais resultados. Na pesquisa de campo final, foi estudado, mais detalhadamente, - caso do PAM, em Ponta Grossa - PR. E os resultados mostram que a antropotecnologia está ligada a todas as atividades do PAM, seja, no ambiente de trabalho industrial, nos treinamentos oferecidos aos colaboradores, nos relacionamentos interpessoais, na transferência do conhecimento e tecnologia nas ações do PAM, junto às empresas parceiras e demais participantes.

Palavras-chave: Antropotecnologia. Transferência de Conhecimento e Tecnologia. Serviços de Emergência. Plano de Auxílio Mútuo 


\section{ABSTRACT}

Anthropotechnology studies the adaptation of the individual to the production process, emphasizing the complexity of the relationship between man, machine and technology, relating it to the well-being of the human being. This work aims to study how the anthropotechnological aspects are inserted in the Mutual Assistance Plan (PAM), compared to the North American Disaster Mutual Assistance (DMA), which works similar to the Brazilian project. WFP is a non-profit institution that seeks to establish and maintain interpersonal relationships and member interaction with federal, state, and municipal authorities responsible for responding to emergencies. The present study has as specific objectives: to identify the characteristics of anthropotechnology and the transfer of knowledge and technology (TCT), to describe the origin of the MAP, to establish a comparison between the MAP and the MAP and to look for the anthropotechnological evidences in the MAP. To reach these objectives, an exploratory bibliographical research was carried out, which adopted the strategy of systematic literature review. For the field research, data were collected from the PAM of Brazil and the State of Paraná, aiming to observe its origin, its evolutionary process and its main results. In the final field research, the case of PAM, in Ponta Grossa - PR, was studied in more detail. And the results show that anthropotechnology is linked to all the activities of WFP, be it in the industrial work environment, the training offered to employees, in interpersonal relationships, in the transfer of knowledge and technology in the actions of WFP, with partner companies and other participants.

Key-words: Anthropotechnology. Knowledge and Technology Transfer. Emergency Services. Plano de Auxílio Mútuo. 


\section{INTRODUÇÃO}

O trabalho sempre esteve presente na sociedade como fator primordial, não somente de subsistência, mas também na valorização pessoal, social e cultural do ser humano. O homem passa mais tempo envolvido em atividades com finalidades econômicas do que em qualquer outra atividade. No auge da primeira Revolução Industrial, a jornada de trabalho chegava a alcançar entre 50 a 56 horas semanais, isso incluía o trabalho de homens, mulheres e crianças que ficavam expostos a condições insalubres e sub-humanas (TEIGER, 2006).

A partir da sistematização dos meios produtivos, protagonizada por Taylor e por Ford através do modelo econômico denominado Fordismo, o trabalho humano passou por uma intensa mudança, tanto em função das tarefas como pelo desenvolvimento da mecanização na produção industrial. Mais adiante na história, com o advento das novas tecnologias caracterizadas pela inserção da automação em processos industriais, e pelos processadores de texto e planilhas eletrônicas nos sistemas organizacionais, mais uma onda de inovações alcança o mundo do trabalho humano.

Neste contexto, Wisner foi um dos primeiros pesquisadores a estudar aspectos e condições do trabalho na perspectiva da antropotecnologia, dedicando suas experiências em encontrar mecanismos que pudessem mudar e melhorar a vida dos trabalhadores. Em sua convicção, ao avaliá-los, pôde perceber o que deveria ser feito, de modo que os dispositivos de produção fossem adaptados às características humanas. Para ele, o trabalho estava além dos sistemas políticos, econômicos e religiosos de um país, suas pesquisas ajudaram a abrir um espaço para a ergonomia e, provavelmente, permitir-lhe conquistar e caracterizar os fundamentos antropotecnológicos do trabalho. (SANTOS, 1997).

A antropotecnologia contextualiza o homem, seu ambiente de trabalho e a transferência das novas tecnologias e seus impactos na vida humana. Pois, analisa e complementa aspectos ergonômicos, de modo a adaptar os trabalhadores às 
máquinas, de forma a obter segurança e conforto no ambiente laboral. (BINDER, 1999).

Conforme os estudos sobre antropotecnologia, transferência de tecnologia e ergonomia foram avançando, desenvolveu-se a visão Antropotecnológica, composta por mecanismos que direcionam a avaliação operacional nas empresas, onde aspectos como postos de trabalho, quantidades de horas trabalhadas, função, sexo, idade, exposições aos riscos, remuneração, condições oferecidas pela empresa quanto aos treinamentos e maquinários disponíveis, entre outros fatores, foram analisados. (WISNER, 1985).

Diante dos estudos realizados, novos conceitos de conforto, saúde e segurança do trabalho foram traçados, bem como o desenvolvimento de ações como treinamentos de capacitação e conscientização de trabalhadores que visassem uma cultura de prevenção. Além das questões preventivas internas das empresas, outros aspectos foram desenvolvidos por parte das lideranças, como as preocupações com efeitos climáticos e adversos, estudando os impactos que grandes incêndios, desabamentos, nevascas, tsunamis e furações, entre outros (PROENÇA, 1996).

Com o intuito de que as ações fossem integradas por parte das empresas e juntamente com os organismos de apoio a desastres, houve assim, a primeira ideia sobre criação do Disaster Mutual Assistance (DMA), no ano de 1844, na cidade da Nova Escócia, no Canadá.

No Brasil, um projeto semelhante foi criado a partir de 1978, de forma documental, conhecido como Plano de Auxílio Mútuo - PAM (SILVA, 2008). Entretanto, somente foi colocado em prática em 1984, na cidade de Cubatão, Litoral de São Paulo.

O PAM tem por finalidade a atuação de forma conjunta com seus integrantes, que são: o Corpo de Bombeiros (na promoção e otimização das ações de respostas às emergências envolvendo o PAM); Órgãos como a Defesa Civil (no apoio e mobilização e de recursos humanos e materiais para suporte aos desabrigados envolvidos nos eventos adversos); Indústrias (devem promover e participar dos treinamentos, assim como, ter sempre pronto o kit mínimo de materiais e equipamentos de apoio); Universidades (atuam com a elaboração de pesquisas e 
projetos de extensão), e; Comunidade (participam dos treinamentos através dos colaboradores atuando como multiplicadores de informações) (CASA MILITAR, 2018).

Estudos relacionados à antropotecnologia estão inteiramente ligados à forma como o colaborador se adapta às novas tecnologias, avaliando o exercício de suas funções, relações humanas e de bem estar no trabalho. Neste contexto, as atividades realizadas pelos atuantes do PAM conduzem todos esses processos, pois coloca em prática a troca de experiências e modelos tecnológicos de máquinas e equipamentos, aspectos de prevenção, equipamentos de segurança, resultando em práticas positivas que são compartilhadas por todos os participantes do grupo.

Embora seja evidenciada na literatura a presença da antropotecnologia como área de estudos para bem-estar e segurança humana, não há estudos que identifiquem as contribuições da antropotecnologia nas atividades do PAM.

\section{PROBLEMA DE PESQUISA}

Os conceitos antropotecnológicos podem ser observados em tempos atuais em várias áreas do conhecimento, como engenharia de produção (na automação industrial, saúde e segurança do trabalho, higiene do trabalho, ergonomia e doenças ocupacionais), na psicologia (psicologia do trabalho, doenças e síndromes), antropologia (concepção do homem e a sociedade onde se insere), na educação (educação profissional, pesquisa, desenvolvimento de modelos e métodos) e na medicina (novos conceitos de tratamentos e atendimentos emergenciais para médicos, bombeiros, socorristas, enfermeiros e demais profissionais) (FERREIRA, 2004).

A antropotecnologia é definida como a ciência que engloba não somente aspectos ergonômicos, como também, aspectos intrínsecos do colaborador em relação à forma como absorve as mudanças que a evolução tecnológica propõe, o seu bem estar físico e mental, as questões de saúde e segurança do trabalho, investimentos em capacitação do profissional, os relacionamentos interpessoais e os modelos de gestão apresentados por cada organização (VIDAL, 2012). 
Já a Transferência do Conhecimento e Tecnologia (TCT) promove dentro das organizações, melhorias nas comunicações pessoal e interpessoal, do clima organizacional estimulando a busca por conhecimento, inovações tecnológicas, inserção de novos equipamentos e métodos de trabalho, entre outras vantagens (EDLER, 2011).

Sendo assim, contribuições das áreas de antropotecnologia e TCT podem ser observadas nos projetos internacionais como Disaster Mutual Assistance (DMA), criado pela Universidade norte-americana, governo e órgãos de socorro e resgate, visando fornecer suporte por meio de treinamento e qualificação sobre emergências pós- catástrofes à população (WANG, 2013).

No Brasil, o Plano de Auxílio Mútuo (PAM) (projeto nacional) foi criado pelo Corpo de Bombeiros, com propósitos semelhantes ao DMA (projeto internacional), de modo a fornecer treinamentos, capacitação e orientações às empresas parceiras e seus colaboradores sobre os principais graus de risco no cotidiano envolvendo, riscos químicos e físicos, combate aos incêndios e acidentes diversos, estimulando ações de prevenção e/ou emergenciais.

Este trabalho busca evidenciar as contribuições da antropotecnologia nas atividades de prevenção de riscos ao trabalho humano, facilitando o estreitando das relações interpessoais, a troca de informações, busca por conhecimento e inserção de novas tecnologias. Esta pesquisa visa responder ao seguinte questionamento:

De que modo a antropotecnologia contribui para a realização de ações diversas nas atividades do PAM?

\section{OBJETIVOS}

A partir da questão formulada, propõem-se os objetivos desta pesquisa.

\section{OBJETIVO GERAL}

Identificar as contribuições da antropotecnologia nas atividades do PAM, no Brasil. 


\section{OBJETIVOS ESPECÍFICOS}

OE1: Descrever a origem do PAM e seus objetivos;

OE2: Identificar as características da Antropotecnologia e sua relação com a Transferência de Tecnologia e Conhecimento, nas atividades do PAM;

OE3: Estabelecer uma comparação das características do DMA e do PAM; e OE4: Articular evidências antropotecnológicas no PAM a partir do referencial teórico e das práticas desenvolvidas no estudo.

\section{JUSTIFICATIVA}

A antropotecnologia contribui com o desenvolvimento e evolução do trabalho do homem nas mais diversas áreas. Quando se estuda as atividades de serviços emergenciais, verifica-se uma lacuna de pesquisas sobre a antropotecnologia e seus impactos positivos, principalmente nas atividades emergenciais e de segurança do trabalhador. Portanto, está dissertação se justifica pela importância das temáticas, relevância acadêmica e contribuições para a sociedade.

O desenvolvimento desse estudo visa apresentar conhecimento sobre a antropotecnologia com uma visão mais aprimorada, tornando-se possível realizar um planejamento e padronização das principais ações desenvolvidas por pesquisadores consagrados da área na interface homem e máquina, homem e ambiente produtivo, $e$ assim, sucessivamente (HENDRICK, 1997).

Quanto à relevância acadêmica, destaca-se a elaboração de revisão de literatura, suprindo carências de pesquisas de antropotecnologia e TCT nos serviços de emergências do DMA e do PAM, conforme a Figura 1. 
Figura 1- Integração entre os elementos da pesquisa.
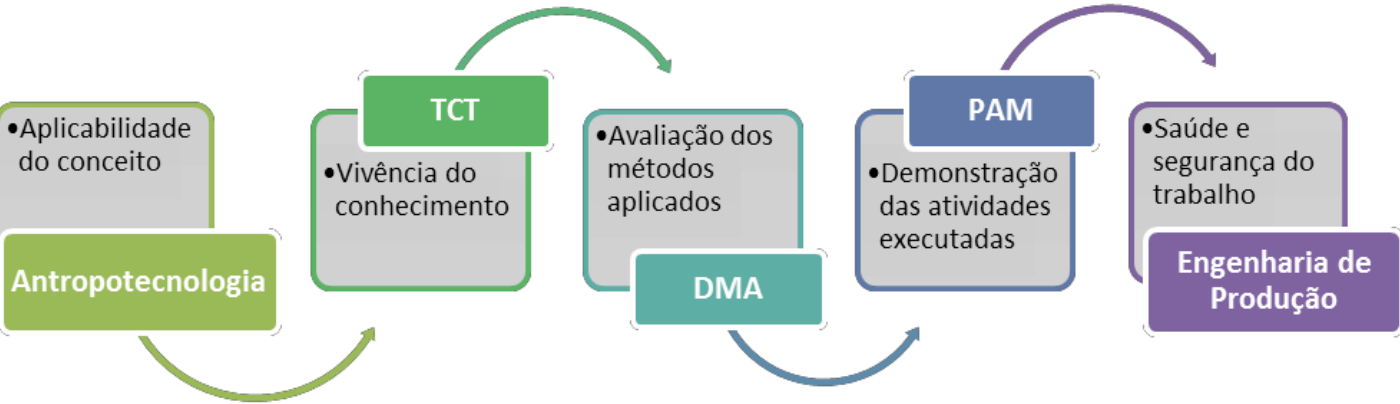

Fonte: Elaborada pela pesquisadora (2018)

Os principais atores que compõem este estudo são o governo (órgãos de socorro, resgate e treinamentos), indústrias (inovações tecnológicas), universidades (pesquisa) e a comunidade (colaboradores e o meio ambiente).

Esta conexão entre órgãos e métodos descrita na Figura 1, faz jus a importância dessa integração, para que, o desenvolvimento de ações se torne cada vez mais acessível e eficiente, entre os diversos atores.

Com relação à área de atuação de profissionais da Engenharia de Produção e áreas afins, constata-se que esta pesquisa está inserida na área de Ergonomia e Segurança do Trabalho, e Saúde e Segurança do Trabalho (ABEPRO) (2008) por meio de atividades de prevenção de riscos e melhora do bem-estar humano.

\section{ESTRUTURA DO TRABALHO}

O presente trabalho está dividido em cinco capítulos, contando com esta introdução (1), revisão de literatura (2), metodologia (3), resultados e discussão (4) e conclusão (5), conforme apresentado na Figura 2. 
Figura 2 - Estrutura da Dissertação.

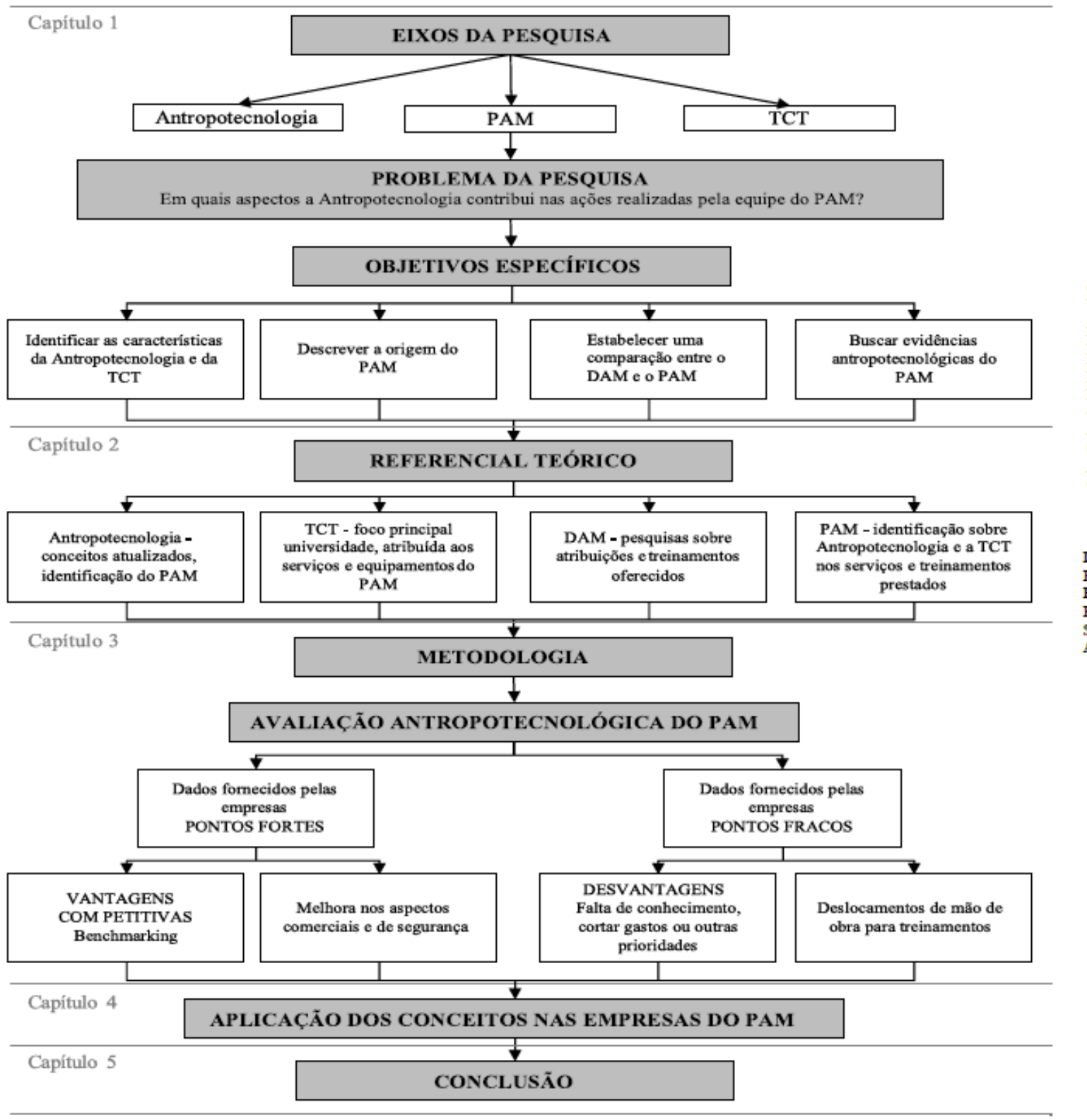

Fonte: Elaborado pela pesquisadora (2019).

Sucedendo a introdução, na parte (2) do trabalho está a revisão de literatura, trazendo os principais conceitos sobre os três temas abordados (antropotecnologia, TCT e serviços emergenciais, o DMA e o PAM).

A parte (3) do trabalho apresenta os procedimentos metodológicos utilizados na busca pelo alcance dos objetivos estabelecidos.

Na parte (4) se encontra a pesquisa de campo, cujos dados obtidos por meio de entrevistas, questionários e revisão de literatura são apresentados.

A parte (5) traz, portanto, a conclusão, as limitações da pesquisa, sugestões para trabalhos futuros. 


\section{REVISÃO DE LITERATURA}

Este trabalho analisa os aspectos da antropotecnologia no PAM. Para isto, faz-se necessário abordar os temas a eles relacionados, e mencionar Transferência de Conhecimento e Tecnologia (TCT), antropotecnologia e serviços emergenciais, como DMA e PAM, respectivamente.

\section{TRANSFERÊNCIA DE CONHECIMENTO E TECNOLOGIA}

No decorrer dos anos, o homem tem buscado métodos e processos de trabalho que minimizem esforços, aperfeiçoando assim, os resultados da própria produção. Para tanto, a transferência de tecnologia foi um marco de transformação entre as atividades artesanais e os processos industriais, em vários ramos e entre organizações, instituições de ensino, classes de trabalhadores, entre outros países e culturas (SANTOS, 1997).

A Transferência de Tecnologia (TT) teve, portanto, após o século XIX, um avanço significativo nos processos industriais, e a partir do século 20 , faz parte do cotidiano das organizações, dentro da engenharia de produção, com novos modelos, processos, avanços e tecnologias, movimentando o mercado mundial de forma atrativa, tanto interna como externamente (SILVA, 2015).

Conforme Barreto (2012), a absorção do conhecimento gerada pela TT somente pode ser concebida, se houver informações acessíveis a todos os envolvidos, de forma a trazê-los o mais próximos da realidade da execução do trabalho, seja na forma intrínseca ou extrínseca, no ramo da pesquisa indústria e universidade, da tecnologia e trabalho e/ou da gestão versus necessidades do colaborador.

Nos países em desenvolvimento como o Brasil, a TT ainda pode ser considerada nova, principalmente nas questões envolvendo parcerias, como governo, 
indústria e sociedade. É necessária para que haja a complementação dos processos de inovação. Na busca, portanto, de conceitos atualizados, a universidade vem trazendo, através das pesquisas, modelos diferenciados e necessários como a Transferência de Conhecimento e Tecnologia (TCT) (CLOSS, 2012).

Um dos primeiros conceitos sobre TCT foi descrito pelo próprio Wisner ao questionar se somente por meio das máquinas ocorreria a TT junto aos funcionários, ou se, seriam necessários investimentos no conhecimento das ciências, estudos e valores humanos, para que assim pudesse haver uma transferência por completa (WISNER, 1985).

De acordo com Arvantinis (2008), a TCT se iniciou com o objetivo da universidade em capacitar as empresas cientificamente, e buscar facilitar o trabalho de forma mais ampla, criando uma consciência constante de aprendizado, troca de informações, experiências e redes de conhecimento e inovações.

Segundo Youtie (2008), as universidades norte-americanas apresentaram um papel muito importante com o passar do tempo no ramo das pesquisas, a partir da implantação de conceitos e novas tecnologias, ampliando assim, as parcerias orientadas para o negócio com stakeholders, startups e clusters industriais.

Conforme Wright (2008), a importância do envolvimento de parceiros como as indústrias, governo e universidades, tornou-se fundamental no desenvolvimento econômico das cidades, criando canais de TCT e oportunizando todas as áreas de pesquisa, desde as mais simples até as mais sofisticadas como empreendimentos e consultorias.

Segundo Morandi (2013, p. 9), a troca de experiências e contato com organizações (cultura organizacional, idioma, inovação e produtos) fazem com que a TCT se torne lúdica e diferenciada. Fato esse, proposto neste trabalho ao se deparar com as inúmeras parcerias entre as multinacionais e o PAM.

Os projetos incluindo a tríplice hélice (governo, universidade e indústria) têm causado efeitos vantajosos para todas as partes, pois promove junto a elas, ações que correlacionam interesses e facilitam a participação de um maior número de pessoas, abrindo espaço para a comunidade, a sociedade e demais parceiros em redes de informações (FARINHA, 2016). 
As organizações necessitam de constantes pesquisas e parcerias, visando continuar sendo atraentes ao mercado de forma segura e inovadora. Sendo assim, a universidade não traz somente pesquisa, tecnologia e aprendizado, mas formação humana complementar, fundamental para acompanhar tais avanços. Para tanto, a troca de informações entre pesquisadores, empresas, governo e sociedade é crucial nos processos de mudança.

Segundo Edler (2011), a troca de experiências entre pesquisadores das universidades de mesmo ou países distintos e/ou em empresas são implantadas no mundo do trabalho e, por consequência, permite enriquecer a TCT.

\section{ANTROPOTECNOLOGIA}

A antropotecnologia é um conceito que articula os termos "anthropos" (homem) e "tecné tecnos" (tecnologia). Pode ser utilizado na arte, na ciência e na literatura para denotar o efeito dos avanços tecnológicos na relação homem versus máquina, e os resultados causados por tais avanços sob a ótica do trabalho. Pelo aspecto tecnológico, pode ser visto como uma ciência que estuda os impactos gerados na sociedade, decorrentes da Transferência de Conhecimento e Tecnologia (TCT) (DWYER, 2006).

Pesquisas sobre o tema propõem reconhecer as características de um país, do seu tecido industrial, sua geografia, antropologia, economia, cultura e religião para desenvolver um estudo selecionado e satisfatório do ambiente de trabalho. A indústria que pode ser conceituada como um conjunto de pessoas, geograficamente localizadas e influenciadas por fatores socioculturais, serviu como um cenário ideal para o fortalecimento antropotecnológico (WISNER, 1985).

No Quadro 1 são apresentados os principais autores de antropotecnologia no mundo. 
Quadro 1 - Principais autores de estudos sobre antropotecnologia.

\begin{tabular}{|c|c|c|}
\hline Autores & Tema abordado & Áreas de estudo \\
\hline $\begin{array}{l}\text { Wisner }(1984,1985, \\
1992)\end{array}$ & Antropotecnologia & $\begin{array}{l}\text { O homem, os equipamentos e o } \\
\text { ambiente. Respeitando aspectos } \\
\text { ergonômicos, condições de trabalho, } \\
\text { pontuando as necessidades de } \\
\text { respeito e segurança ao trabalhador. }\end{array}$ \\
\hline Daniellou (2006) & Visão ergonômica do trabalho & $\begin{array}{l}\text { Minimizar riscos, observar como os } \\
\text { processos poderiam ser menos } \\
\text { danosos à saúde do trabalhador. }\end{array}$ \\
\hline Binder (2006) & $\begin{array}{l}\text { Experimentação do método } \\
\text { árvore das causas - } \\
\text { acidentes de trabalho }\end{array}$ & $\begin{array}{l}\text { Vulnerabilidade dos indivíduos, } \\
\text { limitações e adaptabilidade às novas } \\
\text { tecnologias. Exposição do } \\
\text { trabalhador a efeitos adversos. }\end{array}$ \\
\hline Clot (2006) & $\begin{array}{l}\text { Condições de trabalho, } \\
\text { gestão ergonômica, ação de } \\
\text { transformação dos } \\
\text { ambientes. }\end{array}$ & $\begin{array}{l}\text { Apontamento sobre as péssimas } \\
\text { condições de trabalho da época, } \\
\text { exploração do trabalho e excessos } \\
\text { (Wisner) }\end{array}$ \\
\hline Dwyer (2006) & $\begin{array}{l}\text { Cultura biomecanicista, } \\
\text { fisiologista, buscando a } \\
\text { adaptação. }\end{array}$ & $\begin{array}{l}\text { Observação dos comportamentos e } \\
\text { hiperespecialização }\end{array}$ \\
\hline Soares (2006) & Ergonomia e Antropologia & $\begin{array}{l}\text { Princípios da ergonomia na América } \\
\text { Latina }\end{array}$ \\
\hline Blad (2010) & $\begin{array}{l}\text { Evolução dos homens na } \\
\text { Antropotecnologia }\end{array}$ & $\begin{array}{l}\text { Psicologia do trabalho, aspectos } \\
\text { voltados ao bem-estar e qualidade de } \\
\text { vida. }\end{array}$ \\
\hline Saldanhar (2012) & $\begin{array}{l}\text { Clusters e modelagem } \\
\text { Corporativa }\end{array}$ & $\begin{array}{l}\text { Reconhecimento da forma de } \\
\text { trabalho através do ensino- } \\
\text { aprendizagem }\end{array}$ \\
\hline $\begin{array}{l}\text { Garrigou (2012) } \\
\text { Davis (2017) }\end{array}$ & $\begin{array}{l}\text { Segurança do trabalhador na } \\
\text { agricultura }\end{array}$ & $\begin{array}{l}\text { Atribuições do princípio da } \\
\text { ergotoxicologia como estudo. Efeitos } \\
\text { tóxicos e danos físicos e psicológicos } \\
\text { aos trabalhadores expostos as altas } \\
\text { taxas de veneno. }\end{array}$ \\
\hline Davis (2017) & $\begin{array}{l}\text { Conceitos de ergotoxicologia } \\
\text { (uso de pesticidas) }\end{array}$ & $\begin{array}{l}\text { Saúde do trabalhador, aspectos } \\
\text { ergonômicos do trabalho. }\end{array}$ \\
\hline Meachan (2017) & $\begin{array}{l}\text { Psicologia humana e } \\
\text { Psicofarmacêutica }\end{array}$ & $\begin{array}{l}\text { Limitações e adaptabilidade do } \\
\text { trabalhador às novas tecnologias, } \\
\text { questionamentos sobre necessidade } \\
\text { e bem-estar. }\end{array}$ \\
\hline
\end{tabular}

Fonte: Elaborada pela pesquisadora (2018)

Os primeiros estudos antropotecnológicos acontecerem no final da Segunda Guerra Mundial, quando os jovens corriam em busca de trabalho e na reconstrução de suas vidas. Foi então que Alain Wisner, o propulsor da antropotecnologia, pôde iniciar seus estudos e observar que os trabalhadores, por questões de necessidade, se sujeitavam a todos os tipos de trabalho e estavam expostos diariamente a riscos, doenças, lesões, que poderiam até levá-los à morte, por falta de leis e de respeito aos princípios ergonômicos, de saúde e segurança do trabalho (DANIELLOU, 2006). 
A partir de 1945, Wisner realizou avaliações e pesquisas sobre o mundo do trabalho, primeiramente com trabalhadores afetados pela exposição constante ao ruído, além de altas temperaturas, como era o caso dos maquinistas nas ferrovias e motoristas de ônibus. Após esse período, deixou a função de otorrinolaringologista para se dedicar aos estudos sobre o homem e o trabalho, sendo convidado por Jacques Duraffourg a fazer parte do Laboratório Central dos Metalúrgicos (CLOT, 2006).

Posteriormente, Wisner atuou oito anos como sindicalista, e pôde observar dentro de fábricas, como a Renault francesa, que aspectos ergonômicos eram desconsiderados, não havia orientações por parte da liderança sobre cuidados e segurança. Deparou-se, também, com vários cenários no decorrer desse período como o de trabalhadores com jornadas de 50 a 56 horas de trabalho semanais, carregando baldes de fundição sem nenhuma proteção, com salários e condições deploráveis (WISNER, 1985).

Conforme Garrigou (2012), cada ramo de trabalho observado na época trazia consigo reflexões diferenciadas sobre as inúmeras dificuldades nos processos industriais agrícolas, cujos empregados trabalhavam em contato direto com veneno, causando efeitos devastadores à saúde. Para tanto, estudos sobre a ergotoxicologia junto à antropotecnologia vieram pontuar as reais condições de trabalho oferecido e suas consequências às pessoas.

Posteriormente, Alain e seus companheiros médicos e estudiosos franceses, formaram uma equipe de líderes científicos, composta por fisiologistas, biólogos, neurologistas e psicólogos, principalmente, gerando-se conhecimentos de riscos e condições de trabalho (GOMES, 2017). Para tanto, os aspectos antropotecnológicos buscam estudar o ser humano atuando coletivamente, na execução de uma ou mais tarefas, dentro ou fora de seu ambiente de trabalho, em seu processo produtivo, nas relações interpessoais e na percepção dele como indivíduo (WISNER, 1992).

As características individuais de um país devem ser respeitadas nos quesitos religiosos, geográficos, políticos, antropológicos, culturais, etc. Para que, a partir de então, os aspectos antropotecnológicos possam ser estabelecidos em uma determinada empresa, uma vez que cada uma traz consigo valores e questões pessoais e particulares que cabe a ela somente ser pontuada e, posteriormente, obter uma avaliação concisa (SANTOS, 1997, p.11). 
Para tanto, os processos de ensino e aprendizagem para o trabalho, a troca de informações, as inovações tecnológicas e os treinamentos devem ser sempre estimulados dentro dos processos de TCT, buscando o retorno dos investimentos e pontuando as necessidades de avaliar, junto aos funcionários, elementos prioritários como conforto, bem estar, locomoção à empresa, alimentação, escolaridade, entre outros (SALDANHAR, 2012).

Conforme as pesquisas evoluíam, surgiram diferentes linhas de pensamento com foco em áreas mais distintas do conhecimento. Abrindo assim, um leque de possibilidades, difundindo o tema em vários setores como: psicologia do trabalho, ergotoxicologia (efeitos dos pesticidas na saúde dos empregados), macroergonomia, medicina, modelagem, saúde e segurança, aeronáutica, agricultura, indústria, entre outros, adaptando-se a vários tecidos industriais na esfera do trabalho (DAVIS, 2017), como os conceitos apresentados a seguir.

Meacham (2017, p.12) sugere utilizar a antropotecnologia como aspectos de cuidados e de prevenção, protegendo o ser humano, restaurando o indivíduo e enfatizando as relações sociais e culturais mediadas pela tecnologia, não podendo ser separadas umas das outras.

Conforme Vidal (2012, p. 11), a antropotecnologia estava inicialmente voltada aos aspectos do trabalho e da tecnologia e à adequação do trabalhador ao mesmo, mas sempre próxima às questões ergonômicas. Mas, a partir da década de 90 , com a criação das estratégias organizacionais, como a saúde e segurança do trabalho e a macroergonomia, países como EUA, a Europa e até mesmo o Brasil, mudaram aos poucos seu formato gerencial buscando adequações e bem estar no trabalho.

Segundo Meacham (2017), na verdade, cada ser humano carrega consigo elementos de suma importância que irão contribuir ou não para sua adaptação aos meios de trabalho, oferecidos por cada organização (aspectos culturais, sociais e tecnológicos). E, para que os aspectos antropotecnológicos de cada profissão ou trabalho possam ser observados, necessita que haja uma visão considerável sobre tais elementos, e como cada um reage a estímulos no exercício de sua função.

Conforme Garrigou (2012), o papel inicial da antropotecnologia, criada por Wisner, foi observar como os trabalhadores da época estavam expostos ao trabalho, em meio à implantação de novas tecnologias, pois ignoravam conceitos sobre ela, 
assim como seus recursos e todos os tipos de produtos ao qual estavam expostos. Assim, portanto, as multinacionais da época iniciaram investimentos em pesquisas e estratégias de observação dos funcionários, verificando aquelas que atingissem maiores e melhores índices produtivos, buscando a satisfação física e mental dos mesmos, através de aplicações antropotecnológicas.

Já outras empresas investiram em avaliações das condições de trabalho, passando a inspecionarem os postos de trabalho, com vistas a minimizar impactos e acidentes de trabalho (WISNER, 1985).

A antropotecnologia foi sendo difundida junto à ergonomia, mas, aos poucos, veio trazendo consigo características humanas e pessoais para adaptação do trabalhador como um todo, respeitando sua individualidade, ouvindo suas principais dificuldades e estimulando as relações interpessoais, o aprendizado e a troca de informações no grupo ao qual o mesmo se insere (SALDANHAR, 2012).

Desde então, a antropotecnologia está inserida como a ciência que estuda o comportamento humano, utilizando a TT em seu dia a dia de trabalho. Pontuando assim: Como esse indivíduo se sente ao se deparar com as novas máquinas e equipamentos? Como está preparado para exigências de estar sempre atualizado tecnologicamente? E; Como a organização gerencia e estimula os relacionamentos interpessoais de seus colaboradores?

Tais elementos antropotecnológicos não se inserem somente no ambiente industrial, mas podem ser vistos e estudados em todos os setores da sociedade, em outras profissões e ramos produtivos. Com o intuito de promover essa troca de experiências e formação coletiva, sugiram-se parcerias entre empresas e governo, como é o caso dos serviços de emergência, que treinam e capacitam funcionários em busca de organizar um grupo coeso de ações de prevenção e saúde.

Segundo Proença (1996), as ilhas de antropotecnologia foram desenvolvidas a partir da implantação da TCT no meio industrial. Assim, o processo envolve as filiais em plantas diferenciadas (nacionais e internacionais), nas quais, desenvolvem-se em sistemas produtivos idênticos, buscando protocolar e formalizar a gestão produtiva. Fator esse, vivenciado pelos serviços de emergência, como o PAM, que oferecem treinamentos sistematizados e buscam atuar em conjunto com todas as empresas parceiras, em casos de eventos adversos, sejam eles internos (grandes incêndios, 
vazamentos de produtos químicos, explosões), e/ou externos (climáticos como: vendavais, inundações, desabamentos, entre outros.).

\section{SERVIÇOS DE EMERGÊNCIA DE ATENDIMENTO PRÉ-HOSPITALAR}

Devido ao crescimento globalizado, ao aumento gradativo da população mundial, à expansão e o desenvolvimento industrial e à velocidade das informações têm contribuído para elevar os índices de riscos e perigos no trabalho, entre outros locais.

A visão de saúde, segurança e prevenção do cidadão e mesmo no ambiente de trabalho veio através dos tempos, tornando-se um reflexo positivo na sociedade, por meio de conceitos prevencionistas implantados pela engenharia de produção. Através de treinamentos, podem conectar a prevenção e orientação de situações que possam colocar em risco a vida dos empregados e da população em geral.

Segundo Brewer (1986), as primeiras referências sobre os atendimentos emergenciais referem-se ao médico cirurgião Dominique Jean Larrey (1766-1842), tendo preocupado não somente em resgatar as vítimas nos frontes de batalha, mas, contudo, pensava que o atendimento rápido e preciso seria mais eficaz.

No intuito de minimizar os casos de mortes nos frontes de batalhas, Larrey confeccionou um veículo de tração animal com dois cavalos, conhecido como "ambulâncias voadoras", buscando assim, atender o mais rápido possível o paciente ferido (SILVA, 2010).

Conforme relata Ribeiro (2011), na busca por minimizar os índices de mortos e feridos em guerras foi criada uma força tarefa especializada. E assim, dessa fase, resultou a Cruz Vermelha, criada em 1863, em Genebra (organização vocacionada para operações em tempo de guerra).

Posteriormente, houve a expansão de órgãos mundiais, que fornecessem assistência aos necessitados, como a Cruz Vermelha Internacional, Organização das Nações Unidas e Organização Mundial da Saúde. Tais órgãos tiveram, portanto, a responsabilidade de fornecer à população mundial, o amparo médico de resgate e 
suporte à vida, caso estivessem envolvidas, desprovidas e com riscos eminentes de morte.

Segundo Bowman (1990), a Cruz Vermelha norte-americana foi criada em 1909, inicialmente com um curso de primeiros socorros aos participantes. Já em 1933, foi então elaborado um manual de primeiros socorros voltados aos acidentes ocorridos dentro das indústrias. Iniciando, posteriormente, treinamentos nos anos 70 com a Academia Americana ou Colégio de Cirurgiões e Trauma, envolvendo médicos, alunos e técnicos da área.

Em 1856, foi criado no Brasil, no dia 02 de julho, segundo Decreto assinado pelo Imperador D. Pedro I, o primeiro posto do Corpo de Bombeiros, que deveria primar pela segurança contra incêndios da Corte do Rio de Janeiro (BRASIL, 2018).

Atualmente, segundo Schunder (2016), por questões de segurança da população, existe a necessidade de que em locais com grande circulação de pessoas, como empresas, universidades, shoppings e bancos, tenham-se, entre os colaboradores, funcionários habilitados, e que saibam agir em caso de emergências.

\section{Disaster mutual assistance (DMA)}

Conforme os processos industriais se tornaram cada vez mais complexos, além de efeitos adversos climáticos em vários países, equipes especializadas foram criadas, cuja função principal é fornecer suporte à vida ágil em casos de acidentes, por exemplo. A primeira equipe formada com esse intuito foi organizada a partir de 1848, quando autoridades europeias observaram a necessidade de uma força policial direcionada ao combate de incêndios. Isso, somada a necessidade de atuação dos mesmos em eventos climáticos adversos e riscos nas empresas (DE LOTTINVILLE, 1980).

Conforme Damacena (2011), com o passar dos tempos, os primeiros relatos sobre desastres referidos na literatura mundial tratam-se de acidentes, um deles foi ocorrido no porto de Halifax em 1917 (uma explosão entre um navio francês carregado de explosivos e outro navio belga, ocasionando milhares de mortes). 
Posterior aos acontecimentos, no decorrer dos anos, foram organizados serviços públicos voltados aos desastres ambientais, com intuito de formalizar as pesquisas e ações de emergências (DRABEK, 2003; ASGARY, 2017).

Diante dos acontecimentos, foi criado o Disaster Mutual Assistance (DMA), envolvendo órgãos de defesa (governo) e parceiros (universidades, comissões em indústrias, comunidade e apoiadores como ONGs), que visou formalizar protocolos de treinamentos e orientações devido aos desastres (ALTAY, 2006) nos quesitos: i) Prevenção e planejamento, e; ii) Resposta e recuperação aos danos (MAON, 2009).

Posteriormente, após a passagem devastadora de furacões, tufões e vários outros eventos adversos, os EUA criaram parcerias entre o poder público e privado, tendo como principal objetivo, prestar atendimento ágil e eficaz às vítimas de eventos extraordinários, catástrofes ou até mesmo de ações terroristas (HUANG, 2016). De acordo com Ha e Kyoo-Man (2016), o princípio básico de gerenciamento de desastres é mitigar ou diminuir o impacto de um desastre através de uma mobilização eficiente.

Já na Europa, ações de parcerias entre países são realizadas para auxiliar pessoas em caso de desastres. Tais ações, também poderão ser administradas pela Cruz Vermelha Alemã, pois esses acordos fortalecem os laços de cooperação e buscam otimizar treinamentos.

Além dos treinamentos, tecnologias também são importantes para reduzir impactos causados por desastres. Os Estados Unidos avançam significativamente em seus grupos de pesquisas e utilizam tecnologias de gerenciamento climático capazes de detectar, antecipadamente, possíveis eventos (FLANAGAN, 2011).

\section{Plano de auxílio mútuo (PAM)}

No Brasil, a cultura voltada aos programas de saúde, segurança e prevenção em primeiros socorros está ligada somente aos profissionais das áreas da saúde (médicos, bombeiros, enfermeiros, socorristas, técnicos e brigadistas). Quanto à população em geral, são escassos procedimentos emergenciais. Contudo, nos países desenvolvimentos, treinamentos fazem parte da formação de crianças nas escolas (LIBERAL, 2005). 
Portanto, quanto à população internacional, tais práticas e conhecimentos, são desenvolvidos no próprio sistema educacional. Pois, convive-se com tais práticas constantemente, não somente voltados à rota de evacuação, primeiros socorros básicos, ou possíveis acidentes que venham a ocorrer, mas somados, aos efeitos climáticos extraordinários que venham a acometê-los (terremotos, furacões, tsunamis e o terrorismo). Para tanto, comprovadamente, tais treinamentos orientam a população, minimizam lesões, diminui visivelmente os índices de mortes e geram um grande diferencial econômico para toda a população e governo.

Uma população mais esclarecida faz com que a própria sociedade saiba o que ou não fazer, de forma simples e eficaz, em caso de emergência. Portanto, o conhecimento ministrado à comunidade proporciona a diminuição dos atendimentos médicos de emergência, pois o cidadão sabe quais atitudes deverão ser tomadas, e em caso de necessidade, conduzir a vítima a um atendimento médico ou acionar os serviços especializados. Tais conhecimentos, somente serão aprendidos, quando o cidadão leigo, se torna um profissional de saúde, ou muitas vezes, um colaborador em uma multinacional adquire treinamento.

Para disseminar projetos de como agir perante desastres, é necessário, segundo Alexander (2015), a participação de vários setores da sociedade (político, empresarial, universidades, colaboradores e a comunidade).

O Brasil, ainda não possui uma visão prevencionista voltadas à instrução e treinamentos à população. Geralmente, quando ocorre desastre, as ações são mais corretivas. Inspirado em planos internacionais, os órgãos de socorro e resgate do país elaboraram o projeto PAM, que promove parcerias com bombeiros, defesa civil, a universidade, a indústria e seus colaboradores e a comunidade, unindo formas, na busca de formar uma equipe especializada em socorro, resgate e prevenção.

O projeto PAM foi criado, em 1978, pelo corpo de bombeiros na cidade de Santos em São Paulo. Tal projeto possui uma proposta similar ao $D M A$, pois tem o objetivo de formar equipes especializadas em socorro, resgate, combate a incêndio, vazamentos de produtos perigosos e auxílios aos feridos.

O PAM tem por finalidade a atuação, de forma conjunta, de seus integrantes, na resposta a emergências nas instalações das empresas integrantes e respectiva 
área de atuação, mediante a utilização de recursos humanos e materiais de cada empresa ou instituição integrante (BRASIL, 2018).

No país, o PAM ainda é um projeto novo e está sendo divulgado, buscando com isso, conquistar o maior número de organizações possíveis. Sabendo-se que, várias cidades brasileiras ainda não fazem parte deste projeto por falta de interesse, conhecimento e/ou informação. Para tanto, a busca principal será, envolver tais atores em um leque de ações, planejamentos de riscos, tomadas de decisões, formalizando assim, grupos de apoio na busca de minimizar impactos à vida, ao meio ambiente e à sociedade.

Consequentemente, ao se avaliar o projeto dentro do território nacional, pôdese observar que não existe divulgação de dados ou estudos sobre o PAM. Para tanto, foram realizados comparativos, a nível estadual e em cidades que possuem o PAM, na busca de analisar, se os índices apresentados pelas mesmas atendem os aspectos principais da pesquisa. 
REVISÃO DE LITERATURA

Tabela 1 - Cidades brasileiras que possuem PAM.

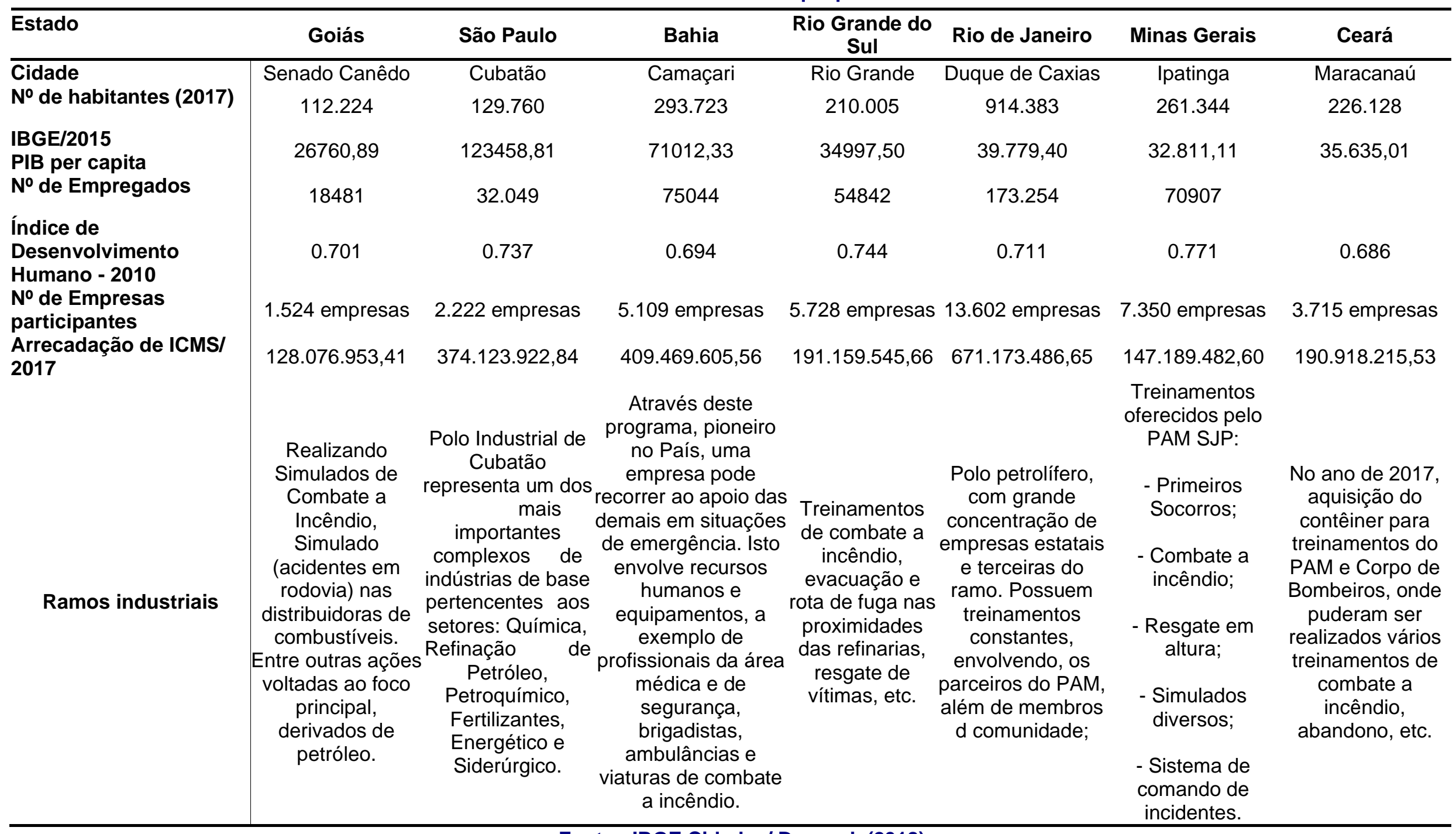

Fonte - IBGE Cidades/ Deepask (2018) 
Contudo, a implantação do PAM em um maior número de cidades brasileiras possíveis, se dá, pela real importância, devido a alguns fatos e acidentes históricos, podendo citar alguns deles:

- Cubatão, SP, em 1984: Houve um vazamento de petróleo em refinaria, cercado de vários outros reservatórios, em um polo petrolífero portuário. Tal ocorrido propagou através de rios e mangues próximos, gerando um enorme incêndio. Após o ocorrido foram encontrados 93 corpos e mais de 500 pessoas desabrigadas, sem contar, o desastre ambiental irreversível (FRANCO, 2011);

- Araucária, PR, em 2000: Vazamento de óleo para refino, cerca de 25 mil barris, contaminando a bacia dos rios Iguaçu e Barigui (BERTOLINI, 2006);

- Boate Kiss, RS, em 2013: Incêndio ocasionado por objetos pirofóricos, em uma casa de shows, ocasionando um grande incêndio que vitimou 242 pessoas (SIEBEN, 2014);

- Rompimento da barragem do Fundão em Mariana, MG, em 2015: Tratase do rompimento de uma barragem de rejeitos de mineração, cerca de 62 milhões de metros cúbicos, deixando 19 mortos e milhares de desabrigados, além de destruir uma cidade histórica. Seu impacto ambiental atingiu vários estados, dizimando o ecossistema, fauna, flora, contaminado lençóis freáticos e rios (LOPES, 2016);

- Largo do Paissandu, SP, em 2018: O evento ocorreu em um dos edifícios condenados pelos bombeiros e defesa por não apresentar condições de segurança estrutural. Tal evento dizimou 9 pessoas, desabrigou centenas, alastrou-se para prédios vizinhos, colocando em riscos a comunidade (MELLO, 2018);

- Museu Nacional, RJ, 2018: Incêndio em grandes proporções. O prédio que já foi a moradia do primeiro Imperador do Brasil - Dom Pedro I - abrigava o acervo histórico nacional, cerca de 200 anos. Na realizada, não havia investimentos em segurança, planejamento estratégicos em caso de incêndio, equipes especializadas na proteção do acervo (BBC NEWS, 2018), entre outros, e;

- Rompimento da barragem do córrego do feijão, na cidade de Brumadinho, MG, no ano de 2019: Vitimou 206 pessoas e ainda existem cerca de 102 pessoas desaparecidas. Além da devastação de toda região, pelo verdadeiro Tsunami de lama, que dizimou a fauna e flora, causando um impacto ambiental sem precedentes (FOLHA DE SÃO PAULO, 2019). 
A falta de investimentos contínuos nas corporações de socorro e resgate, assim como, em uma maior fiscalização nas empresas quanto aos riscos oferecidos em seus processos produtivos fizeram com que houvesse a necessidade ações para prevenção de acidentes e atendimento às vítimas.

\section{Defesa civil do Paraná}

O processo de globalização mundial vem contribuir substancialmente para o aquecimento global, em que o aumento da produção industrial, extração exacerbada de recursos naturais e as forças climáticas proporcionam o aumento gradual dos efeitos adversos no planeta.

Devido aos impactos ambientais, como, enchentes, naufrágios, vendavais, deslizamentos de encostas, catástrofes, desmoronamentos, entre outros, surge no país a Defesa Civil, definida como estratégia de redução de riscos de desastres (MIN, 2016). A defesa civil brasileira pode ser descrita como um órgão que possui a competência de promover conjuntos de ações preventivas de socorro, assistenciais e reconstrutivas destinadas a evitar ou minimizar os desastres, preservar o moral da população e restabelecer a normalidade (CASTRO, 1988).

Segundo Santos (2014), a comunicação de riscos e desastres é uma área de pesquisa ainda pouco explorada no Brasil. Isso representa um problema para a sociedade em geral e para as instituições envolvidas na gestão do risco e do desastre, inclusive as empresas.

No estado do Paraná, por exemplo, os desastres ambientais apresentaram maiores incidências, conforme o Gráfico 1. 


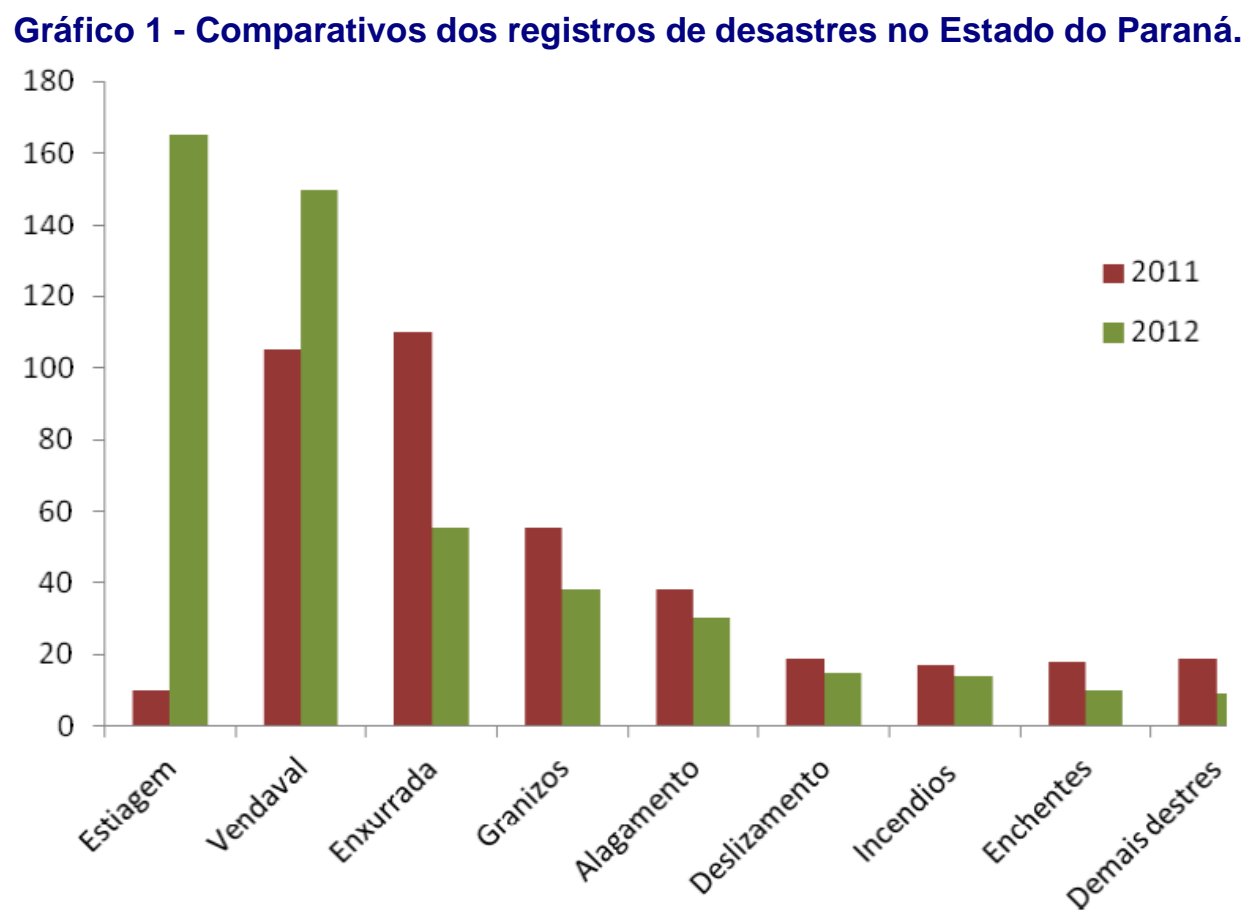

Fonte: Adaptado de Pinheiro (2014).

Em um período mais amplo, a Gráfico 2 descreve os impactos à sociedade devidos os desastres no estado do Paraná.

Gráfico 2 - Comparativo dos dados de impactos decorrentes de desastres.

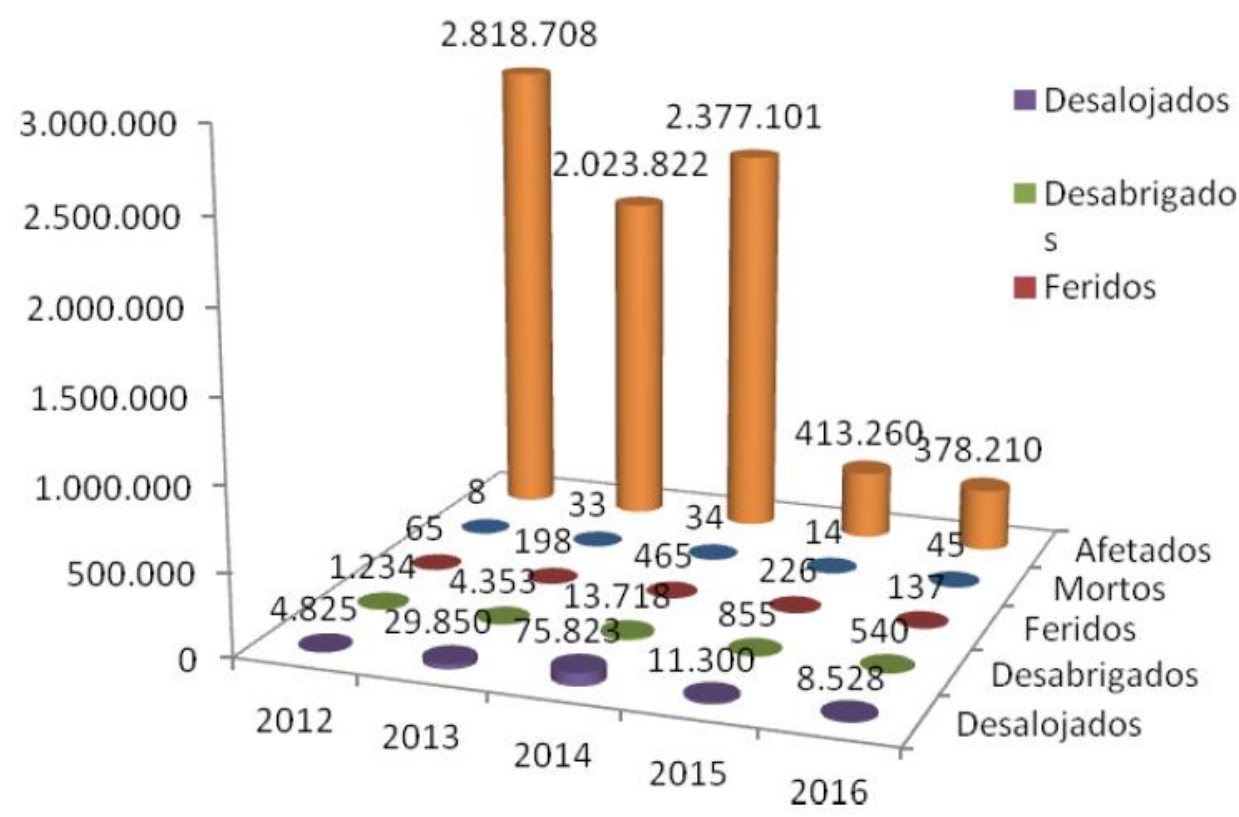

Fonte: Adaptado Business Intelligence/CEPDEC (2017)

As ações climáticas observadas e seus impactos podem retratar de forma clara, a necessidade de um trabalho em grupo que conte com todos os principais órgãos competentes de diversas áreas correlatas, aprimorando pesquisas e ações. 


\section{METODOLOGIA DE PESQUISA}

O objetivo desse capítulo será apresentar o caminho metodológico seguido para a construção da pesquisa, bem como os materiais e elementos conjugados para este trabalho, correlacionando os conceitos teóricos com os dados empíricos.

Esta pesquisa se caracteriza como exploratória e descritiva (GIL, 1994).

Esta pesquisa é exploratória, pois visou explorar, descobrir e compreender os temas abordados.

É descritiva, pois além da pesquisa bibliográfica, será também realizada uma pesquisa de campo, cujos resultados serão descritos em detalhes nesta pesquisa.

Os procedimentos técnicos utilizados se classificam como pesquisas do tipo bibliográficas, documental, coleta de dados e observação assistemática participante (VALADARES, 2007; YIN, 2001; LAKATOS; MARCONI, 2005; GOMES, 2015).

No Quadro 2 são apresentadas as etapas da pesquisa, as atividades e procedimentos correspondentes a cada uma das etapas. 
Quadro 2 - Procedimento metodológico da pesquisa.

\begin{tabular}{|c|c|c|c|}
\hline Etapas & Atividades & Procedimentos & $\begin{array}{c}\text { Objetivos a serem } \\
\text { Atingidos }\end{array}$ \\
\hline $1^{0}$ & $\begin{array}{l}\text { Revisão Sistemática } \\
\text { de Literatura }\end{array}$ & $\begin{array}{l}\text { Levantamento bibliográfico dos } \\
\text { estudos sobre antropotecnologia. } \\
\text { Pesquisa exploratória sobre como a } \\
\text { antropotecnologia e a TCT estão } \\
\text { sendo aplicadas junto ao PAM. } \\
\text { Definição da pergunta de partida. }\end{array}$ & $\begin{array}{l}\text { OE1: Descrever a origem } \\
\text { do PAM e seus principais } \\
\text { objetivos; } \\
\text { OE2: Identificar as } \\
\text { características da } \\
\text { antropotecnologia e sua } \\
\text { relação com TCT, nas } \\
\text { atividades do PAM; } \\
\text { OE3: Comparar as } \\
\text { características do DMA e } \\
\text { do PAM. }\end{array}$ \\
\hline $2^{0}$ & $\begin{array}{l}\text { Pesquisa de Campo } \\
\text { no Paraná }\end{array}$ & $\begin{array}{l}\text { Observação assistemática participante } \\
\text { do } 2^{\circ} \text { Seminário Técnico Científico do } \\
\text { PAM; } \\
\text { Análise documental através de atas, } \\
\text { ofícios, documentos do Corpo de } \\
\text { Bombeiros do PR; } \\
\text { Coleta de dados por meio da aplicação } \\
\text { de questionário; } \\
\text { Estudo de Caso: PAM em Ponta } \\
\text { Grossa: Pesquisa de campo nas } \\
\text { empresas participantes do PAM. }\end{array}$ & $\begin{array}{l}\text { OE4: Articular as } \\
\text { evidências } \\
\text { antropotecnológicas no } \\
\text { PAM. }\end{array}$ \\
\hline $3^{\circ}$ & $\begin{array}{l}\text { Tabulação, análise } \\
\text { e descrição dos } \\
\text { dados }\end{array}$ & $\begin{array}{l}\text { Participação dos treinamentos, } \\
\text { coletando dados e aplicando o } \\
\text { questionário nas empresas } \\
\text { participantes, através de entrevistas, } \\
\text { filmagens e gravações. }\end{array}$ & $\begin{array}{l}\text { Propor uma análise de } \\
\text { dados coletados durante } \\
\text { este trabalho, na busca } \\
\text { de avaliar a } \\
\text { antropotecnologia } \\
\text { desenvolvida pelos } 4 \\
\text { atores: (Governo, } \\
\text { Universidade, Indústria e } \\
\text { Sociedade). }\end{array}$ \\
\hline $4^{\circ}$ & $\begin{array}{l}\text { Discussão e } \\
\text { conclusão }\end{array}$ & Análise dos dados à luz da literatura & $\begin{array}{l}\text { OG: Identificar as } \\
\text { contribuições da área de } \\
\text { antropotecnologia nas } \\
\text { atividades do PAM, no } \\
\text { Brasil. }\end{array}$ \\
\hline
\end{tabular}

Fonte: Elaborada pela pesquisadora (2018)

A seguir, cada uma das fases será explicada em detalhes.

\section{PROCEDIMENTO DE ELABORAÇÃO DA REVISÃO DE LITERATURA}

A revisão sistemática de literatura foi realizada visando atender aos objetivos específicos propostos na pesquisa. Também, pode ser conhecida ou denominada por revisão bibliográfica ou ainda referencial teórico. Pois se torna parte integrante de um projeto de pesquisa que revela explicitamente o universo de contribuições científicas de autores sobre um tema específico (SANTOS; CANDELORO, 2006). 
Para que haja a compreensão clara de um projeto de pesquisa, existe a necessidade da realização de uma revisão de literatura criteriosa, para que assim, compreenda-se corretamente sua proposta. Tal levantamento visa à descrição do estado da arte, ou seja, conhecimento relevante o tema (BARRAL, 2007).

A busca para definir o caráter teórico constituiu-se nas seguintes etapas:

a) Selecionar bases de dados bibliográficos;

b) Estabelecer palavras-chave e combinações de palavras-chaves;

c) Definir critérios de buscas nas bases de dados;

d) Executar as buscas nas bases de dados;

e) Eliminar artigos em duplicidade;

f) Definir e aplicar critérios para eliminar artigos incompatíveis com o tema proposto;

g) Ordenar artigos a partir do cálculo e análise de valores de InOrdinatio da Methodi Ordinatio de Pagani; Kovaleski; Resende (2015), e;

h) Leituras completas de artigos.

As palavras-chave definidas foram: i) Antropotecnologia; ii) Transferência do Conhecimento e Tecnologia; iii) Disaster Mutual Assistance (DMA), e; iv) Plano de Auxílio Mútuo (PAM). Essas palavras-chave foram incorporadas em nove grupos de combinações:

i) "Anthropotechnology";

ii) "Anthropotechnology" and "Knowledge and Technology Transfer";

iii) "Anthropotechnology" and "Disaster Mutual Assistance";

iv) "Knowledge and Technology Transfer" and "Disaster Mutual Assistance";

v) "Disaster Mutual Assistance”;

vi) "Disaster Mutual Assistance" and "Disaster Mutual Assistance”;

vii) "Disaster Mutual Assistance" and "Anthropotechnology";

viii) Antropotecnologia, e;

ix) Plano de Auxílio Mútuo. 
As buscas foram realizadas na base de dados bibliográficos Web of Science, Science Direct, Scopus, Emerald e PubMed.

A lacuna identificada na revisão de literatura foi quanto aos aspectos antropotecnológicos nos quais está inserida a Transferência do Conhecimento e Tecnologia nos serviços de emergência.

Baseando-se nas diretrizes da Methodi Ordinatio de Pagani, Kovaleski e Resende (2015; 2018) foram aplicados os procedimentos de filtragem e eliminação de trabalhos em duplicatas, sendo priorizados os trabalhos relevantes.

Por fim, os artigos foram analisados por meio de leituras na íntegra e coleta de dados e informações para discussões.

\section{PESQUISA DE CAMPO}

\section{Observação assistemática}

Os dados foram coletados por meio de observação assistemática junto ao $2^{\circ}$ Seminário Técnico Científico de Prevenção e Proteção a Desastres. Este seminário ocorre anualmente e conta com a participação das principais autoridades nacionais militares nas áreas de socorro, resgates, salvamentos (aquático, terrestre, aéreo), segurança contra desastres e eventos extraordinários.

O Seminário contou com participantes internacionais dos principais órgãos de defesa e resgate através de palestras, workshops, entrevistas, exposições de artigos e apresentações dos mais modernos equipamentos, enfatizando o intuito de salvar a vida dos cidadãos. Isto se justifica, uma vez que os locais de trabalho concentram várias pessoas, gerando-se conhecimento e informações (GARDNER; CHEN; MORAN, 2009).

Houve também, a participação nos treinamentos oferecidos pelo PAM, durante 2017, 2018 e 2019, em suas reuniões mensais organizadas no Quartel do Corpo de Bombeiros. 


\section{Entrevistas}

Para as entrevistas, foi elaborado um instrumento de coleta de dados. Um questionário foi aplicado nas 19 empresas participantes do PAM, contemplando 5.517 colaboradores indiretamente, visando mensurar os pontos fortes, fracos e as principais sugestões para serem estudadas.

Um Questionário foi aplicado aos representantes das empresas participantes no segundo semestre de 2018. Em conjunto com o questionário, foram realizadas entrevistas semiestruturas com os funcionários de empresas participantes.

\section{Pesquisa participante}

Tal pesquisa caracteriza as investigações, onde se coletam dados junto às pessoas (fotos, filmagens, dados brutos, entre outros) (FONSECA, 2002).

No PAM de Ponta Grossa, Paraná, e região, por meio de pesquisa participativa foi possível o mapear os stakeholders envolvidos nas prestações de serviços à população.

Além do PAM, um projeto foi desenvolvido (SOS UTFPR), visando gerar subsídios para a construção do conhecimento sobre TCT em primeiros socorros e antropotecnologia.

Posteriormente, as informações repassadas pelas principais autoridades competentes foram organizadas na forma descritiva, ilustrativa e gráfica.

As pessoas envolvidas nas coletas de dados foram representadas pelo Estado Maior, com o:

- Governo Federal Ministérios das Cidades e a Política Nacional de Proteção e Defesa Civil (Secretaria Nacional de Desenvolvimento Urbano);

- Comando Geral do Corpo de Bombeiros do Paraná, assim como representantes do comando de Brasília, São Paulo, Minas Gerais, etc. 
- Exército Brasileiro, Polícia Militar, Cidades - Departamento de Gestão de Riscos e Mobilidade Urbana, Defesa Civil do Estado e Comando Geral do Corpo de Bombeiros do Paraná e principais representantes formais do PAM do Estado do Paraná. 


\section{RESULTADOS E DISCUSSÃO}

\section{BIBLIOMETRIA}

A revisão sistemática de literatura realizada neste trabalho resultou na descoberta da não existência de estudos de antropotecnologia no DMA e PAM. Os resultados brutos obtidos nas bases de dados pesquisadas estão apresentados na Tabela 6.

Foram pesquisados os artigos nas principais bases de dados, como: Science Direct, Scopus, Web of Science, Emerald, PubMed e Scielo, foi obtido um total de 938 artigos (grupo1: com 24; grupo 2: 785; grupo 4: 127; grupo 5: 0; grupo: 6: 0; grupo 7: 0; grupo 8: 3 e grupo 9: 0).

Os dados obtidos foram submetidos a processos de filtragem, seguindo os princípios metodológicos, buscando estudos que tivessem relevâncias. Visando selecionar apenas artigos diretamente relacionados com o tema de pesquisa, foram aplicados procedimentos de filtragem, individualmente para os grupos definidos: i) Eliminar artigos em duplicidade; ii) Eliminar artigos publicados em conferências (pelo fato de não possuírem fator de impacto); e, iii) Eliminar artigos não relacionados com o tema em estudo, conforme demonstrados no Quadro 3. 
Quadro 3 - Procedimentos de filtragem e resultados obtidos

\begin{tabular}{|c|c|c|}
\hline \multirow{2}{*}{ Critério de filtragem } & \multicolumn{2}{|c|}{ GRUPO 1} \\
\hline & Total bruto de artigos & Total de artigos após filtragem \\
\hline a) Artigos em duplicidade & 24 & 10 \\
\hline b) Artigos de conferência & 10 & 8 \\
\hline c) Artigos fora do escopo & 8 & 7 \\
\hline Critério de filtracem & \multicolumn{2}{|c|}{ GRUPO 2} \\
\hline & Total bruto de artigos & Total de artigos após ffltragem \\
\hline a) Artigos em duplicidade & 785 & 504 \\
\hline b) Artigos de conferência & 504 & 102 \\
\hline c) Artigos fora do escopo & 102 & 77 \\
\hline \multirow{2}{*}{ Critério de ffltragem } & \multicolumn{2}{|c|}{ GRUPO 4} \\
\hline & Total bruto de artigos & Total de artigos após filtragem \\
\hline a) Artigos em duplicidade & 127 & 127 \\
\hline b) Artigos de conferência & 127 & 127 \\
\hline c) Artigos fora do escopo & 127 & 127 \\
\hline \multirow{2}{*}{ Critério de ffltragem } & \multicolumn{2}{|c|}{ GRUPO 8} \\
\hline & Total bruto de artigos & Total de artigos após filtragem \\
\hline a) Artigos em duplicidade & 3 & 3 \\
\hline b) Artigos de conferência & 3 & 3 \\
\hline c) Artigos fora do escopo & 3 & 3 \\
\hline
\end{tabular}

Entre os grupos pesquisados, após as filtragens, o Grupo 4 (“Knowledge and Technology Transfer" and "Disaster Mutual Assistance") e o Grupo 2 ("Knowledge and Technology Transfer") apresentaram quantidades superiores de artigos, se comparados aos demais grupos, respectivamente. Para tanto, esses grupos foram submetidos à Methodi Ordinatio para a seleção de melhores artigos.

Tabela 2 - Justificativa da seleção dos artigos

\begin{tabular}{ccc|c} 
Grupo & $\begin{array}{c}\text { Total de artigos após } \\
\text { filtragem }\end{array}$ & $\begin{array}{c}\text { Total de artigos } \\
\text { analisados a partir da } \\
\text { Methodi Ordinatio }\end{array}$ & Artigos descartados \\
Grupo 1 & 7 & 7 & 0 \\
Grupo 2 & 77 & 20 & 57 \\
Grupo 4 & 127 & 20 & 107 \\
Grupo 8 & 3 & 3 & 0 \\
TOTAL & 214 & 50 & 164 \\
\hline
\end{tabular}

Fonte: Elaborada pela pesquisadora (2018)

As respectivas quantidades de artigos analisados por grupo foram: 7 artigos no Grupo 1; 20 artigos no Grupo 2; 20 artigos no Grupo 4; e, 3 artigos no Grupo 8. Portanto, obteve-se um portfólio de 50 artigos, que foram analisados por meio de leitura na íntegra, coleta de dados e informações relevantes.

Visando contribuir com o panorama dos trabalhos sobre antropotecnologia (inseridos no Grupo 1), foram identificados os principais meios de publicação desses estudos, descritos na Gráfico 3. 
Gráfico 3 - Fonte de publicação sobre Antropotecnologia.

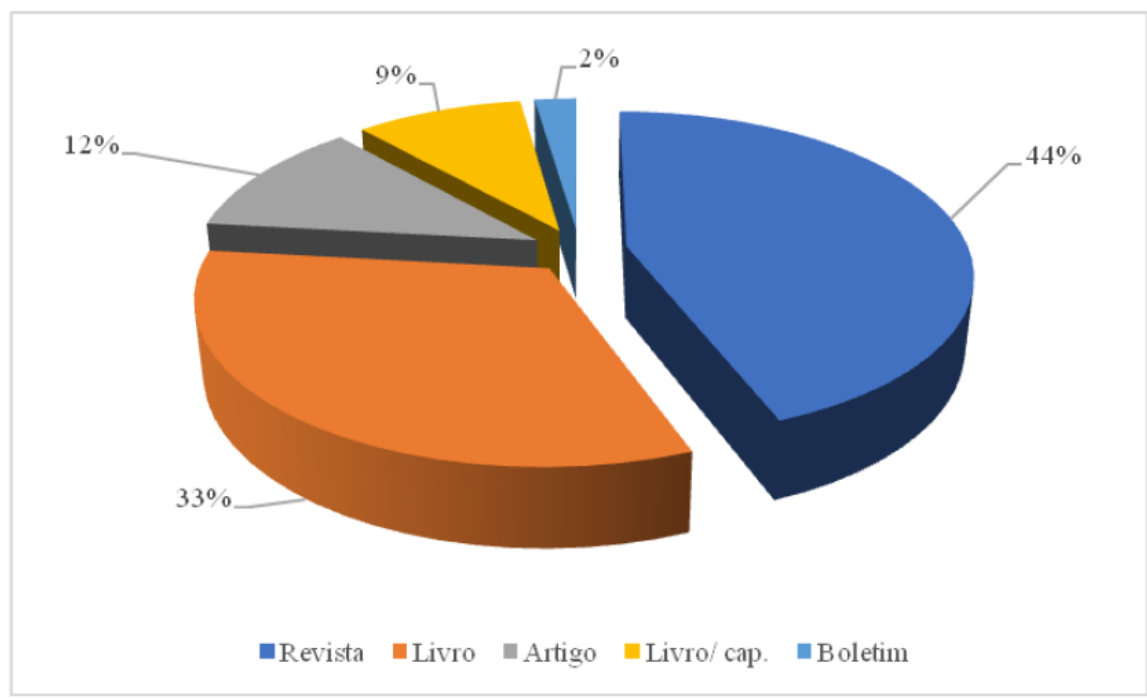

Fonte: Elaborada pela pesquisadora (2018)

Observa-se que a maior parcela de estudos encontra-se inserida em revistas (44\%), seguidos de livros (33\%), artigos (12\%), livros/capítulos com (9\%) e ao final, boletins com (2\%).

A Gráfico 4 apresenta as áreas onde a antropotecnologia está inserida.

\section{Gráfico 4 - Áreas que estudam a Antropotecnologia.}

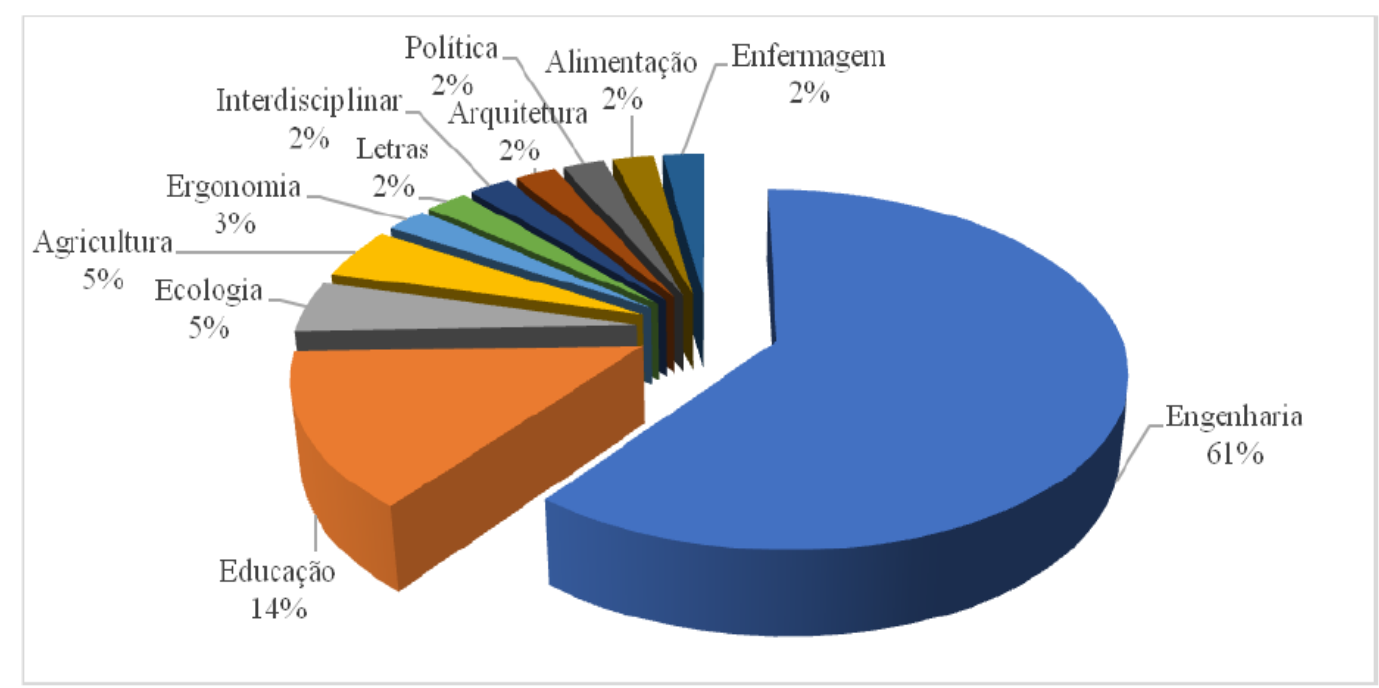

Fonte: Elaborada pela pesquisadora (2018)

Entre os estudos sobre a antropotecnologia, foram encontrados 45 artigos, e neles, a área de engenharia é predominante nas contribuições, correspondendo a (61\%). Os demais 39\% seguem conceitos diferenciados e áreas correlatas, como: agricultura, alimentação, arquitetura, ecologia, educação, ergonomia, interdisciplinar e política, de forma decrescente, conforme descritos na Tabela 3. 
Tabela 3 - Áreas da Engenharia e correlatas que estudam a antropotecnologia.

Áreas voltadas aos estudos sobre Antropotecnologia

1. Engenharias, $63 \%$

2. Educação, $14 \%$

3. Ecologia, $5 \%$

4. Agricultura, $5 \%$

5. Outros, $12 \%$
Temas abordados

Análise do trabalho e sistema produtivo (6)

Design industrial e inovação tecnológica (4)

Estudos do conforto (1)

Saúde e segurança do trabalho (2)

Higiene e medicina do trabalho (1)

Antropotecnologia e TCT (4)

Sistema energético e abastecimento (1)

Tecnologia de informação e sistemas (1)

Normas regulamentadoras - NR33 (1)

Acidentes de trabalho (1)

Trabalho e a exploração do homem (2)

Doenças relacionadas ao trabalho (1)

Construção civil e novas tecnologias (2)

Trabalho nas montadoras/Renault (2)

Educação, psicologia do trabalho e a TCT (3)

Educação para a segurança do trabalho (1)

Universidade, educação e tecnologia (1)

Evolução biológica e tecnológica (1)

Sustentabilidade (1)

Produtos tóxicos e contaminações (1)

Produção de Agrotóxicos e Ergotoxicologia (1)

Transferência de tecnologia nos pesticidas (1)

Genótipos de agentes cancerígenos (1)

Aspectos antropotecnológicos na nutrição (1)

Aspectos antropotecnológicos e culturais (2)

Psicologia do trabalho (2)

A comunicação e o trabalho (1)

Fonte - Dados da pesquisa bibliográfica (2018)

O Gráfico 5 se refere às revistas e aos Jornais onde a antropotecnologia foi referenciada pelos autores, sendo que a Elsevier Science obteve o maior número de publicações. 
Gráfico 5 - Publicações por revista científica.

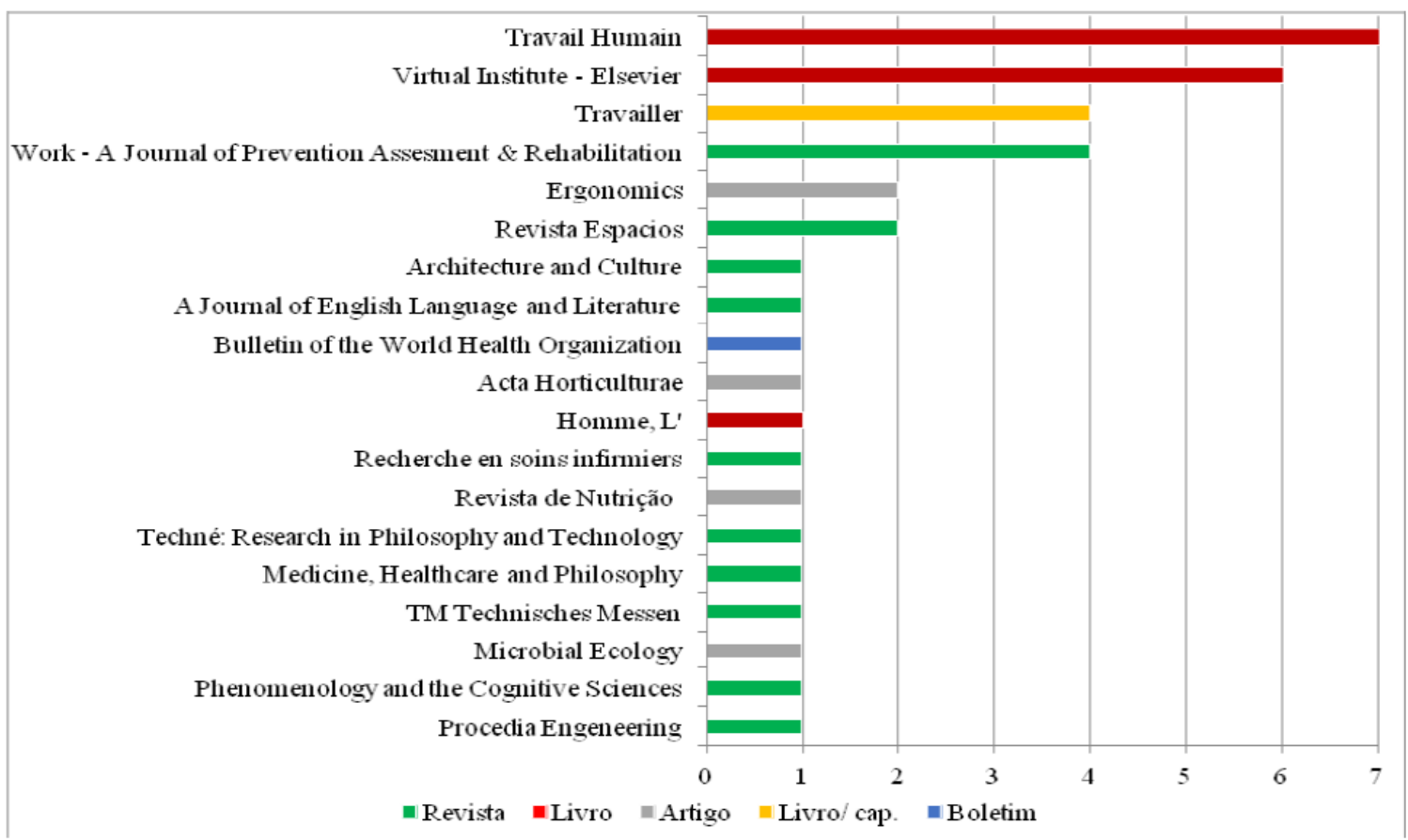

Fonte: Elaborada pela pesquisadora (2018)

Após a descoberta dos conceitos iniciais sobre antropotecnologia, realizada por Wisner, iniciaram-se os processos de inovações tecnológicas e industriais. Os melhores artigos, pertencentes ao Grupo 1 (tratam da antropotecnologia), são descritos no Quadro 4. 
Quadro 4 - Análise qualitativa de artigos

\begin{tabular}{|c|c|c|}
\hline $\begin{array}{c}\text { Artigos sobre } \\
\text { antropotecnologia }\end{array}$ & Autor & Foco do artigo \\
\hline $\begin{array}{l}\text { Science and technology policy } \\
\text { in Latin America: The political } \\
\text { activity and the } \\
\text { anthropotechnology in } \\
\text { technology transfer processes }\end{array}$ & $\begin{array}{c}\text { Gomes, M. and } \\
\text { Kovaleski, J. }\end{array}$ & $\begin{array}{l}\text { Investimentos por parte do governo, em políticas } \\
\text { voltadas a inovações tecnológicas e projetos em } \\
\text { TT e a antropotecnologia, incluindo os } 3 \\
\text { principais atores: a Universidade, as Empresas e } \\
\text { o Governo; }\end{array}$ \\
\hline $\begin{array}{l}\text { Pesticides and the paradox of } \\
\text { the Anthropocene: From natural } \\
\text { to synthetic to synthesised } \\
\text { nature }\end{array}$ & Davis, F. & $\begin{array}{l}\text { A observação dos trabalhadores rurais e a } \\
\text { exposição aos mesmos a pesticidas, ocorridos } \\
\text { em parreirais franceses, em plantações de arroz } \\
\text { asiáticas. Propondo com isso, mecanismos de } \\
\text { prevenção, uso de EPI, orientações aos } \\
\text { trabalhadores, e cobrança dos empresários em } \\
\text { busca da saúde e segurança dos trabalhadores; }\end{array}$ \\
\hline $\begin{array}{l}\text { Introduction: Critiquing } \\
\text { technologies of the mind: } \\
\text { enhancement, alteration, and } \\
\text { anthropotechnology }\end{array}$ & Meacham, D. & $\begin{array}{l}\text { Intervenções tecnológicas sobre, o } \\
\text { relacionamento humano, voltadas às relações } \\
\text { interpessoais, respeitando a cultura, questões } \\
\text { hereditárias, linguagem, aspectos sociais, } \\
\text { abrindo as avaliações para um novo debate, } \\
\text { envolvendo tecnologias que estreitem essas } \\
\text { interações; }\end{array}$ \\
\hline $\begin{array}{l}\text { Anthropotechnology: Sloterdijk } \\
\text { on Environmental Design and } \\
\text { the FoamWorlds of Co-Isolation }\end{array}$ & Mugerauer, R. & $\begin{array}{l}\text { A história da arquitetura e urbanismo, frente aos } \\
\text { aspectos antropotecnológicos, avaliados e } \\
\text { reorganizados, de forma a atender novos } \\
\text { quesitos, como construções que promovam o } \\
\text { bem estar e a qualidade de vida de seus } \\
\text { moradores; }\end{array}$ \\
\hline $\begin{array}{l}\text { The use of pesticides in French } \\
\text { viticulture: a badly controlled } \\
\text { technology transfer! }\end{array}$ & $\begin{array}{l}\text { Garrigou, A., } \\
\text { Baldi, I. and } \\
\text { Jackson, M. }\end{array}$ & $\begin{array}{l}\text { A ergotoxicologia, e os demais pesticidas } \\
\text { utilizados nas viniculturas, inicialmente, } \\
\text { contribuíram com diversas doenças do trabalho. } \\
\text { Tornando-se necessário um investimento maior } \\
\text { em transferência de tecnologia, para adquirir } \\
\text { mecanismos que assegure a saúde dos } \\
\text { trabalhadores; }\end{array}$ \\
\hline $\begin{array}{l}\text { The impact of } \\
\text { 'anthropotechnology' on human } \\
\text { evolution }\end{array}$ & Blad, S. & $\begin{array}{l}\text { Estudos genéticos da psicologia, desde nossos } \\
\text { ancestrais, e a ligação entre a transferência de } \\
\text { tecnologia e as evoluções dos seres humanos, } \\
\text { pois ela veio gradativamente e hoje está inserida } \\
\text { em todas as áreas evolutivas; }\end{array}$ \\
\hline $\begin{array}{l}\text { Towards an } \\
\text { Anthropotechnology. } x \text {. a new } \\
\text { activity for the United Nations in } \\
\text { the service of economic } \\
\text { development: specifying } \\
\text { requirements for Technology } \\
\text { Transfers in } \\
\text { given geographical and } \\
\text { anthropological locations } \\
\end{array}$ & Wisner, A. & $\begin{array}{l}\text { Visão antropotecnológica sobre os primeiros } \\
\text { contatos com as inovações tecnológicas, iniciada } \\
\text { pelos estudos ergonômicos e posteriormente, } \\
\text { atribuídos às inúmeras ciências como: questões } \\
\text { sociais, culturais, demográficas, etc. Observando } \\
\text { que as conexões e evoluções dos temas, } \\
\text { estavam ligadas a forma com que o povo se } \\
\text { relacionava com seus governantes, as máquinas } \\
\text { e o trabalho. }\end{array}$ \\
\hline
\end{tabular}

Após a revisão de literatura, iniciou-se o estudo conectivo entre os principais artigos e os temas abordados, seguindo a análise dos mesmos. 


\section{PLANO DE AUXÍlIO MÚTUO (PAM) NO BRASIL E NO ESTADO DO PARANÁ}

O PAM está estruturado em cada cidade através de ações de parcerias entre as principais empresas, sendo contatadas pelo Corpo de Bombeiros local, que realiza visitas a elas, buscando demonstrar a necessidade de sua participação. Através dessas parcerias podem ser ofertados treinamentos mensais envolvendo um grupo de funcionários brigadistas que, em caso de emergência, venham a compor uma equipe especializada a apoios.

Para a efetividade no atendimento à emergência com recursos de empresas, é necessário que o PAM seja eficiente nas ações de atendimento à emergência e na utilização dos recursos materiais e humanos. Para isso, se faz necessária à criação de uma estrutura que envolva todos os participantes do PAM para definição de responsabilidades, recursos, treinamento e simulados (CALIXTO, 2011).

A finalidade de implementação do PAM é estabelecer as linhas de ação a serem seguidas pelas indústrias e órgãos públicos, nominalmente envolvidos no escopo do plano, visando à adoção de procedimentos coordenados que permitam o controle eficaz de emergências no polo industrial (MACEDO, 1994).

Na Figura 3 é apresentada a estrutura hierárquica do PAM. 
Figura 3 - Divisão hierárquica e funcional do PAM.

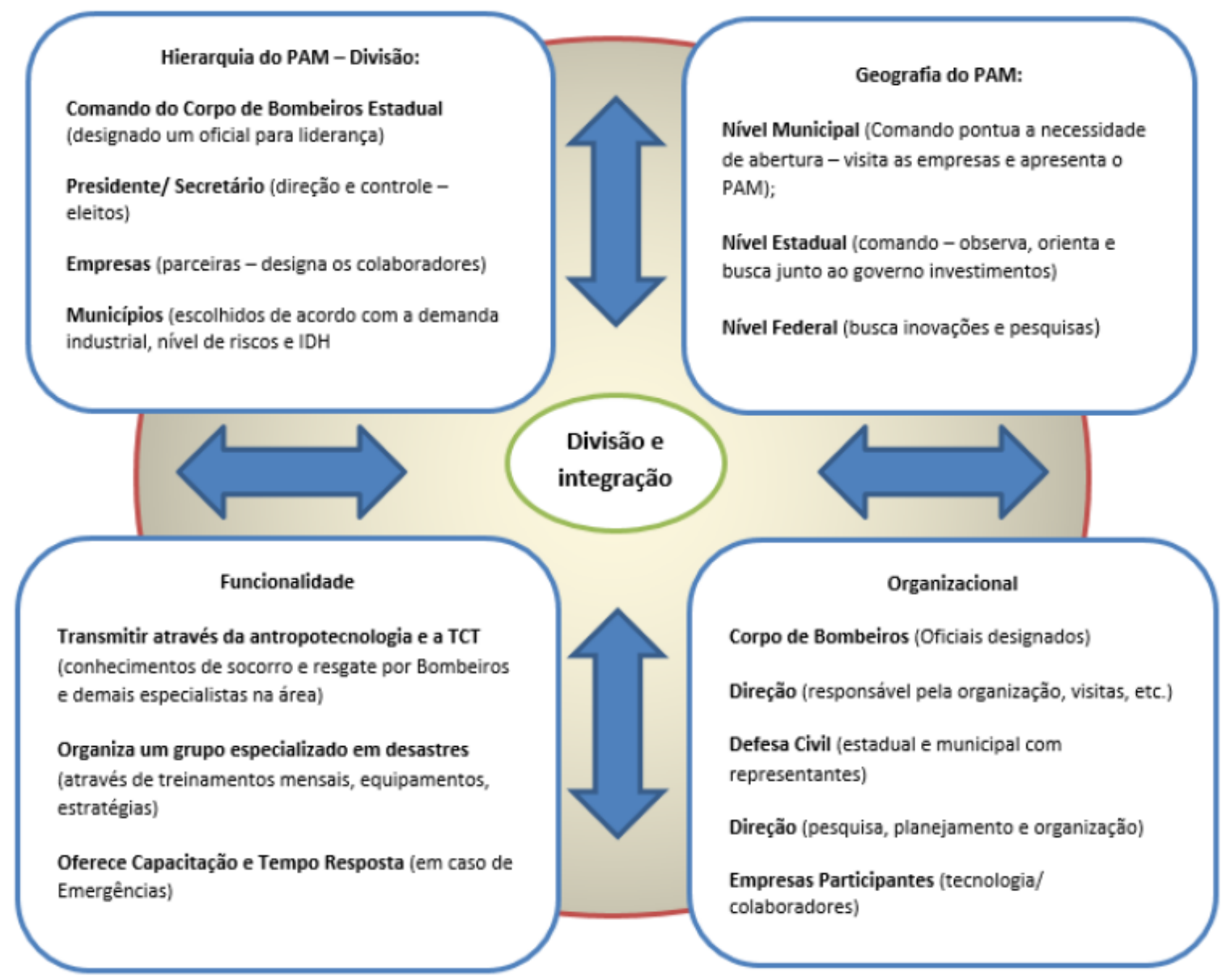

Fonte: Elaborada pela pesquisadora (2018)

Dentro da coleta de dados do PAM existe um sistema hierárquico que conduz as equipes de trabalho, relacionando as tarefas e o desempenho de cada participante, conforme apontado na Figura 3.

No Brasil, o PAM ainda é um projeto novo, e ainda não possui um modelo padronizado, pois cada região atende à padrões diferenciados (criação de estatuto e normas). Portanto, o que se observou dentro das pesquisas, foi que o Corpo de Bombeiros, de cada região, fiscaliza as indústrias, avaliando o plano de riscos (produtos químicos, riscos de acidentes, riscos ambientais, etc.), e com isso, se verifica a necessidade de implantação de ações.

Já o PAM no Paraná, dentre aos demais estados do país, se sobressai, devido aos aspectos somados à visão de prevenção, alinhada aos valores e culturas compostas pelas multinacionais situadas no Estado. Para as organizações, aspectos preventivos são mais econômicos, seguros e valorizados pelos seus stakeholders e comunidade. 
A estratégia do projeto PAM deve ser avaliada e adaptada ao número de empresas parceiras, estabelecendo: Quais os principais ramos de atuação de que faz parte?; Quais são os agentes químicos e principais produtos perigosos que compõem seu processo produtivo?; e, Quais são as rotas de fuga e escape nas suas imediações?

Pode-se dizer que a criação de PAM nas cidades do Paraná está ocorrendo de forma pontual e gradativa. Dados esses fornecidos pelo representante do comando maior do Estado, o Chefe da $8^{\text {a }}$ Seção do Corpo de Bombeiros, Tenente-Coronel Gabriel Mocelin e Tenente Coronel Fábio Mariano de Oliveira (fundador do PAM no Estado): “... O processo de conscientização da necessidade de implantar o Plano de Auxílio Mútuo tem sido repassado às empresas, através dos responsáveis em cada município, cujos índices de aceitação e envolvimento das empresas têm se apresentados satisfatórios".

$\mathrm{Na}$ Tabela 4 são apresentadas as cidades paranaenses que possuem ações do PAM. 
Tabela 4 - Perfil das cidades paranaense que possuem PAM

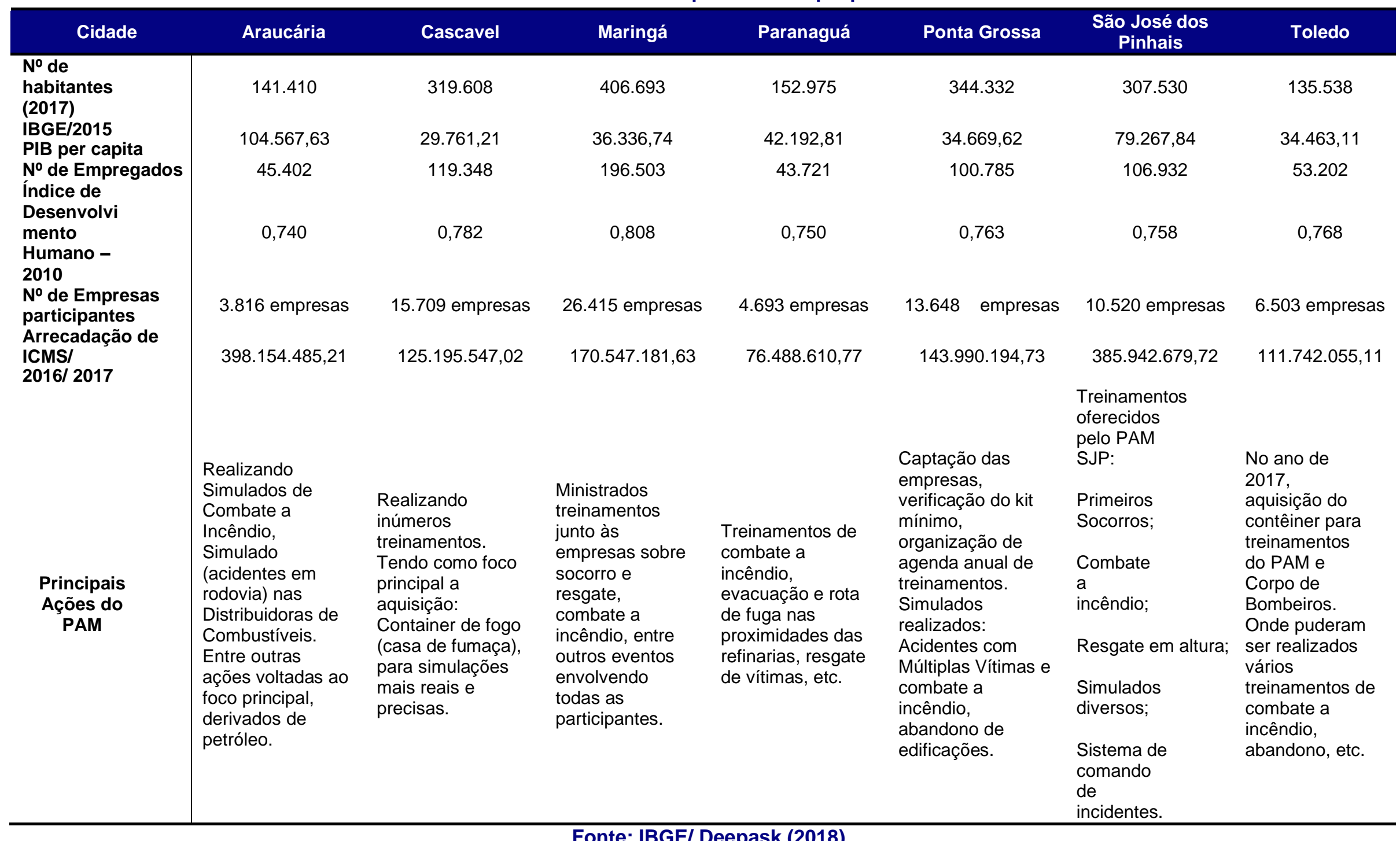

Fonte: IBGE/ Deepask (2018) 
A partir deste momento foram apresentados projetos PAM, já atuantes, em alguns municípios do Estado do Paraná, como: Ponta Grossa, Toledo, Araucária, Maringá, Cascavel, São José dos Pinhais, Paranaguá, e demais ações.

\section{Plano de auxílio mútuo (PAM) em Ponta Grossa, no Paraná}

Cada município tem suas particularidades e devem ser respeitadas, pois geralmente as empresas trazem consigo determinada resistência. Para tanto, 0 trabalho inicial foi nada menos do que o contato e demonstração sobre como se tornou importante à implantação do PAM neste município (Ponta Grossa).

Muitas empresas vieram e veem se instalar na região de Ponta Grossa, Paraná, devido à valorização logística. Para tanto, se torna de suma importância que elas possuam ações em grupo que possam dar suporte técnico, com equipamentos e pessoal capacitado, de forma que, após a solicitação e direcionamento de ações, possam, em conjunto, oferecer suporte às vidas de colaboradores.

O PAM em Ponta Grossa foi organizado e implantado em 23 de março de 2017, segundo informações do comando atual do Major Saqueta, Capitão Marcelo e sob o comando do Capitão André Lopes, responsáveis pelo PAM, na cidade. O projeto atualmente conta com mais de 30 empresas participantes, sendo que 19 delas estão ativas no momento.

A priori foi verificado junto aos profissionais responsáveis pela segurança das empresas, se eles tinham ciência e conhecimento sobre o PAM. Dessa forma, foi detectado que o projeto era do conhecimento dos colaboradores e que na cidade já havia sido implantado algo parecido, pois algumas empresas já realizavam treinamentos emergenciais em conjunto, mas por falta de conhecimento e técnicas supervisionadas, acabaram por desistir dessas primeiras ações.

Inicialmente, o PAM foi constituído por 19 empresas descritos no Quadro 6, e 4 órgãos públicos representados pelo Corpo de Bombeiros, Polícia Militar, SAMU e Defesa Civil. A inserção dos órgãos públicos visa justamente tomar conhecimento e fazer parte do projeto para que, em caso de necessidade, todos possam atuar com 
ações coesas, obtendo então, respostas rápidas no menor espaço de tempo e com segurança.

$\mathrm{Na}$ fase inicial, foram aplicados questionários a todas as pessoas envolvidas, buscando assim, mensurar seus índices de conhecimento. A partir do momento em que fosse lançado o calendário de atividades, todos pudessem ter níveis básicos de conhecimento. Em seguida, foi oferecido aos participantes cursos de nivelamento, buscando facilitar o aproveitamento em tempo real. O nivelamento busca que o grupo possa atender às expectativas reais em caso de emergência, não somente o conhecimento, como também o uso de EPIs. Iniciaram-se, portanto, os treinamentos sobre primeiros socorros, produtos perigosos, armazenagem, a utilização do kit mínimo, ações de emergências, entre outros, seguindo o calendário mensal.

Tais exigências e treinamentos buscam criar condições para que esses profissionais ofereçam de forma rápida, precisa e consciente, os primeiros passos em caso de qualquer emergência que possa ocorrer dentro da empresa e, até mesmo, acionar o Corpo de Bombeiros, caso haja maior gravidade e seja necessária a intervenção do PAM. O resumo de ações promovidas pelo PAM é apresentado no Quadro 5. 
Quadro 5 - Ações estratégicas promovidas pelo PAM, em Ponta Grossa (2017 e 2018)

\begin{tabular}{|l|c|}
\hline \multicolumn{1}{|c|}{ Mês } & Treinamentos desenvolvidos com os participantes \\
\hline $1^{\circ}$ jun. & Reunião para apresentação do projeto PAM \\
\hline $2^{\circ}$ jul. & Reunião para adesão ao PAM \\
\hline $3^{\circ}$ ago. & Palestra de SCI, rádio comunicação, segurança pessoal e EPI \\
\hline $4^{\circ}$ set. & Simulado SCl, comunicação, segurança pessoal e EPI \\
\hline $5^{\circ}$ out. & Palestra sobre primeiros socorros AMUVI (acidente com múltiplas vítimas) \\
\hline $6^{\circ}$ nov. & Treinamento abandono de edificações \\
\hline $7^{\circ}$ dez. & Simulado de abandono de edificações \\
\hline $8^{\circ}$ fev. & Palestra sobre combate a incêndios \\
\hline $10^{\circ}$ mar. & Palestra NPT 17 (brigadistas) \\
\hline $11^{\circ}$ abr. & Palestra do Batalhão de Polícia Militar de Operações Aéreas \\
\hline $12^{\circ}$ mai. & Reunião de Eleição do PAM \\
\hline $13^{\circ}$ jun. & Armazenamento e Transporte de Produtos Perigosos - BPMOA \\
\hline $14^{\circ}$ jul. & Treinamento de RCP (parada cardiorrespiratória) e o uso do DEA (desfibrilador \\
& automático) \\
\hline $15^{\circ}$ ago. & Resgate Vertical \\
\hline $16^{\circ}$ set. & Instrução de NR 35 \\
\hline $17^{\circ}$ out. & Treinamento de NR 35 \\
\hline $18^{\circ}$ nov. & Relatório final das ações estabelecidas em 2018 e programação para 2019 \\
\hline
\end{tabular}

Fonte - Elaborada pela pesquisadora (2018)

No final do ano de 2018 foi realizada, junto às empresas participantes e seus líderes, elaboração de propostas pelos mesmos que poderá ser colocada em prática para o ano de 2019. Para tanto, os dados foram coletados através de pesquisa documental, aplicada na última reunião de encerramento e prestação de contas do ano. 


\begin{tabular}{|c|c|c|c|c|c|c|c|}
\hline $\begin{array}{c}\text { Ramo } \\
\text { industrial }\end{array}$ & $\begin{array}{c}\text { Relevância e } \\
\text { melhorias sobre os } \\
\text { treinamentos } \\
\text { oferecidos pelo } \\
\text { PAM }\end{array}$ & Aulas teóricas & Aulas práticas & Aspectos positivos & $\begin{array}{l}\text { Aspectos } \\
\text { negativos }\end{array}$ & Sugestões & $\begin{array}{c}\text { Na de } \\
\text { colaboradores }\end{array}$ \\
\hline \begin{tabular}{|} 
Cooperativa \\
agroindustrial \\
de derivados de \\
leite, carnes e \\
agricultura
\end{tabular} & \begin{tabular}{|} 
Reforça o \\
entrosamento entre \\
as equipes de \\
trabalho.
\end{tabular} & $\begin{array}{l}\text { Muito boas, e que } \\
\text { possam conter } \\
\text { temas mais } \\
\text { aprofundados às } \\
\text { realidades das } \\
\text { empresas. }\end{array}$ & $\begin{array}{l}\text { Excelente, que } \\
\text { possam ser mais } \\
\text { próximas. }\end{array}$ & $\begin{array}{l}\text { Conhecimento teórico/ } \\
\text { prático, sendo trocado } \\
\text { entre multinacionais. }\end{array}$ & $\begin{array}{c}\text { Falta de espaço } \\
\text { físico próprio para } \\
\text { os treinamentos. }\end{array}$ & \begin{tabular}{|c|} 
Aprova a \\
revitalização do \\
Centro de \\
Capacitação dos \\
Bombeiros para \\
os encontros. \\
\end{tabular} & 170 \\
\hline $\begin{array}{c}\text { Fabricação de } \\
\text { bebidas }\end{array}$ & $\begin{array}{c}\text { Houve pouca } \\
\text { participação das } \\
\text { empresas em } 2017 .\end{array}$ & $\begin{array}{l}\text { Boas, mas muito } \\
\text { longas. }\end{array}$ & Muito poucas. & $\begin{array}{l}\text { Participação de mais } \\
\text { empresas, maior } \\
\text { integração. }\end{array}$ & $\begin{array}{c}\text { Não houve } \\
\text { Apontamento da } \\
\text { empresa nesse } \\
\text { quesito. }\end{array}$ & \begin{tabular}{|c|} 
Realizar tour \\
informativo nas \\
empresas \\
participantes, \\
informando \\
principais riscos e \\
áreas de escape.
\end{tabular} & 475 \\
\hline $\begin{array}{l}\text { Fabricação de } \\
\text { adubos, } \\
\text { fertilizantes e } \\
\text { manuseio de } \\
\text { sementes }\end{array}$ & $\begin{array}{c}\text { Após treinamentos é } \\
\text { nítida a motivação e } \\
\text { interesse vindo dos } \\
\text { participantes em } \\
\text { replicar os } \\
\text { conhecimentos. }\end{array}$ & \begin{tabular}{|} 
Muito boa, mas \\
deve-se buscar, a \\
cada dia, melhorar e \\
cuidar com \\
aspectos de \\
repetição dos \\
temas.
\end{tabular} & $\begin{array}{l}\text { Muito boas, espera- } \\
\text { se que haja mais. }\end{array}$ & $\begin{array}{l}\text { Após o treinamento do } \\
\text { PAM, a empresa adota o } \\
\text { procedimento de replicar } \\
\text { informações obtidas dos } \\
\text { participantes, reportando } \\
\text { os novos conhecimentos. }\end{array}$ & \begin{tabular}{|c|} 
Ainda não foi \\
organizado um \\
plano de gestão a \\
longo prazo, \\
buscando com isso \\
a qualidade de \\
conhecimento e \\
aprendizagem \\
ministrados.
\end{tabular} & \begin{tabular}{|} 
Realizar eleições \\
da gerência do \\
PAM 2018, cuidar \\
com gestão \\
repetitiva, \\
organizar \\
planejamento de \\
gestão de riscos \\
para treinamentos.
\end{tabular} & 320 \\
\hline
\end{tabular}


Quadro 6 - Parceiros participantes do PAM.

\begin{tabular}{|c|c|c|c|c|c|c|c|}
\hline $\begin{array}{c}\text { Ramo } \\
\text { industrial }\end{array}$ & $\begin{array}{c}\text { Relevância e } \\
\text { melhorias sobre os } \\
\text { treinamentos } \\
\text { oferecidos pelo } \\
\text { PAM }\end{array}$ & Aulas teóricas & Aulas práticas & Aspectos positivos & $\begin{array}{l}\text { Aspectos } \\
\text { negativos }\end{array}$ & Sugestões & $\begin{array}{c}\mathrm{N} \text { ㄹ de } \\
\text { colaboradores }\end{array}$ \\
\hline $\begin{array}{l}\text { Fabricação de } \\
\text { óleos vegetais }\end{array}$ & \begin{tabular}{|} 
Abertura de acesso \\
do Corpo de \\
Bombeiros, \\
acompanhamento, \\
maior acesso e \\
ensino de técnicas \\
dentro das indústrias.
\end{tabular} & $\begin{array}{c}\text { Importantes, mas } \\
\text { muito extensas, } \\
\text { necessárias, mas } \\
\text { devem ser mais } \\
\text { concisas e ágeis } \\
\text { nas explicações. }\end{array}$ & \begin{tabular}{|c|} 
Muito boas, mas \\
devem ter o tempo \\
diminuído em \\
apresentações das \\
empresas nas quais \\
os treinamentos \\
ocorrerão, para que \\
a prática seja \\
estendida.
\end{tabular} & \begin{tabular}{|} 
Integração de toda a \\
equipe, acesso a \\
respostas em tempo real, \\
aprendizado coletivo, \\
conhecimento da \\
realidade de cada \\
indústria e seus \\
principais fatores de risco \\
e contribuições.
\end{tabular} & $\begin{array}{c}\text { Tempo muito } \\
\text { Prolongado nos } \\
\text { simulados, (pré e } \\
\text { pós- } \\
\text { treinamentos). } \\
\text { Ocasionando } \\
\text { assim, alterações } \\
\text { nos processos } \\
\text { produtivos das } \\
\text { mesmas. }\end{array}$ & \begin{tabular}{|c|} 
Organizar um \\
Centro de \\
Treinamentos - \\
Casa de Fumaça \\
- para que eles \\
possam ser mais \\
reais junto à \\
comunidade do \\
PAM, além de \\
focar nas \\
questões \\
ambientais. \\
\end{tabular} & 260 \\
\hline $\begin{array}{c}\text { Fabricação de } \\
\text { Produtos } \\
\text { Químicos }\end{array}$ & \begin{tabular}{|} 
Muito importante \\
fazer parte do PAM, \\
pois ampliou os \\
conhecimentos junto \\
aos colaboradores.
\end{tabular} & \begin{tabular}{|c|} 
Muito importante \\
para o aprendizado \\
e o reconhecimento \\
de novos protocolos \\
de atendimento a \\
emergências \\
químicas.
\end{tabular} & $\begin{array}{c}\text { Muito importante, } \\
\text { pois estamos com } \\
\text { uma equipe mais } \\
\text { madura e melhor } \\
\text { preparada, visto a } \\
\text { ampliação dos } \\
\text { treinamentos. }\end{array}$ & \begin{tabular}{|c|} 
Proporcionou o ambiente \\
mais seguro, pois trouxe \\
o conhecimento sobre a \\
identificação e o controle \\
dos protocolos de \\
produtos químicos.
\end{tabular} & \begin{tabular}{|c|} 
Não achei nenhum \\
fator negativo, mas \\
acredito que os \\
membros da \\
comissão \\
poderiam ser mais \\
motivadores e \\
incentivar mais a \\
equipe. \\
\end{tabular} & \begin{tabular}{|c|} 
Realizar um \\
simulado na \\
rodovia, com um \\
cenário contendo \\
vítimas, \\
emergência \\
ambiental com \\
produtos químicos \\
e fogo. \\
\end{tabular} & 156 \\
\hline $\begin{array}{c}\text { Fabricação de } \\
\text { sistemas de } \\
\text { movimentações } \\
\text { Logísticas }\end{array}$ & $\mid \begin{array}{c}\text { Na minha concepção } \\
\text { técnica todos os } \\
\text { treinamentos } \\
\text { agregaram } \\
\text { conhecimentos no } \\
\text { quesito de prevenção } \\
\text { e segurança do } \\
\text { trabalho na empresa. }\end{array}$ & \begin{tabular}{|c|} 
Todos os \\
treinamentos \\
agregarão \\
conhecimentos no \\
quesito de \\
prevenção e \\
segurança do \\
trabalho na \\
empresa. \\
\end{tabular} & $\begin{array}{c}\text { Muito boas, mas } \\
\text { deveria ter menos } \\
\text { aulas teóricas e } \\
\text { mais práticas. }\end{array}$ & $\begin{array}{c}\text { Continuar trabalhando } \\
\text { com o conceito de } \\
\text { prevenção dentro das } \\
\text { empresas participantes, e } \\
\text { treiná-las conforme a } \\
\text { necessidade de cada } \\
\text { uma conforme o grau de } \\
\text { risco. }\end{array}$ & \begin{tabular}{|c|} 
Fatores negativos \\
não encontrados, \\
mas como \\
sugestão poderia \\
fazer treinamentos \\
visando à \\
realidade de cada \\
empresa e suas \\
condições. \\
\end{tabular} & $\begin{array}{c}\text { Sugere que haja } \\
\text { fundamentação de } \\
\text { lei para apoio e } \\
\text { recursos. }\end{array}$ & 609 \\
\hline
\end{tabular}




\begin{tabular}{|c|c|c|c|c|c|c|c|}
\hline $\begin{array}{c}\text { Ramo } \\
\text { industrial }\end{array}$ & $\begin{array}{c}\text { Relevância e } \\
\text { melhorias sobre os } \\
\text { treinamentos } \\
\text { oferecidos pelo } \\
\text { PAM }\end{array}$ & Aulas teóricas & Aulas práticas & Aspectos positivos & $\begin{array}{l}\text { Aspectos } \\
\text { negativos }\end{array}$ & Sugestões & $\begin{array}{c}\mathrm{N}^{\mathrm{a}} \mathrm{de} \\
\text { colaborador } \\
\text { es }\end{array}$ \\
\hline $\begin{array}{l}\text { Reflorestam } \\
\text { ento de } \\
\text { pinus e } \\
\text { processame } \\
\text { nto para } \\
\text { exportação }\end{array}$ & $\begin{array}{l}\text { Houve maior } \\
\text { valorização dos } \\
\text { colaboradores } \\
\text { envolvidos na } \\
\text { brigada, pois } \\
\text { atuam como } \\
\text { multiplicadores de } \\
\text { informações. }\end{array}$ & $\begin{array}{c}\text { Trouxe } \\
\text { conhecimento } \\
\text { muito importante } \\
\text { que anteriormente } \\
\text { não foram } \\
\text { adquiridos. }\end{array}$ & $\begin{array}{l}\text { Promoveu } \\
\text { entrosamento } \\
\text { entre os } \\
\text { colaboradores } \\
\text { das outras } \\
\text { plantas da } \\
\text { empresa. }\end{array}$ & $\begin{array}{l}\text { Fortalecimento dos } \\
\text { interesses dos } \\
\text { participantes da } \\
\text { brigada e da } \\
\text { segurança. }\end{array}$ & $\begin{array}{l}\text { Em alguns dos } \\
\text { treinamentos } \\
\text { não dá para } \\
\text { participar devido } \\
\text { ao trabalho. }\end{array}$ & $\begin{array}{l}\text { Realizar mais } \\
\text { treinamentos nas } \\
\text { empresas. }\end{array}$ & 890 \\
\hline $\begin{array}{l}\text { Fabricação e } \\
\text { processame } \\
\text { ntos de } \\
\text { placas de } \\
\text { MDF para as } \\
\text { indústrias } \\
\text { moveleiras. }\end{array}$ & $\begin{array}{l}\text { Envolvida desde o } \\
\text { início, trouxe nos } \\
\text { simulados } \\
\text { integração entre } \\
\text { todos os setores da } \\
\text { empresa. }\end{array}$ & $\begin{array}{c}\text { Muito boas e muito } \\
\text { importantes. }\end{array}$ & $\begin{array}{c}\text { Proveitosa } \\
\text { envolvendo todo o } \\
\text { grupo. }\end{array}$ & $\begin{array}{l}\text { Capacitação de forma } \\
\text { gratuita, muito melhor } \\
\text { do que aquelas } \\
\text { prestadas por } \\
\text { empresas externas nos } \\
\text { treinamentos. }\end{array}$ & $\begin{array}{l}\text { Não tenho o que } \\
\text { informar. }\end{array}$ & $\begin{array}{l}\text { Sugere o local } \\
\text { próprio para } \\
\text { treinamentos, pois } \\
\text { muitas vezes as } \\
\text { empresas não } \\
\text { possuem tempo e } \\
\text { espaço para os } \\
\text { treinamentos. }\end{array}$ & 302 \\
\hline $\begin{array}{l}\text { Companhia } \\
\text { de alimentos } \\
\text { multinacional }\end{array}$ & $\begin{array}{l}\text { Convidada a } \\
\text { participar desde o } \\
\text { início e conta com } \\
\text { a participação dos } \\
\text { colaboradores } \\
\text { brigadistas. }\end{array}$ & $\begin{array}{l}\text { Treinamentos e a } \\
\text { integração de } \\
\text { pessoas }\end{array}$ & $\begin{array}{l}\text { Deveriam ser } \\
\text { mais voltadas à } \\
\text { realidade de cada } \\
\text { empresa. }\end{array}$ & $\begin{array}{c}\text { Organização e } \\
\text { interação. }\end{array}$ & $\begin{array}{l}\text { Deveria ter um } \\
\text { foco mais } \\
\text { próprio às } \\
\text { realidades de } \\
\text { produtos de } \\
\text { cada } \\
\text { organização. }\end{array}$ & $\begin{array}{l}\text { Que haja maior } \\
\text { espaçamento } \\
\text { entre um } \\
\text { treinamento e } \\
\text { outro. }\end{array}$ & 1160 \\
\hline
\end{tabular}




\begin{tabular}{|c|c|c|c|c|c|c|c|}
\hline Ramo industrial & \begin{tabular}{|c|} 
Relevância e \\
melhorias sobre \\
os treinamentos \\
oferecidos pelo \\
PAM
\end{tabular} & Aulas teóricas & Aulas práticas & Aspectos positivos & $\begin{array}{l}\text { Aspectos } \\
\text { negativos }\end{array}$ & Sugestões & $\begin{array}{c}\text { Na de } \\
\text { colaborador } \\
\text { es }\end{array}$ \\
\hline $\begin{array}{c}\text { Companhia de } \\
\text { concessionária } \\
\text { de rodovias. }\end{array}$ & $\begin{array}{c}\text { Muito relevante, } \\
\text { pois propicia } \\
\text { conhecimento } \\
\text { aos } \\
\text { colaboradores } \\
\text { de forma a } \\
\text { minimizar } \\
\text { impactos de } \\
\text { acidentes. }\end{array}$ & $\begin{array}{c}\text { Participação } \\
\text { integral muitas } \\
\text { vezes sendo } \\
\text { aplicadas pela } \\
\text { própria } \\
\text { concessionária } \\
\text { reforça os } \\
\text { conhecimentos. }\end{array}$ & $\begin{array}{c}\text { Disponibiliza os } \\
\text { próprios materiais } \\
\text { de } \\
\text { Profissionais para } \\
\text { oferecer } \\
\text { treinamentos. }\end{array}$ & $\begin{array}{l}\text { Muito importante, pois } \\
\text { disponibiliza } \\
\text { conhecimento sobre } \\
\text { ações iniciais às } \\
\text { vítimas de acidentados } \\
\text { ou em eventos } \\
\text { adversos. }\end{array}$ & Não encontrado. & $\begin{array}{l}\text { Que haja uma } \\
\text { formação cada dia } \\
\text { mais sólida do } \\
\text { grupo e que em } \\
2019 \text { possa haver } \\
\text { mais treinamentos. }\end{array}$ & 570 \\
\hline $\begin{array}{l}\text { Empresa global } \\
\text { de comércio } \\
\text { envolvida na } \\
\text { agricultura, } \\
\text { processamento } \\
\text { de alimentos, } \\
\text { transporte } \\
\text { Internacional e } \\
\text { finanças. }\end{array}$ & $\begin{array}{l}\text { O início da } \\
\text { participação foi } \\
\text { há alguns } \\
\text { meses e ainda } \\
\text { a participação } \\
\text { está sendo } \\
\text { adaptada. }\end{array}$ & Muito boas. & $\begin{array}{c}\text { Muito } \\
\text { conhecimento } \\
\text { para ser } \\
\text { explorado. }\end{array}$ & $\begin{array}{l}\text { Interessante e é } \\
\text { aplicado a todos. }\end{array}$ & $\begin{array}{c}\text { A empresa ainda } \\
\text { enfrenta } \\
\text { dificuldades em } \\
\text { liberação dos } \\
\text { colaboradores } \\
\text { para a } \\
\text { participação. }\end{array}$ & $\begin{array}{c}\text { Propôs que a } \\
\text { liderança do PAM } \\
\text { realize visitas aos } \\
\text { Diretores da } \\
\text { empresa, } \\
\text { divulgando melhor } \\
\text { o trabalho }\end{array}$ & 250 \\
\hline $\begin{array}{c}\text { Fabricação de } \\
\text { breu e } \\
\text { terebintina. }\end{array}$ & $\begin{array}{l}\text { Iniciou sua } \\
\text { participação há } \\
\text { alguns meses. }\end{array}$ & $\begin{array}{c}\text { Informações } \\
\text { pertinentes aos } \\
\text { conhecimentos } \\
\text { dos brigadistas. }\end{array}$ & $\begin{array}{l}\text { Muito } \\
\text { interessante e } \\
\text { possibilita a } \\
\text { participação do } \\
\text { grupo. } \\
\end{array}$ & $\begin{array}{c}\text { Estimula e abre espaço } \\
\text { à participação de todas } \\
\text { as empresas } \\
\text { interessadas em fazer } \\
\text { parte da equipe. }\end{array}$ & $\begin{array}{c}\text { Dificuldades de } \\
\text { participar muitas } \\
\text { vezes pela } \\
\text { própria rotina de } \\
\text { produção da } \\
\text { empresa. } \\
\end{array}$ & $\begin{array}{c}\text { Abordar temas } \\
\text { diferenciados para } \\
2019 .\end{array}$ & 50 \\
\hline $\begin{array}{c}\text { Empresa } \\
\text { produtora de } \\
\text { cargas minerais } \\
\text { voltadas às } \\
\text { indústrias }\end{array}$ & \begin{tabular}{c|} 
Há quatro \\
meses aderiu \\
ao PAM e ainda \\
está se \\
adequando aos \\
treinamentos. \\
\end{tabular} & $\begin{array}{l}\text { As estratégias do } \\
\text { PAM estão } \\
\text { totalmente } \\
\text { voltadas às } \\
\text { realidades das } \\
\text { empresas. }\end{array}$ & Muito boas. & Práticas e objetivas. & $\begin{array}{l}\text { Ainda não foi } \\
\text { observado. }\end{array}$ & $\begin{array}{l}\text { Que haja visitas } \\
\text { em todas as } \\
\text { demais empresas } \\
\text { que ainda não } \\
\text { participaram. }\end{array}$ & 31 \\
\hline
\end{tabular}


Para o ano de 2019, a liderança do PAM projetará novas ações que envolvam um maior número de empresas, ações conjuntas com a comunidade e investimentos.

O PAM de Ponta Grossa pode ser considerado, um dos mais estruturados do Estado, pois é o único que possui cede própria, com $10.075 \mathrm{~m}^{2}$; de acordo com as normas técnicas ambientais, disponível para efetuar diversos treinamentos, como: combate a incêndio, resgate em altura, resgate em escombros, simulados em casa de fumaça, entre outros. Contudo, a partir de 2019, esse espaço será articulado como, centro estratégico de comando pra todos os órgãos e integrantes.

Tais mudanças, o grupo especializado de Ponta Grossa do PAM poderá ser referenciado, não somente no Estado, mas também, em todo o país. Principalmente, pela integração da equipe, o trabalho, a busca por novas empresas e parcerias, solidificando os aspectos antropotecnológicos e a TCT, direcionados ao governo, universidade, indústria, a comunidade e ao meio ambiente.

\section{ASPECTOS ANTROPOTECNOLÓGICOS NO PAM}

A antropotecnologia e a TCT estão inseridas em diversas áreas do trabalho, ao manusear uma máquina ou equipamento, em treinamentos e orientações, na utilização das tecnologias, no contato e interações entre colaboradores, entre outras. Os aspectos antropotecnológicos estão inseridos nas atividades desenvolvidas pelo PAM, conforme a Figura 4. 
Figura 5 - Aspectos antropotecnológicos do PAM.

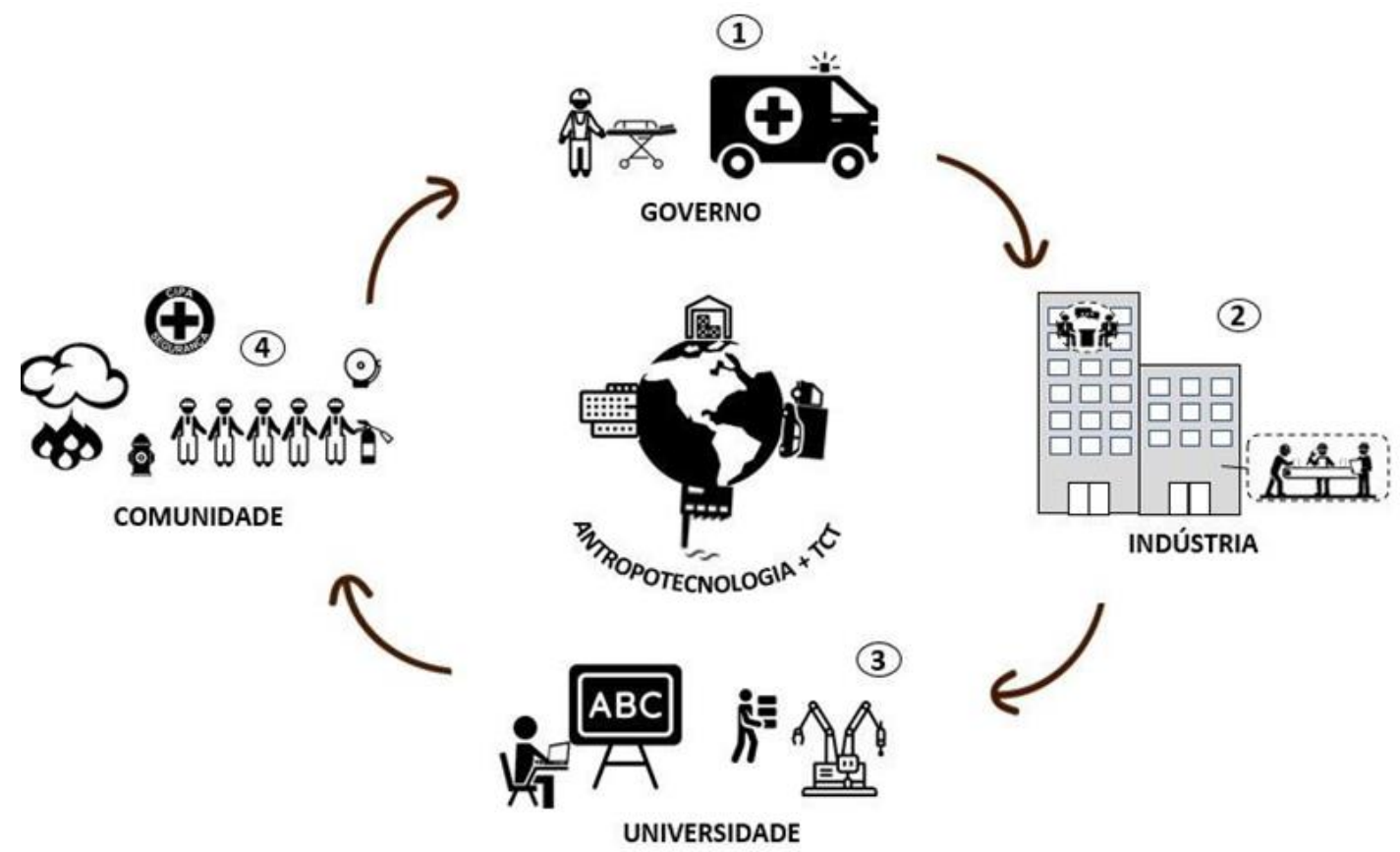

Fonte: Elaborada pela pesquisadora (2018)

Quatro principais atores são avaliados neste estudo, a mencionar:

- Governo: estrategicamente, o PAM foi formado pelo Corpo de Bombeiros, na busca de criar uma equipe especializada dentro das indústrias, que pudesse oferecer os primeiros atendimentos e apoio aos serviços de emergências em caso de eventos adversos. Tendo como intuito, fornecer conhecimentos constantes às empresas participantes do projeto, geralmente, composta pelo polo industrial de cada município. Para tanto, ocorrem treinamentos mensais sobre socorro, resgate, combate à incêndio, plano de abando, vazamentos de produtos químicos e demais tipos de eventos adversos (compostos de conhecimento teórico/ prático, simulações, apresentações de novos equipamentos e tecnologia de ponta);

- Indústria: Utiliza tais aspectos através das inovações tecnológicas na automação, na transferência de conhecimento levado aos colaboradores, através de treinamentos e reuniões, dos novos processos produtivos, respeitando aspectos de segurança e saúde do trabalhador, estimulando, contudo, a participação integral dos colaboradores, nos aspectos de crescimento e desenvolvimento da empresa; 
- Universidade: Tem como papel principal transmitir o conhecimento através da pesquisa, ensino e aprendizagem, enfatizando a implantação e aproveitamento de novos modelos e experiências, entre a tecnologia de novos materiais e equipamentos, e;

- Comunidade: Estão envolvidas e participam do processo de conhecimento e aprendizagem, trazendo experiências vivadas no dia a dia de trabalho, fornecem sugestões de melhoria e/ou adaptações e tecnologias. São incentivados a serem multiplicadores de informações aos demais companheiros de trabalho, nos aspectos de prevenção, de cuidados com possíveis acidentes de trabalho e com aspectos voltados à saúde individual e familiar.

Segundo os estudos realizados sobre antropotecnologia, pôde-se observar que ela estava intrinsecamente voltada aos aspectos ergonômicos, o que levou, posteriormente, a estabelecer relações entre outros aspectos do trabalho, como: A TCT que facilita e aprimora o trabalho; As inovações tecnológicas voltadas à necessidade constante de se aprimorar e, principalmente; Às relações interpessoais dentro dos ambientes, pois proporcionam menores índices de acidentes, menores gastos com manutenções e quebras de maquinários e diminuição visível dos índices de doenças do trabalho e afastamentos.

O trabalho em si, buscou identificar os aspectos antropotecnológicos nas ações do PAM, juntamente, em seus demais quatro atores. Pôde-se, portanto, observar a execução das ações conjuntas, através da TCT desenvolvida através de novas tecnologias, equipamentos e treinamentos. 
Quadro 7 - Aspectos antropotecnológicos dos principais autores.

\begin{tabular}{|c|c|c|}
\hline Aspectos antropotecnológicos & Autor & $\begin{array}{c}\text { Observação sobre o que o PAM faz } \\
\text { para as Empresas }\end{array}$ \\
\hline $\begin{array}{l}\text { Melhoria contínua das relações } \\
\text { interpessoais; }\end{array}$ & Dwyer, 2006 ,p.12 & $\begin{array}{l}\text { Na promoção mensal dos treinamentos } \\
\text { promove estreitamento dessas relações; }\end{array}$ \\
\hline $\begin{array}{l}\text { Visão ampliada sobre medicina do } \\
\text { trabalho e psicologia do trabalho ou } \\
\text { industrial, tendo a preocupação com os } \\
\text { processos de seleção e motivacionais; }\end{array}$ & Wisner, 1985, p.6 & $\begin{array}{l}\text { A antropotecnologia e a TCT } \\
\text { demonstrada nos treinamentos, } \\
\text { oportuniza a valorização pessoal e } \\
\text { investimento pessoal em saúde. }\end{array}$ \\
\hline $\begin{array}{l}\text { Aspectos psicofisiológicos voltados à } \\
\text { administração do estresse (doenças do } \\
\text { trabalho - ergonomia); }\end{array}$ & $\begin{array}{l}\text { Hendrick, } 1997 \\
\text {,p.4 }\end{array}$ & $\begin{array}{l}\text { Estimula a utilização dos aspectos } \\
\text { ergonômicos ao dia a dia do trabalho, } \\
\text { respeitando e proporcionando bem-estar; }\end{array}$ \\
\hline $\begin{array}{l}\text { Maior acessibilidade da transferência do } \\
\text { conhecimento e tecnologia aos } \\
\text { participantes; }\end{array}$ & Wisner, 1992, p. 2 & $\begin{array}{l}\text { O PAM busca através da TCT promover } \\
\text { junto aos participantes, o conhecimento } \\
\text { integral das ações, equipamentos, novos } \\
\text { materiais e técnicas, de forma que haja a } \\
\text { compreensão do maior número possível }\end{array}$ \\
\hline $\begin{array}{l}\text { Oportunidade de manter contato com as } \\
\text { inovações tecnológicas apresentadas } \\
\text { pelas multinacionais, que já estão sendo } \\
\text { utilizadas em outros países (em suas } \\
\text { demais plantas); }\end{array}$ & $\begin{array}{c}\text { Wisner, 1985, p. } \\
29\end{array}$ & $\begin{array}{l}\text { Ilhas de antropotecnologia, empresas } \\
\text { parceiras em busca de um trabalho } \\
\text { conjunto. }\end{array}$ \\
\hline $\begin{array}{l}\text { Contato maior com grande parte dos } \\
\text { colaboradores, oportunizando aos } \\
\text { mesmos que exponham seus medos e } \\
\text { dificuldades em seu trabalho; }\end{array}$ & Wisner, p. 6 & $\begin{array}{l}\text { Abertura para ouvir e mensurar as } \\
\text { dificuldades encontradas pelos } \\
\text { colaboradores durante o trabalho; }\end{array}$ \\
\hline $\begin{array}{l}\text { Abertura para que profissionais externos } \\
\text { possam trazer e dividir novos } \\
\text { conhecimentos com todos; }\end{array}$ & Vidal, 2012 & $\begin{array}{l}\text { O PAM busca adequar-se às realidades e } \\
\text { diferenças do grupo, ajustando da melhor } \\
\text { forma possível os meios de transmissão } \\
\text { do conhecimento, operacionalidade, } \\
\text { trabalho em equipe e aspectos } \\
\text { motivacionais; }\end{array}$ \\
\hline $\begin{array}{l}\text { Profissionais de inúmeras áreas, ramos } \\
\text { e setores dividindo conhecimentos } \\
\text { intrínsecos e extrínsecos na busca de } \\
\text { formar uma equipe especializada; }\end{array}$ & Clot, 2006 & $\begin{array}{l}\text { O PAM estimula que a visão } \\
\text { prevencionista venha da liderança, } \\
\text { chegando a todos os demais } \\
\text { colaboradores nas organizações; }\end{array}$ \\
\hline $\begin{array}{l}\text { Relatos de experiências e aspectos } \\
\text { antropotecnológicos demonstrado pelos } \\
\text { participantes no decorrer do tempo de } \\
\text { trabalho oferecido em cada empresa; }\end{array}$ & Binder, 1999 & $\begin{array}{l}\text { Primeiros estudos antropotecnológicos } \\
\text { avaliados no início da pesquisa; }\end{array}$ \\
\hline $\begin{array}{l}\text { Troca de oportunidades, experiências, } \\
\text { respeito e contato com novas culturas, } \\
\text { etnias, religiões, conceitos, vivenciados } \\
\text { pelos participantes ao trabalharem em } \\
\text { outras plantas; }\end{array}$ & Wisner, 1992 & $\begin{array}{l}\text { A relação criada pelo PAM entre seus } \\
\text { participantes oportuniza a abertura do } \\
\text { conhecimento para o novo, abrindo } \\
\text { espaços de diálogos e trocas de } \\
\text { experiências; }\end{array}$ \\
\hline $\begin{array}{l}\text { Criado novos modelos de gestão através } \\
\text { da observação dos impactos } \\
\text { antropotecnológicos seja com pessoas, } \\
\text { nos riscos, na automação, na logística e, } \\
\text { principalmente, na Gestão de } \\
\text { Emergência; }\end{array}$ & Binder, 1999 & $\begin{array}{l}\text { Avaliação fisiopsicosocial do trabalho, } \\
\text { apontando as dificuldades e a realidade } \\
\text { na época; }\end{array}$ \\
\hline $\begin{array}{l}\text { Motivação, competitividade e qualidade } \\
\text { de vida, adquiridas nas trocas de } \\
\text { experiências e } \\
\text { informações entre colaboradores de } \\
\text { áreas diferenciadas; }\end{array}$ & Soares, 2006 & $\begin{array}{l}\text { Os treinamentos proporcionam interesse } \\
\text { entre o grupo, em busca sempre mais do } \\
\text { conhecimento, tornando-os participativos } \\
\text { e competitivos; }\end{array}$ \\
\hline $\begin{array}{l}\text { Apontamentos sobre como a } \\
\text { antropotecnologia pode minimizar os } \\
\text { riscos de acidentes e a evolução dos } \\
\text { conceitos de segurança das empresas }\end{array}$ & Dwyer, 2006 & $\begin{array}{l}\text { Primeiros relatos sobre os índices de } \\
\text { acidentes nas indústrias e no campo; }\end{array}$ \\
\hline
\end{tabular}




\begin{tabular}{|l|l|l|}
\hline $\begin{array}{l}\text { A antropotecnologia sendo descrita aos } \\
\text { participantes de forma a valorização } \\
\text { profissional, conhecimento e cuidados } \\
\text { com produtos químicos, conceitos } \\
\text { prevencionistas, aos cuidados com o } \\
\text { corpo e a mente do colaborador; }\end{array}$ & Garrigou, 2012 & $\begin{array}{l}\text { O PAM procura demonstrar aos } \\
\text { colaboradores, fatores que } \\
\text { proporcionaram doenças irreversíveis e } \\
\text { até mesmo a morte, por } \\
\text { desconhecimento ou falta de prevenção } \\
\text { no trabalho; }\end{array}$ \\
\hline $\begin{array}{l}\text { Preocupação com o conforto, saúde e } \\
\text { qualidade de vida dos colaboradores, } \\
\text { objetivando ambientes propícios, dentro } \\
\text { dos aspectos ergonômicos, seguros e } \\
\text { confiáveis para a execução do trabalho; }\end{array}$ & Meachan, 2017 & $\begin{array}{l}\text { O PAM trabalha junto às empresas } \\
\text { incentivando os aspectos ergonômicos } \\
\text { como o uso do EPls, utilização e } \\
\text { adaptação ao trabalho das ferramentas }\end{array}$ \\
\hline $\begin{array}{l}\text { Facilidade do uso da Transferência e } \\
\text { Conhecimento e Tecnologia através de } \\
\text { novos equipamentos, softwares, } \\
\text { máquinas. Acompanhadas por todos a } \\
\text { cada treinamento. }\end{array}$ & Hendrick, 1997 & $\begin{array}{l}\text { Apontamento da transferência de } \\
\text { tecnologia como facilitadora dos } \\
\text { processos antropotecnológicos. }\end{array}$ \\
\hline
\end{tabular}

Conforme os estudos avançaram, houve um posicionamento por parte dos atores envolvidos diretamente no PAM de Ponta Grossa, apresentando-se pontos fortes e fracos.

\section{Pontos fortes e fracos apontados pelas empresas participantes}

Para que se pudesse elaborar ações assertivas quanto aos treinamentos oferecidos pela coordenação do PAM, foram coletadas informações juntas aos participantes das empresas, com objetivo de analisar pontos fortes e pontos fracos a serem trabalhados nos próximos eventos, conforme descritos nos Quadros 8 e 9. 


\section{Quadro 8 - Aspectos antropotecnológicos e suas vantagens competitivas (pontos fortes)}

\begin{tabular}{|c|c|c|}
\hline Aspectos & Autor, ano & Pontos fortes \\
\hline $\begin{array}{l}\text { Entrosamento e entre as empresas participantes, } \\
\text { troca de experiências, novas tecnologias e } \\
\text { gestão de segurança; }\end{array}$ & Sznelwar, 2006 & $\begin{array}{l}\text { As empresas observaram oportunidades de } \\
\text { ampliar aspectos relacionados à saúde e } \\
\text { segurança, estendida a todos os } \\
\text { trabalhadores. Aprofundando os } \\
\text { conhecimentos tecnológicos e de segurança. }\end{array}$ \\
\hline $\begin{array}{l}\text { Treinamentos periódicos sobre urgência e } \\
\text { emergência, evitando acidentes com produtos } \\
\text { químicos, combate a incêndio, entre outros; }\end{array}$ & Clot, 2006 & $\begin{array}{l}\text { Iniciaram pensamentos sobre a necessidade } \\
\text { de inserir profissionais voltados a medicina e } \\
\text { prevenção dentro das indústrias, atitudes } \\
\text { consideradas pelos empresários, sinônimos } \\
\text { de valorização profissional e bem-estar no } \\
\text { local de trabalho. }\end{array}$ \\
\hline $\begin{array}{l}\text { Abertura da sociedade para conhecer e auxiliar } \\
\text { nos trabalhos dos órgãos de segurança e defesa } \\
\text { (Corpo de Bombeiros, Defesa Civil). }\end{array}$ & Wisner, 1985 & $\begin{array}{l}\text { Empresas diversas, de todos os tamanhos e } \\
\text { órgãos públicos unidos no intuito de } \\
\text { solidificar a promoção e prevenção de } \\
\text { acidentes. }\end{array}$ \\
\hline $\begin{array}{l}\text { Oportunidade de envolvimento nos treinamentos } \\
\text { ou reuniões, a participação de um maior número } \\
\text { de colaboradores das empresas. }\end{array}$ & Vidal, 2012 & $\begin{array}{l}\text { Necessidade e preocupação em fornecer } \\
\text { formação a um maior número de pessoas } \\
\text { sobre socorro e resgate, na busca de mitigar } \\
\text { eventos adversos; }\end{array}$ \\
\hline $\begin{array}{l}\text { Capacitar os colaboradores para que os } \\
\text { levem os conceitos prevencionistas pare } \\
\text { lares e ambientes (casa, escolas, clubes }\end{array}$ & $\begin{array}{l}\text { Dias Júnior, } \\
2000\end{array}$ & $\begin{array}{l}\text { Incentivo e promoção de uma cultura } \\
\text { preventiva a toda a sociedade; }\end{array}$ \\
\hline $\begin{array}{l}\text { Abertura ilimitada de empresas participantes, } \\
\text { com culturas e climas organizacionais } \\
\text { diversificados, buscando a interação e a } \\
\text { qualidade de vida no trabalho de todos; }\end{array}$ & Carayon, 2000 & $\begin{array}{l}\text { Respeito às culturas representadas por todas } \\
\text { as multinacionais em um país. Sabendo que } \\
\text { elas possuem valores, missão e visão } \\
\text { diferentes, mas as mesmas dificuldades, } \\
\text { produtividade e desempenho. }\end{array}$ \\
\hline $\begin{array}{l}\text { Inspeção e acompanhamento do Corpo de } \\
\text { Bombeiros nas empresas participantes, de forma } \\
\text { a apontar seus principais produtos e riscos por } \\
\text { elas oferecidos, dentro dos aspectos produtivos e } \\
\text { fatores substanciais de acidentes de trabalho; }\end{array}$ & Binder, 1999 & $\begin{array}{l}\text { Incentivar que possa ser realizado um plano } \\
\text { de risco que atenda as necessidades das } \\
\text { empresas. Ministrando recomendações sobre } \\
\text { e propostas sobre treinamentos e } \\
\text { simulações pertinentes à possíveis acidentes. }\end{array}$ \\
\hline $\begin{array}{l}\text { Oferecer conhecimento teórico/prático sobre as } \\
\text { ações emergenciais referentes a cada empresa e } \\
\text { seus principais produtos químicos, na busca de } \\
\text { mitigar ao máximo os efeitos adversos e } \\
\text { impactos naturais; }\end{array}$ & Hendrick, 1997 & $\begin{array}{l}\text { Posicionamento das empresas sobre número } \\
\text { de acidentes, índices de afastamentos, } \\
\text { estresse, problemas com desempenho e } \\
\text { motivação e qualidade de vida. }\end{array}$ \\
\hline $\begin{array}{l}\text { Multiplicação e disseminação dos conhecimentos } \\
\text { transmitidos nos treinamentos e reuniões para } \\
\text { todo o efetivo das corporações. Ações } \\
\text { necessárias e buscadas nas inovações; }\end{array}$ & Daniellou, 2006 & $\begin{array}{l}\text { Avaliação ergonômica dentro dos postos de } \\
\text { trabalho, respeitando as evoluções e } \\
\text { tendências de mercado, primando pelo } \\
\text { conforto e menores lesões. Oferecendo } \\
\text { conhecimento aos colaboradores }\end{array}$ \\
\hline $\begin{array}{l}\text { Oportunizar trabalhos cognitivos, inovações e } \\
\text { trabalhos junto às comunidades próximas às } \\
\text { empresas, na busca de minimizar impactos que } \\
\text { as mesmas ofereçam ao meio ambiente e à } \\
\text { população; }\end{array}$ & Sousa, 2005 & $\begin{array}{l}\text { Promover ações que beneficiem a } \\
\text { comunidade, desafiando os colaboradores a } \\
\text { trazerem ideais e participações. Apontando } \\
\text { assim maiores dificuldades vividas pelos } \\
\text { moradores próximos as empresas e } \\
\text { associações, diminuindo internamentos e } \\
\text { doenças. }\end{array}$ \\
\hline $\begin{array}{l}\text { Treinamentos periódicos sobre urgência, } \\
\text { emergência, produtos químicos, combate a } \\
\text { incêndio, entre outros; }\end{array}$ & Meachan, 2017 & $\begin{array}{l}\text { Informar sobre a importância dos } \\
\text { treinamentos, simulações e aulas sobre } \\
\text { emergências, agilizando os atendimentos e } \\
\text { as relações interpessoais somados as } \\
\text { novas tecnologias. }\end{array}$ \\
\hline
\end{tabular}

Fonte - Elaborado pela pesquisadora (2018) 
Quadro 9 - Aspectos antropotecnológicos e seus pontos fracos.

\begin{abstract}
\begin{tabular}{|c|}
\hline Aspectos \\
Falta de interesse na participação de algumas
\end{tabular} empresas no projeto, por considerarem possuir um sistema de gestão de riscos eficaz o suficiente, para não necessitar de ajuda;
\end{abstract} Autor, ano Pontos fracos

Desinteresse das empresas em criar uma equipe
de colaboradores que obtenham tempo livre para de colaboradores que obtenham tempo livre para estando à disposição do projeto;

Ha, 2016

A maioria das organizações industriais acredita possuir planos de riscos seguros e eficazes para continuidade dos negócios. $E$ geralmente, acreditam que nunca sofrerão eventos extraordinários em suas plantas ou a seus funcionários;

Os empresários preveem ações que sua organização irá passar antecipadamente.

Wisner, 1985 Isso não acontece quando existe a necessidade de liberação para treinamentos, pois para muitos incorre como perda de tempo e dinheiro para a organização.

Falta de interesse das empresas por ter que obter os equipamentos de segurança (ex: combate à incêndio) e, disponibilizá-los em caso de emergência, além de ter que oferecer treinamentos sobre manuseio e uso aos seus colaboradores;

Chen, 2013

Somente quando fortaleceram as simulações e treinamentos de combate a incêndio, promovendo a evacuação dos colaboradores, puderam observar a importância e com isso a diminuição dos riscos.

A falta de mão-de-obra especializada nas áreas de saúde e segurança, estão ligadas a

Grande rotatividade de colaboradores nas empresas, fazendo com que a equipe do PAM possa estar desfalcada, ou ofereça um grande treinamento ao funcionário e, logo em seguida, ter que dispensá-lo da empresa;

Dwyer, 1991 alta rotatividade que as organizações promovem.

Impossibilitando, contudo, que o capital intelectual seja explorado da melhor forma possível;

Por razões complexas, cada indivíduo

Falta de interesse de alguns colaboradores ou brigadistas em fazer parte do PAM, uma vez que, em caso de emergência, tenham que se deslocar para oferecer apoio devido falta de conhecimento sobre a importância dessas ações;

Wisner, 1989 apresenta relações diferenciadas no mesmo ambiente de trabalho. Isso também se relaciona a expectativas futuras, sonhos, ideais, cultura, incentivos, entre outros. Por isso, alguns se apresentam desmotivados e pouco representativos;

Cada organização foca principalmente em suas dificuldades se estão inseridas em ilhas

As empresas, muitas vezes, buscam que os treinamentos oferecidos pelo PAM possam focar única e exclusivamente aos riscos que elas ofereçam constantemente;

Walter, 2017 antropotecnológicas, podem mesmo assim, apresentarem-se como egoístas e solitárias, esquecendo-se que os maiores prejudicados por elas não evoluírem constantemente é seus trabalhadores.

Falta de investimento pelo governo nas áreas de saúde e segurança, para a população incentivando para que as empresas possam fazê-lo, inicialmente com seus colaboradores e a comunidade;

Falta de mais treinamentos e simulações dentro das próprias empresas, que promovam cada vez mais as brigadas de emergência;

Ribeiro, 2011

Wisner, 1985

Considera que, única a maneira de responder efetivamente aos desafios de um país em desenvolvimento, são investimentos em políticas públicas que busquem erradicar a pobreza e em seus processos de industrialização e tecnologia;

Promoção da criação de equipes de colaboradores aptos a agirem em caso de possíveis desastres e com formação prevencionista, que atuem como multiplicadores de informações; e que atuem em constantemente para mitigar maiores impactos;

A transferência do conhecimento e tecnologia deve ocorrer em áreas diversas nas

Inserir treinamentos de resgate, vítimas de afogamentos, choques elétricos.
Garrigou, 2012 organizações. Ampliando não somente a

produção, mas em vários aspectos voltados a vida do colaborador. 


\begin{tabular}{|l|l|l|}
\hline $\begin{array}{l}\text { Deveriam marcar mais reuniões com a Direção } \\
\text { das Organizações, esclarecendo sobre a } \\
\text { importância do projeto. Para que assim, seja } \\
\text { disseminado para as outras plantas; }\end{array}$ & Santos, 2014 & $\begin{array}{l}\text { Torna-se importante, que a liderança das } \\
\text { organizações possui um papel de reconhecer } \\
\text { seus possíveis riscos, e habilitar e orientar } \\
\text { seus profissionais para atuarem em momentos } \\
\text { de crise; }\end{array}$ \\
\hline $\begin{array}{l}\text { Contatar novas empresas que ainda não se } \\
\text { interessam pelo projeto, na busca de torná-la } \\
\text { parceira; }\end{array}$ & Asgary, 2012 & $\begin{array}{l}\text { As parcerias das organizações proporcionam } \\
\text { uma identificação entre elas, de forma a } \\
\text { promover troca de experiências no intuito de } \\
\text { desenvolver um grupo de assistência mútua. }\end{array}$ \\
\hline
\end{tabular}

Fonte - Elaborado pela pesquisadora (2018)

$\mathrm{Na}$ realidade, segundo as descrições obtidas no Quadro 8, muitas empresas parceiras do projeto PAM acreditam que os benefícios foram consideravelmente visíveis. Pois houve a consolidação das interações e trocas de experiências, de conhecimentos, treinamentos e simulações, que proporcionaram economia nos gastos, evolução nos processos de segurança, alternativas de implantação de planos de riscos concisos e de acordo com as realidades de cada indústria, além da proximidade dos órgãos de emergências para possíveis eventualidades.

Portanto, pôde-se observar como os aspectos antropotecnológicos estão inseridos em conjunto aos dados coletados no Projeto PAM, agindo como facilitador entre o homem, a máquina e o trabalho, posicionando-se perante a necessidade dessa relação ser mais humana, coerente e prática.

As multinacionais trazem consigo novos mecanismos de trabalho, conceitos inovadores, tecnologias aprimoradas e, contudo, elas reconhecem o quanto se tornou importante primar pela vida, pela satisfação e pelo bem-estar do colaborador, oferecendo, ao mesmo tempo, produtos de qualidade e diferenciados no mercado internacional.

Em meio a tanta modernidade, agilidade de processos e serviços, a integração entre os empresas e órgãos de saúde e segurança trouxe uma versão atualizada sobre o conhecimento e os cuidados à saúde humana, buscando com isso, diminuir riscos e impactos aos funcionários, ao meio ambiente, aos moradores do entorno às empresas, além de minimizar custos.

Uma população mais consciente e esclarecida multiplica informações e, com isso, facilita o trabalho dos órgãos de defesa e segurança, além de diminuir os acidentes de trabalho nas organizações. Essa é uma das intenções do PAM no país, levar o conhecimento teórico/prático ao maior número de trabalhadores, oferecendo assim, em caso de acidentes de grandes proporções, apoio imediato e especializado 
o mais rápido possível, mitigando assim, efeitos adversos que venham colocar a população em perigo.

Promove uma relação tanto no micro como macro ambiente de trabalho, que respeita a tecnologia, os métodos e os treinamentos necessários para a utilização eficiente e segura das máquinas e equipamentos, de forma correta e consciente, ampliando assim, as relações antropotecnológicas e interpessoais como um todo.

A antropotecnologia pode ser caracterizada como uma ferramenta de aprendizagem, trazendo ao homem a possibilidade de desenvolver as relações de trabalho, sua execução e a evolução das tecnologias envolvidas, de forma a desenvolver o sistema como um todo.

$\mathrm{Na}$ busca por validar este estudo, observou-se como os aspectos antropotecnológicos vêm contribuindo na construção de novos conceitos de trabalho (DUTRA, 1999). Aliada à TCT, a antropotecnologia desenvolve técnicas atualizadas de resgate, na implementação de ferramentas nos aspectos humanos, interpessoais e psicológicos. Elementos estes que propõem este estudo junto às ações do PAM, na cidade de Ponta Grossa, no Paraná,

A antropotecnologia aliada à com a TCT visa avaliar e propor mecanismos de interações e readequações das empresas e seus colaboradores. Dessa forma, observa-se, como as atuações do PAM, se tornam essenciais e relevantes nos quesitos: conceitos de prevenção; valorização pessoal e profissional; promoção do conhecimento e da saúde; capacitação para ações; aumento da produtividade com segurança, e; incentivos para que os colaboradores se tornem multiplicadores de informações no trabalho e na comunidade.

Para tanto, a antropotecnologia e a TCT podem ser vistas no PAM dentro das ações:

- Promoção e educação para a segurança dos trabalhadores, estimulando o aprendizado e a integração;

- Minimização de gastos com ações trabalhistas, como é o caso de acidentes de trabalho; 
- Interação entre as empresas participantes do PAM, se tornando conhecidos os produtos e serviços por elas fornecidos, estreitando laços comerciais entre as mesmas;

- Pontuar os principais riscos dos produtos inseridos em seu quadro de produção, promovendo com isso, ações de suma relevância nos atendimentos iniciais em caso de acidentes, mitigando maiores impactos;

- Estimular a participação de todos os participantes do PAM a feiras, congressos, treinamentos e simulados na busca de que novos conhecimentos agreguem valor final a todos;

- Facilitar para que o corpo de bombeiros e demais órgãos participantes de defesa troquem experiências, e;

- Atribuir novos conceitos sobre como os atendimentos possam ficar mais ágeis, fáceis e seguros.

Sendo assim, torna-se de suma importância que haja a fusão de tais elementos como a antropotecnologia, TCT e as ações do PAM, na busca de novas estratégias que possam alavancar países em desenvolvimento a outros patamares de ações estratégicas.

Os estudos desenvolvidos sobre aspectos antropotecnológicos, desde a criação do tema (1962) até os dias atuais, podem resultar no fortalecimento entre as relações do homem, o trabalho e a tecnologia, formando assim, um viés entre tais relações.

A relação obtida pela antropotecnologia dentro do PAM se mostrou muito importante como benefício mútuo entre o homem, o trabalho e a sociedade, criando, portanto, um novo formato de visão tecnológica e empreendedora, proporcionando assim, inúmeros benefícios aos atores envolvidos, atuando positivamente para o bemestar de todos.

A aplicabilidade dos aspectos antropotecnológicos e da TCT no PAM podem ser observadas pela ótica de quatro atores, descritos no Quadro 10. 
Quadro 10 - Identificação dos aspectos antropotecnológicos nas perspectivas dos 4 atores.

1 ATOR - O ESTADO - CORPO DE BOMBEIROS

\section{CONTRIBUIÇÕES/ PAPEL e BENEFÍCIOS}

Trazer conhecimento ao público sobre desastres, buscando com isso, diminuir dos índices de catástrofes, promovendo a educação para segurança coletiva do Estado.

Desafogar a atuação da corporação, priorizando atendimentos mais graves, beneficiando assim, às comunidades desprovidas

Maior agilidade nos atendimentos a serem prestados em caso de vítimas graves de acidentes nas indústrias, como incêndios. Visto que os primeiros atendimentos já foram ministrados pelos componentes do PAM

Aprendizado com o próprio ensinamento, oportunizando novos conhecimentos, novos componentes e novas realidades industriais

Reconhecimento e monitoramento pela equipe da corporação sobre os produtos químicos das empresas envolvidas, pontuan atitudes exatas a serem tomadas em casos de emergências, promovendo a sustentabilidade

Maior conscientização por parte da população industrial sobre prevenção, segurança e promoção à vida e à saúde, diminuindo consideravelmente, os riscos de acidentes de maiores

proporções e, consequentemente, a demanda do Estado

Ao se deslocar em caso de acidente ou ocorrência, em uma das

empresas participantes, ter o conforto em saber que para a vítima já foram oferecidos, de forma rápida e precisa, os atendimentos iniciais com qualidade, minimizando maiores sequelas

Oportunidade de oferecer à comunidade conceitos básicos sobre os primeiros socorros e atitudes simples que podem ser tomadas, primando pela segurança e pelos cuidados à vida.

\section{AUTORES}

Santos (2014)

O esclarecimento de um povo traz consigo um crescimento ordenado, capaz de gerenciar possíveis riscos que o próprio cidadão se coloque. Para tanto, a contribuição dos veículos de comunicação e o governo, proporcionar conhecimento a população de forma simples e coerente.

Cada ocorrência proporciona um nível de fadiga diferente. Para tanto, a diminuição de

Pau, 2014 todos

O possível evento extraordinário, que possam acometer uma indústria, uma rodovia, ou proximidades, dificilmente ocorrerá com um anúncio prévio. Geralmente, ocorre subitamente, para tantas equipes bem treinadas de colaboradores podem mitigar maiores impactos à comunidade, empresa e a comunidade

Chen, 2013

A TCT, pode ser aprendida através de formação dentro ou fora da indústria, ainda quando criança, as questões cognitivas, estão associadas a forma com que o conhecimento é transmitido. Contudo, tais inovações se tornam vivaz para o

Sznelwar, 2008 crescimento organizacional, principalmente quando envolvem o maior número de pessoas possível

As grandes multinacionais hoje buscam conceber eco cidadãos, capazes de vivenciar

Abeysekera, 198 7 cuidados com riscos eminentes, principalmente aqueles apresentados em suas plantas. Assim como, preservar o ecossistema e de forma sustentável

Wisner,1995

A falta de cuidados com os funcionários nos aspectos saúde e segurança, proporciona ambiente insalubres e perigosos. Assim, quanto maior o nível de informações treinamentos aos mesmos, maior os índices que qualidade de vida no trabalho

Os riscos de acidentes industriais, geralmente estão ligados à falta de conhecimento na implantação de inovações tecnológicas, atos e condições inseguras, além da falta de manutenção e falha na administração e observação dos mecanismos de produção. A

Binder, 1999 boa comunicação, os métodos usados na prevenção e segurança devem ser pautados constantemente

A adaptação dos aspectos antropotecnológicos ao novo contexto industrial, é a

mentalidade dos empresários e líderes do futuro. Isso requer também, oferecer à

Dias Júnior, comunidade local, serviços simples e oportunidade de manter-se informada e apta, a 2000 atuarem tanto no mercado de trabalho, quanto em inúmeras situacões 
Quadro 10 - Identificação dos aspectos antropotecnológicos nas perspectivas dos 4 atores.

20 ATOR - A INDÚSTRIA - PARTICIPANTES DO PAM

\begin{tabular}{|c|c|c|}
\hline CONTRIBUIÇÕES/ PAPEL e BENEFÍCIOS & AUTORES & REFERÊNCIAS SEGUNDO AUTOR \\
\hline $\begin{array}{l}\text { Diminuir consideravelmente o número de acidentes de trabalho, } \\
\text { incentivando o uso correto de equipamentos de proteção }\end{array}$ & $\begin{array}{l}\text { Garrigou, 2012, } \\
\text { p.6 }\end{array}$ & $\begin{array}{l}\text { Responsabilidade e conscientização, por parte das empresas sobre o uso de EPI, EPC, e } \\
\text { principais produtos químicos e seus efeitos }\end{array}$ \\
\hline $\begin{array}{l}\text { Maior e melhor interação entre as indústrias participantes do PAM, } \\
\text { podendo ampliar questões comerciais, tecnológicas e interpessoais }\end{array}$ & Sousa, 2005, p.5 & $\begin{array}{l}\text { Oportunidades às empresas se relacionar com novos métodos, tecnologias, conhecimentos, clima } \\
\text { organizacionais, culturas, costumes e etnias }\end{array}$ \\
\hline Menor índice de afastamento por invalidez ou doenças do trabalho & $\begin{array}{l}\text { Saldanhar, } 2012 \\
\text { p. } 6\end{array}$ & $\begin{array}{l}\text { Reconhecimento pelos empresários, sobre a necessidade em investimento em ergonomia, } \\
\text { informações sobre cuidados com a saúde e segurança durante o exercício do trabalho }\end{array}$ \\
\hline $\begin{array}{l}\text {-Diminuição de gastos decorrentes de ações trabalhistas e maior } \\
\text { economia, cuidado com máquinas e equipamentos }\end{array}$ & Dwyer, 2006, p.4 & $\begin{array}{l}\text { Verificação por parte das organizações, sobre os principais riscos, doenças ocupacionais, e } \\
\text { problemas relacionados aos ambientes de trabalho, buscando minimizar os riscos }\end{array}$ \\
\hline $\begin{array}{l}\text {-Melhor absorção das inovações tecnológicas que venham a ser } \\
\text { implantadas na empresa }\end{array}$ & Binder, 1999, p. 4 & $\begin{array}{l}\text { Neste contexto, os principais riscos associados ao uso de máquinas para equipamentos e } \\
\text { treinamento de informações para gerenciamento, bem como treinamento e controle de operadores }\end{array}$ \\
\hline $\begin{array}{l}\text { Processo produtivo mais eficiente, moderno e de alta competitividade, } \\
\text { pois nele estão presentes, profissionais qualificados e capacitados para } \\
\text { atuarem com maior destreza e precisão }\end{array}$ & $\begin{array}{l}\text { Pfaffenberger, } \\
\text { 1992, p. } 8\end{array}$ & $\begin{array}{l}\text { As novas tecnologias implantadas, sem o respeito e a oportunidade de inserir totalmente os } \\
\text { colaboradores, torna-se inviável, desnecessário e oneroso }\end{array}$ \\
\hline $\begin{array}{l}\text { Estímulo de troca de experiências entre as indústrias participantes, } \\
\text { podendo ser } \\
\text { pontuadas suas dificuldades anteriores e, consequentemente, como elas } \\
\text { realizaram mudanças que contribuíram para tais melhorias }\end{array}$ & Clot, 2006, p.11 & $\begin{array}{l}\text { Oportunidade de explorar o comportamento dos colaboradores, na busca de favorecer o diálogo e } \\
\text { a troca de informações experiências, mesmo aquelas que foram negativas }\end{array}$ \\
\hline $\begin{array}{l}\text { Criar padrões, métodos, guias e protocolos padronizados para a } \\
\text { execução de } \\
\text { determinadas atuações em caso de emergências que venham a atender } \\
\text { todas as empresas participantes }\end{array}$ & Dutra, 1999, p. 47 & $\begin{array}{l}\text { A busca de melhorar os aspectos voltados a qualidade total dos produtos, torna-se intrinsecamente } \\
\text { a qualidade de vida dos funcionários. Para tanto, busca-se orientar e elaborar modelos de gestão } \\
\text { de emergência }\end{array}$ \\
\hline $\begin{array}{l}\text { Multiplicação de informações, transferência de conhecimento e } \\
\text { tecnologia, em várias plantas ou unidades da empresa }\end{array}$ & Wisner, 1992, p.4 & $\begin{array}{l}\text { A TCT transmitida a todas as áreas da empresa, respeitando as particularidades e proporcionando } \\
\text { para que todos os colaboradores possam fazer parte das oportunidades }\end{array}$ \\
\hline $\begin{array}{l}\text { Proporcionar junto aos colaboradores e familiares, condutas } \\
\text { prevencionistas que tragam, desde suas casas, as atitudes seguras } \\
\text { esperadas dentro das organizações, } \\
\text { criando conceitos corretos e duradouros na vida do cidadão. }\end{array}$ & Soares, 2006, p.3 & $\begin{array}{l}\text { Organização dos projetos das organizações, voltadas ao bem-estar dos funcionários, familiares e } \\
\text { demais pessoas da comunidade }\end{array}$ \\
\hline $\begin{array}{l}\text { Promover ações junto à comunidade dentro dos aspectos da } \\
\text { sustentabilidade }\end{array}$ & Gomes, 2017, p. 6 & $\begin{array}{l}\text { Preocupação com o meio ambiente e ações de promoção da sustentabilidade dentro e fora das } \\
\text { indústrias }\end{array}$ \\
\hline $\begin{array}{l}\text { Evolução na aquisição de matéria-prima, destino correto dos resíduos, } \\
\text { produção limpa }\end{array}$ & $\begin{array}{l}\text { Kovaleski, } 2016 \\
\text { p. } 2\end{array}$ & $\begin{array}{l}\text { Aplicação de novas tecnologias, oportunidade de parcerias, novos formatos de gerenciamentos, } \\
\text { buscando uma } \\
\text { produção limpa, consciente e segura. Para tais mudanças, abra-se espaço para novas empresas e } \\
\text { novos formatos de gestão, com a participação da universidade e seus hotéis tecnológicos }\end{array}$ \\
\hline
\end{tabular}

Quadro 10 - Identificação dos aspectos antropotecnológicos nas perspectivas dos 4 atores. 


\section{ATOR - UNIVERSIDADE - PESQUISA}

CONTRIBUIÇÕES/ PAPEL e BENEFÍCIOS

AUTORES

\section{REFERÊNCIAS SEGUNDO AUTOR}

Promoção sobre pesquisa, analisando a antropotecnologia, a TCT e as professores, acadêmicos e o trabalho nas empresas

Estudos relacionados, a processos produtivos com energia limpa, controle de emissão de gases e, oportunizando para que as indústrias possam contribuir com a sustentabilidade e ecocidadania

Oportunidade de pesquisar temas pertinentes a áreas diferentes do seu viés de ensino, ampliando o conhecimento docente

$2008, p$

2

De Coninck, 2008

p. 6

Leydesdorff, 1998

Oportunidade de se inserir a um número muito maior de empresas, podendo assim, colocar em prática os conhecimentos teóricos aplicados na academia

Abertura, de um número maior de vagas para estágios, empregos, e projetos para os acadêmicos e demais alunos

Proporcionar aos acadêmicos, dentro da visão industrial cedida pelas empresas participantes, uma oportunidade de abrirem seu próprio negócio

Ampliar o contato direto entre as multinacionais, costumes, formas de transferências de conhecimento e tecnologia utilizada por cada uma delas

Ampliar as fronteiras do conhecimento, através de estágios internacionais, nas filiais no exterior, das empresas parceiras. 4 ,p.8
A Universidade, podendo apresentar seus experimentos e novas tecnologias obtidas, através da pesquisa, podendo oferecer às empresas através de parcerias, o conhecimento aos profissionais interessados

Em resposta as inovações tecnológicas, as organizações estão buscando torna-se cada vez mais sustentáveis.

Para tanto, as pesquisas desenvolvidas nas universidades vêm contribuir para a promoção dessa conscientização e melhoria, junto aos empresários e colaboradores

. desenvolver juntamente com elas, ferramentas que venham a sanar os problemas ou melhorar a forma do trabalho

Morandi, 2013, p. A colaboração entre a universidade X indústrias, acordos e parcerias, na busca de minimizar impactos da falta de planejamentos estratégico e geração de inovações

Gimenez, 2015, A universidade empreendedora, é aquela que modificou uma visão anterior de ser somente uma instituição de ensino, e passa assim, a promover a integração acadêmica com novas oportunidades, sendo proativa e inovadora

Kovaleski, 2017, $\quad$ Buscar oportunidades, dentro da conexão de bases tecnológicas, oferecidas às empresas, p. $1 \quad$ promovendo a pesquisa e desenvolvendo mecanismos de capitalização de recursos, através de inovações

2018 Como os investimentos em pesquisas, dentro das universidades é pouco por parte dos governos, p. 6 , condição, de manter-se atualizadas as pesquisas e o desenvolvimento

Landry, 2013, p. 2 O aprendizado, desenvolvido na academia, podendo ser aprimorado através das incubadoras tecnológicas, e patenteados, e posteriormente, disponibilizados monetariamente às empresas. Totalizando benefícios à ambos 
Quadro 10 - Identificação dos aspectos antropotecnológicos nas perspectivas dos 4 atores.

\begin{tabular}{|c|c|c|}
\hline CONTRIBUIÇÕES/ PAPEL e BENEFÍCIOS & AUTORES & REFERÊNCIAS SEGUNDO AUTOR \\
\hline Proteção ao meio ambiente & \begin{tabular}{|} 
Protogerou, 2013, \\
p. 3
\end{tabular} & $\begin{array}{l}\text { Investimentos e políticas públicas, que favoreçam as comunidades, juntamente com a } \\
\text { universidade e as empresas, promovendo aspectos de qualidade de vida }\end{array}$ \\
\hline $\begin{array}{l}\text { Ações junto a comunidade sobre evacuação em caso de perigoso, } \\
\text { pânico, tumultuo, manifestações e ações que obstrua e dificulte a } \\
\text { ordem geral }\end{array}$ & $\begin{array}{l}\text { Spekman, 2004, } \\
\text { p. } \\
1\end{array}$ & $\begin{array}{l}\text { A promoção do ensino de ações de emergências, contra desastres naturais, com incêndios, e } \\
\text { demais acontecimentos. Por falta de conhecimento e planejamento, dos órgãos competentes }\end{array}$ \\
\hline $\begin{array}{l}\text { Segurança contra catástrofes e desastres e prevenção contra acidentes } \\
\text { industriais e respeito às leis de sustentabilidade }\end{array}$ & $\begin{array}{l}\text { Drabek, 2003, p. } \\
\quad 4\end{array}$ & $\begin{array}{l}\text { Segundo informações, em cada região, pode ocorrer em momentos diferentes, com populações } \\
\text { diversas, podendo acontecer possíveis deslizamentos, queda de encostas, vendavais, cuidado } \\
\text { com área de contaminação por produtos químicos, treinamentos dos cidadãos, etc. }\end{array}$ \\
\hline $\begin{array}{l}\text { Mitigar efeitos adversos, que venham acometer as comunidades no } \\
\text { entorno das regiões industriais condições climáticas e até mesmo } \\
\text { aquelas provocadas pelo homem }\end{array}$ & Paton, 2001, p. 2 & $\begin{array}{l}\text { Promover estratégias, junto as comunidades, oferecendo aulas sobre prevenção, proteção, } \\
\text { cuidados com o meio ambiente, coleta seletiva, impactos naturais e seus riscos }\end{array}$ \\
\hline $\begin{array}{l}\text { Reduzir os impactos ambientais, disponibilizando às indústrias } \\
\text { tecnologias, que diminua contudo, a incidência de contaminação por } \\
\text { extravasamento de produtos químicos das indústrias, em rios e } \\
\text { afluentes }\end{array}$ & $\begin{array}{l}\text { Alexander, } 2005 \\
\text { p. } 6\end{array}$ & $\begin{array}{l}\text { Os planos de riscos das organizações, devem estar sempre atualizados, podendo contar com a } \\
\text { participação das universidades, para a implantação e gestão. Além de, ser necessário que ele } \\
\text { abranja com fidelidade, todos os produtos pertinentes aos processos de produção }\end{array}$ \\
\hline $\begin{array}{l}\text { Diminuir os impactos de doenças nos cidadãos (ex: proliferação de } \\
\text { câncer, doenças de pele, respiratórias, entre outras) }\end{array}$ & Kapucu, 2010 & $\begin{array}{l}\text { A implementação, de ações combinadas entre o governo, as universidades, indústrias, e a } \\
\text { comunidade, pode desenvolver mecanismos de prevenção contra contaminações, intoxicações e } \\
\text { até epidemias. Favorecendo, contudo, a saúde da sociedade, mas precisa de apoio concreto para } \\
\text { acontecer }\end{array}$ \\
\hline
\end{tabular}

Fonte - Elaborada pela pesquisadora (2018) 
A vida é o bem mais precioso de uma nação, pois sem ela não há desenvolvimento. Por esse motivo, os conceitos de saúde e segurança devem ser priorizados, não somente pela cobrança dos governos com respeitos às leis, mas como uma versão aprimorada de melhoria continuada no Brasil. 


\section{CONCLUSÕES}

Este estudo conseguiu atender sua proposta quanto aos objetivos proposto, pois, pode identificar os aspectos antropotecnológicos relacionados com a transferência de conhecimento e tecnologia e os trabalhos do PAM. Observando que, ela está relacionada em todos os segmentos do trabalho, das inovações tecnológicas, dos equipamentos de resgate, procedimentos e protocolos utilizados para salvar e mitigar impactos à vida, assim como, nas pesquisas e planejamentos propostos em ações futuras.

Assim, este trabalho pode descrever a origem do PAM no Brasil, suas principais características, observando que o projeto é novo, e pouco foi encontrado, dentro do embasamento teórico. Mas o mesmo está se disseminando através da conscientização e necessidade de implantação, nos polos industriais e cidades com o perfil prevencionista e biosustentáveis.

Desta forma, quanto às pesquisas relacionadas ao DMA internacional, se comparadas ao PAM brasileiro, viu-se que, existe uma relação diferenciada, mas atende aos mesmos propósitos, nos quesitos treinamentos, prevenção, socorro e resgate de vítimas de desastres. Mas também, se constatou que, o DMA, faz parte integrante de toda a sociedade internacional, pois, conta com pesquisas constantes, além do apoio do governo, das universidades, indústrias e a comunidade em geral.

Quanto ao PAM no Brasil, sua aceitabilidade quanto a necessidade de implantação, por parte das indústrias e sociedade em geral, ainda é pequena. Pois falta investimento nas áreas de conscientização, publicidade, parcerias, divulgação e trabalhos diretos com a indústria, a universidade, e a sociedade, na busca de aprimorar os aspectos de prevencionistas, de proteção e segurança em todo o país.

Pois, o processo de conscientização em segurança no Brasil, deve ocorrer gradativamente, pois o mesmo, ainda possui uma mentalidade —corretivall e não preventiva. Assim, de acordo com os dados descritos anteriormente, sobre desastres ocorridos no Brasil neste trabalho, certas atitudes por parte do governo, só foram 
colocadas em prática, após a morte de várias pessoas, causando impactos negativos no mundo sobre cuidados de segurança.

A antropotecnologia por sua vez, veio atuar como a ciência que proporciona uma análise das relações de trabalho, somadas à TCT, nas condições de saúde e segurança, na promoção do estreitamento nas relações interpessoais, agindo como ponte entre, ações preventivas, de estímulo ao bem-estar e qualidade de vida aos colaboradores.

Os resultados obtidos mostraram que a antropotecnologia, pode ser verificada, como instrumento de análise das relações de trabalho existentes na atualidade. E como, os colaboradores sentiram a evolução da máquina, que aos poucos veio substituir trabalhadores, fazendo com que muitos buscassem mais conhecimentos, para manter-se empregados.

Para tanto, as evidências antropotecnológicas foram observadas dentro dos trabalhos do PAM em Ponta Grossa, junto às indústrias parceiras, através de inúmeros aspectos de trabalho. Como, o conhecimento transmitido através de treinamentos mensais com as empresas parceiras, a apresentação de novas técnicas e equipamentos voltados à área de resgate, de novas tecnologias, dos estreitamentos das relações interpessoais entre o grupo.

Além dos colaboradores participantes, se tornarem dentro de suas instituições, verdadeiros multiplicadores de informações, formando condutas prevencionistas e modificadoras de opiniões. Pois o projeto, atende atualmente cerca de 5.517 funcionários envolvidos diretamente, e esse número ampliado em 2019, pois existem outras empresas interessadas em fazer parte do PAM.

Contundo, muitas são as contribuições deste estudo para toda a sociedade, pois aponta de forma clara, a necessidade de preparar a população, para possíveis desastres que venham ocorrer no país, como eventos extraordinários diversos, que de forma inesperada pode colocar a vida de muitos em risco.

Desta forma, a formação de equipes especializadas como é o caso do PAM, busca formar e habilitar trabalhadores e suas indústrias, para atuarem de forma consciente, em momentos de possíveis catástrofes, desastres, eventos climáticos severos, vendavais, desabamentos, grandes incêndios, inundações, acidentes. 
$\mathrm{Na}$ busca de fortalecer a identificação dos aspectos antropotecnológicos nos trabalhos do PAM, juntamente com a TCT, buscou-se avaliar as interações das equipes, nos relacionamentos interpessoais, na qualidade de vida no trabalho, no bem-estar dos atores propostos, no profissionalismo, respeitando, contudo, as novas culturas e métodos transmitidos, através de uma sociedade evolutiva e crescente.

Para tanto, o objetivo deste trabalho foi atingido, pois pôde-se verificar uma nova visão sobre a antropotecnologia, como ela se relacionada com o mundo moderno do trabalho no século XXI. Da mesma forma, avaliou como a TCT está intrinsecamente ligada aos trabalhos do PAM, na forma de aplicação de novos conhecimentos, equipamentos, treinamentos e como todos esses aspectos puderam ser identificados, nas relações entre o trabalho, o homem e máquina. 


\section{REFERÊNCIAS}

ABAD, J. et al. Comparison of national strategies in France, Germany and Switzerland for DRR and cross-border crisis management. Procedia engineering, v. 212, p. 879-886, 2018.

ABEYSEKERA, J.; SHAHNAVAZ, H. Ergonomics of technology transfer. International Journal of Industrial Ergonomics, v. 1, n. 4, p. 265-272, 1987.

ALEXANDER, D. Towards the development of a standard in emergency planning. Disaster Prevention and Management: An International Journal, v. 14, n. 2, p. 158-175, 2005.

ALEXANDER, D. E. Disaster and emergency planning for preparedness, response, and recovery. United Kingdom: Oxford University Press, 2015.

ALTAY, N.; GREEN, W. G. OR/MS research in disaster operations management. European journal of operational research, v. 175, n. 1, p. 475-493, 2006.

ARVANITIS, S.; KUBLI, U.; WOERTER, M. University-industry knowledge and technology transfer in Switzerland: What university scientists think about cooperation with private enterprises. Research Policy, v. 37, n. 10, p. 1865-1883, 2008.

ASGARY, A. et al. Developing disaster mutual assistance decision criteria for electricity industry. Disaster Prevention and Management: An International Journal, v. 26, n. 2, p. 230-240, 2017.

BARBOSA, A. C. Responsabilidade social corporativa do polo industrial de Camaçari: a influência do conselho comunitário consultivo. 2003. $150 \mathrm{f}$. Dissertação. (Mestrado em Gerenciamento e Tecnologia Ambiental no Processo Produtivo) - Universidade Federal da Bahia, 2003.

BARRAL, W. Metodologia da pesquisa jurídica. Belo Horizonte: Editora del Rey, 2007.

BARRETO, A. A. A transferência de informação, o desenvolvimento tecnológico e a produção de conhecimento. Base de dados em Ciência da Informação, v. 1, n. 2, p. 2-10, 1995.

BBCNEWS. Desaster, 2018. Disponível em: $<$ https://www.bbc.com/portuguese/brasil-45391771>. Acesso em 06 de nov. 2018.

BENGHI PINTO, E. Incidentes com Produtos perigosos: Prevenção e Resposta. In: SEMINÁRIO TÉCNICO CIENTÍFICO DE PREVENÇÃO E PROTEÇÃO A DESASTRES, 12., 2017. Cascavel. Anais... Cascavel: 2017. 
BERTOLI, A. L.; RIBEIRO, M. S. Passivo ambiental: estudo de caso de Petróleo Brasileiro SA- Petrobrás. A repercussão ambiental nas demonstrações contábeis, em conseqüência dos acidentes ocorridos. Revista de Administração Contemporânea, v. 10, n. 2, p. 117-136, 2006.

BINDER, M. C.; DE ALMEIDA, I. M.; MONTEAU, M. Anthropotechnological analysis of industrial accidents in Brazil. Bulletin of the World Health Organization, v. 77, n. 12, p. 1008, 1999.

BOWMAN, Warren D. The development and current status of wilderness prehospital emergency care in the United States. Journal of Wilderness Medicine, v. 1, n. 2, p. 93-102, 1990.

BOZEMAN, B. Technology transfer and public policy: a review of research and theory. Research policy, v. 29, n. 4, p. 627-655, 2000.

BRASIL, Estatuto PAM - Coordenadoria Estadual de Proteção e Defesa Civil do Paraná. Disponível em: <www.defesacivil.pr.gov.br/> Acesso em 14 ago. 2018.

BREWER, R. D. L. A. Baron Dominique Jean Larrey (1766-1842). Father of modern military surgery, innovater, humanist. The Journal of thoracic and cardiovascular surgery, v. 92, n. 6, p. 1096-1098, 1986.

CASA MILITAR - Coordenadoria Estadual de Proteção e Defesa Civil. PAM. Disponível em: <http://www.defesacivil.pr.gov.br>. Acesso em 08 de fev. 2018.

CALIXTO, E. Contribuições para plano de contingência para derramamento de petróleo e derivados. 2011. 301 f. Dissertação (Mestrado em Planejamento Energético) - Universidade Federal do Rio de Janeiro, Rio de Janeiro, 2011.

CAPPELLE, M. C. A.; MELO, M. C. O. L.; GONÇALVES, C. A. Analysis of contents and analysis of speech in social sciences, 2003.

CAPPELLE, M. C. A.; MELO, M. C. O. L.; GONÇALVES, C. A. Análise de conteúdo e análise de discurso nas ciências sociais. Organizações Rurais \&

Agroindustriais, v. 5, n. 1, p. 1-15, 2003.

CARAYANNIS, E. G.; ROZAKIS, S.; GRIGOROUDIS, E. Agri-science to agribusiness: the technology transfer dimension. The Journal of Technology Transfer, v. 43, n. 4, p. 837-843, 2018.

CARAYON, P.; SMITH, M. J. Organização do trabalho e ergonomia. Ergonomia aplicada, v. 31, n. 6, p. 649-662, 2000.

CHEN, F. et al. The integrated strategies for fire safety of long road tunnels in Taiwan. Procedia Engineering, v. 62, p. 36-45, 2013.

CLOSS, L. et al, A transferência de tecnologia universidade-empresa no contexto brasileiro: uma revisão de estudos científicos publicados entre os anos 2005 e 2009. Gestão \& Produção, v. 19, n. 2, p. 419-432, 2012.

CLOT, Y.; WISNER, A. Unhéritage «disputé». Travailler, n. 1, p. 185-198, 2006. 
CORPO DE BOMBEIROS DO PARANÁ. Trabalho do Corpo de Bombeiros, 2017. Disponível em: <http://www.bombeiros.pr.gov.br/>. Acesso em 20 ago. 2018.

SILVA, E. A. C. et al. Aspectos históricos da implantação de um serviço de atendimento pré-hospitalar. Revista Eletrônica de Enfermagem, v. 12, n. 3, p. 571-577, 2010.

DAMACENA, F. D. L. A formação sistêmica de um direito dos desastres. 2011. 157 f. Dissertação (Mestrado em Direito) - Universidade do Vale do Rio do Sinos, São Leopoldo, 2011.

DANIELLOU, F. «Je me demanderais ce que la société attend de nous...» À propos des positions épistémologiques d'Alain Wisner. Travailler, n. 1, p. 23-38, 2006.

DARA, S. I. et al. Worldwide disaster medical response: an historical perspective. Critical care medicine, v. 33, n. 1, p. 52-56, 2005.

DAVIS, F. R. Insecticides, agriculture, and the Anthropocene. Global Environment, v. 10, n. 1, p. 114-136, 2017.

DE CASTRO, A. L. C.. Glossário de Defesa Civil: estudos de riscos e medicina de desastres. Ministério do Planejamento e Orçamento, Secretaria Especial de Políticas Regionais, Departamento de Defesa Civil, 1998.

DE CONINCK, H. et al. International technology-oriented agreements to address climate change. Energy Policy, v. 36, n. 1, p. 335-356, 2008.

DE LOTTINVILLE, P.; WEAVER, J. C. The conflagration and the city: disaster and progress in British North America during the nineteenth century. Histoire Sociale, v. 13, n. 26, 1980.

DIAS JÚNIOR, N. N. Aspectos sócio-antropológicos da ergonomia: A antropotecnologia e suas contribuições para os estudos ergonômicos. Ensaios de Ergonomia. Revista Virtual de Ergonomia. Universidade Federal de Santa Catarina. Florianópolis, 2000.

DOS SANTOS, V.; CANDELORO, R. J. Trabalhos Acadêmicos. São Paulo: Editora AGE Ltda, 2006.

DUTRA, A. R. A. Análise de custo/benefício na transferência de tecnologia: estudo de caso utilizando a abordagem antropotecnológica. Tese (Doutorado) Universidade Federal de Santa Catarina, Centro Tecnológico, Santa Catarina, 1999.

DWYER, T. Alain Wisner .Etlasociologie: entre proximité et distance. Travailler, n. 1, p. 165-183, 2006.

DWYER, T.; RAFTERY, A. E. Industrial accidents are produced by social relations of work: A sociological theory of industrial accidents. Applied Ergonomics, v. 22, n. 3, p. 167-178, 1991.

DRABEK, T. E.; MCENTIRE, D. A. Emergent phenomena and the sociology of disaster: lessons, trends and opportunities from the research literature. Disaster 
Prevention and Management: An International Journal, v. 12, n. 2, p. 97-112, 2003.

EDLER, J.; FIER, H.; GRIMPE, C. International scientist mobility and the locus of knowledge and technology transfer. Research Policy, v. 40, n. 6, p. 791-805, 2011.

FARINHA, L.; FERREIRA, J.; GOUVEIA, B. Networks of innovation and competitiveness: a triple helix case study. Journal of the Knowledge Economy, v. 7, n. 1, p. 259-275, 2016.

FERREIRA, L. L. Três lições do professor Wisner. Revista Brasileira de Saúde Ocupacional, v. 29, n. 109, p. 55-61, 2004.

FLANAGAN, B. E. et al. A social vulnerability index for disaster management. Journal of homeland security and emergency management, v. 8, n. 1, 2011.

FOLHA DE SÃO PAULO, Tragédia de Brumadinho, 2019. Disponível em: $<$ https://www1.folha.uol.com.br/cotidiano/tragedia-em-brumadinho/>. Acesso em 19 de março de 2019.

FRANCO, M. H. P. Percepção De Riscos E Comportamento Da Comunidade Diante De Acidentes Ambientais Em Áreas Portuárias De Santos E De São Sebastião. 2011. 119 f. Conclusão de Curso (Pós doutorado) - Pontifícia Universidade Católica, São Paulo, 2011.

FONSECA, J. J. S. Metodologia da Pesquisa Científica. São Paulo: Saraiva, 2002.

GARDNER, H.; CHEN, J.; MORAN, S. Inteligências múltiplas. Penso Editora, 2009.

GARRIGOU, AI.; BALDI, I.; JACKSON, M. The use of pesticides in French viticulture: a badly controlled technology transfer! Work, v. 41, n. 1, p. 19-25, 2012.

GESLIN, P. Secret kinship: The ethnographer and the anthropotechnologist. Travail Humain, v. 60, n. 3, p. 299-311, 1997.

GESLIN, P. Anthropotechnology - Handbook of human factors and ergonomic methods. Taylor \& Francis Group: 2004.

GIL, A. C. Métodos e técnicas de pesquisa social. São Paulo: Atlas, 1994.

GIMENEZ, A. M. N.; BONACELLI, M. B. Reflexões sobre as relações da universidade com o seu entorno: o engajamento acadêmico, 2015.

GOMES, M. A. S.; KOVALESKI, J. L. Política de Ciência e Tecnológia na América Latina: A atividade política e a antropotecnologia em processos de transferência de tecnologia. Política, v. 38, n. 4, 2017.

GRAHAM, C. A.; SINCLAIR, M. T. A survey of advanced trauma life-support training for trainees in acute surgical specialties. Injury, v. 27, n. 9, p. 631-634, 1996. 
HA, K. Disasters can happen to anybody: The case of Korea. Environmental Impact Assessment Review, v. 57, p. 1-9, 2016.

HENDRICK, H. W. Organizational design and macroergonomics. Handbook of human factors and ergonomics, v. 2, p. 594-627, 1997.

HUANG, J.; ASGARY, A.; WU, J. Advanced disaster, emergency and rapid response simulation (ADERSIM). Big Data \& Information Analytics, v. 1, n. 1, p. 665-689, 2016.

KAPUCU, N.; ARSLAN, T.; DEMIROZ, F. Collaborative emergency management and national emergency management network. Disaster Prevention and Management: An International Journal, v. 19, n. 4, p. 452-468, 2010.

KOVALESKI, J. L. et al. Uma abordagem antropotecnológica na formação de Spinoffs. Revista Espacios, v. 37, n. 31, 2016.

LANDRY, R. A. N.; CLOUTIER, J. S.; HALILEM, N. Technology transfer organizations: Services and business models. Technovation, v. 33 n. 12, p. 431449, 2013.

LEMOS JÚNIOR, M. R. et al. A indústria de petróleo e os derramamentos de óleo no mar: uma abordagem exploratória. 2016.

LEYDESDORFF, L.; ETZKOWITZ, H. The triple helix as a model for innovation studies. Science and public policy, v. 25, n. 3, p. 195-203, 1998.

LIBERAL, E. F. et al. Escola segura. Jornal de Pediatria, v. 81, n. 5, p. 155-63, 2005.

LIM, C.; McALEER, M. Time Series Forecastsof International Travel Demand for Australia. Tourism Management: 2001.

MACEDO, A. R. M. Uma experiência de um plano de auxílio mútuo no polo industrial do Macuripe. Revista Tecnologia, v. 1, n. 15, p.24-27, 1994.

MAKRIDAKIS, S.; WHEELWRIGHT, S.; HYNDMAN, R.J. Forecasting Methods and Applications. 3., ed. New York: John Wiley\& Sons, 1998.

MEACHAM, D. Introduction: Critiquing technologies of the mind: enhancement, alteration, and anthropotechnology. Phenomenology and the Cognitive Sciences, v. 16, n. 1, p. 1-16, 2017.

MELLO, R. L. R. A tragédia do Paissandú, entre o perene e o efêmero. Revista Ara., v. 5, n. 5, p. 57-75, 2018.

MINISTÉRIO DA INTEGRAÇÂO NACIONAL. Histórico da defesa civil, 2016. Disponível em http://www.integracao.gov.br/historico-sedec. Acesso em 20 fev. 2018. 
MORANDI, V. The management of industry-university joint research projects: how do partners coordinate and control R\&D activities? The Journal of Technology Transfer, v. 38, n. 2, p. 69-92, 2013.

PAGANI, R. N. et al. Modelo de transferência de conhecimento e tecnologia entre universidades parceiras na mobilidade acadêmica internacional. 2016.

PATON, D.; JOHNSTON, D. Disasters and communities: vulnerability, resilience and preparedness. Disaster Prevention and Management: An International Journal, v. 10 , n. 4 , p. $270-277,2001$.

PAU, M.; KIM, S.; NUSSBAUM, M. A. Fatigue-induced balance alterations in a group of Italian career and retained firefighters. International Journal of Industrial Ergonomics, v. 44, n. 5, p. 615-620, 2014.

PFAFFENBERGER, B. Social anthropology of technology. Annual review of Anthropology, v. 21, n. 1, p. 491-516, 1992.

PELLEGRINI, F. R.; FOGLIATTO, F. Estudo comparativo entre modelos de Winters e de Box-Jenkins para a previsão de demanda sazonal. Revista Produto \& Produção, v. 4, p. 72-85, 2000.

PINHEIRO, E. G. et al. Desastres: percepção comparativa do impacto econômico e financeiro sobre o Estado do Paraná em 2012. Revista Paranaense de Desenvolvimento, v. 35, n. 126, p.207-222, 2014.

PROENÇA, R. P. C. et al. Aspectos organizacionais e inovação tecnológica em processos de transferência de tecnologia: uma abordagem antropotecnológica no setor de alimentação coletiva, 1996.

PROTOGEROU, A.; CALOGHIROU, Y.; SIOKAS, E. Twenty-five years of scienceindustry collaboration: the emergence and evolution of policy-driven research networks across Europe. The Journal of Technology Transfer, v. 38, n. 6, p. 873895, 2013.

RIBEIRO, L. Socorristas e socorro de urgência, uma abordagem do processo de tomada de decisão imediata, 2011.

SALDANHAR, M. C. V.; ALMEIDA, J. D. Situated modelling in the drawing workshop for bobbin lace. Work, v. 41, n. 1, p. 683-689, 2012.

SANTOS, N. et al. Antropotecnologia: a ergonomia dos sistemas de produção. Curitiba: Gênesis, 1997.

SANTOS, J. F. A. et al. Do desastre para o risco: qualidade na cobertura em revistas semanais de informação, 2014.

SASSO DE LIMA, T. C.; TAMASO MIOTO, R. C. Procedimentos metodológicos na construção do conhecimento científico: a pesquisa bibliográfica. Revista Katálysis, v. $10,2007$. 
SCHUNDER-TATZBER, S. et al. Cardiac arrest at the workplace: results from an international survey about first aid on red cross and red crescent societies and international companies network. Resuscitation, v. 108, p. 1-3, 2016.

SIEBEN, M. Prevenção e segurança contra incêndio: legislação, normas e instruções técnicas para extração e controle de fumaça, 2014.

SILVA, A. V. F. G. Inserção das instituições públicas de saúde de Betim na gestão dos riscos de acidentes industriais ampliados na área da refinaria Gabriel Passos-Petrobras. 2008. Tese de Doutorado. Dissertação de mestrado, Universidade Federal de Minas Gerais, Belo Horizonte, MG, Brasil.

SOARES, M. M. Ergonomics in Latin America: Background, trends and challenges. Applied ergonomics, v. 37, n. 4, p. 555-561, 2006.

SANTOS, J. F. L. et al. Do desastre para o risco: qualidade na cobertura em revistas semanais de informação, 2014.

SOUSA, A. A.; COSTA, R. P. P. La gestion des soins nutritionnels dans le secteur hospitalier: une étude comparative Brésil-France. Recherche en soins infirmiers, $\mathrm{n}$. 4, p. 28-33, 2005.

SPEKMAN, R. E.; DAVIS, E. W. Risky business: expanding the discussion on risk and the extended enterprise. International Journal of Physical Distribution \& Logistics Management, v. 34, n. 5, p. 414- 433, 2004.

STEDILE, M. Gerenciamento de Risco para Indústria Química de Médio Porte, 2014.

SVENSSON, A. et al. Firefighters as first incident persons: Breaking the chain of events and becoming a new link in the chain of survival. International Journal of Emergency Services, v. 7, n. 2, p. 120- 133, 2018.

SZNELWAR, L. I.; SILVA, M. T.; MASCIA, F. L. Working in public health services in Brazil: The relationship between different rationalities. Applied ergonomics, v. 39, $\mathrm{n}$. 4, p. 500-508, 2008.

TEIGER, C. et al. Quand les ergonomes sont sortis du laboratoire.... à propos du travail des femmes dans l'industrie électronique (1963-1973). Rétro-réflexion collective sur l'origine d'une dynamique de coopération entre action syndicale et recherche-formation-action. Perspectives interdisciplinaires sur le travail et la santé, v. 1, n. 8, 2006.

VIDAL, M. C. Introdução à ergonomia. São Paulo: 2012.

YOUTIE, J.; SHAPIRA, P. Building an innovation hub: A case study of the transformation of university roles in regional technological and economic development. Research policy, v. 37, n. 8, p. 1188- 1204, 2008.

ZHAO, J. L. et al. The Quantitative risk Analysis for Oil Tank Storage Areas Considering Different Firefighting Ability. Industrial Technology and Management Science. v. 34, 655-658, 2015. 
WALTER, J. Safety management at the frontier: Cooperation with contractors in oil and gas companies. Safety Science, v. 91, p. 394-404, 2017.

WANG, J. Post-disaster cross-nation mutual aid in natural hazards: case analysis from sociology of disaster and disaster politics perspectives. Natural hazards, v. 66, n. 2, p. 413-438, 2013.

WISNER, A. Ergonomics in industrially developing countries. Ergonomics, v. 28, n. 8, p. 1213-1224, 1985.

WISNER, A. Variety of physical characteristics in industrially developing countriesergonomic consequences. International journal of industrial ergonomics, v. 4, n. 2, p. 117-138, 1989.

WISNER, A. A antropotecnologia. Estudos avançados, v. 6, n. 16, p. 29-34, 1992.

WISNER, ALAIN. The Etienne Grandjean Memorial Lecture Situated cognition and action: implications for ergonomic work analysis and anthropotechnology.

Ergonomics, v. 38, n. 8, p. 1542-1557, 1995.

WRIGHT, M. et al. Mid-range universities' linkages with industry: Knowledge types and the role of intermediaries. Research policy, v. 37, n. 8, p. 1205-1223, 2008. 


\section{APÊNDICES}

\section{APÊNDICE A}

Tabela 5.a - Resultados obtidos na revisão de literatura* com o tema antropotechnological.

\begin{tabular}{|c|c|c|c|c|c|}
\hline Author & Title & Year & Citation & JCR & InOrdinatio \\
\hline $\begin{array}{l}\text { Gomes, M. and } \\
\text { Kovaleski, J. }\end{array}$ & $\begin{array}{c}\text { Science and technology policy in Latin America: The political } \\
\text { activity and the anthropotechnology in technology transfer } \\
\text { processes }\end{array}$ & 2017 & 7 & & 97 \\
\hline Davis, F. & $\begin{array}{c}\text { Pesticides and the paradox of the Anthropocene: From natural to } \\
\text { synthetic to synthesised nature }\end{array}$ & 2017 & 1 & 2,526 & 91 \\
\hline Meacham, D. & $\begin{array}{c}\text { Introduction: Critiquing technologies of the mind: enhancement, } \\
\text { alteration, and anthropotechnology }\end{array}$ & 2017 & 0 & & 90 \\
\hline Mugerauer, $\mathrm{R}$. & $\begin{array}{c}\text { Anthropotechnology: Sloterdijk on Environmental Design and the } \\
\text { FoamWorlds of Co-Isolation }\end{array}$ & 2016 & 0 & & 80 \\
\hline $\begin{array}{l}\text { Garrigou, A., } \\
\text { Baldi, I. and } \\
\text { Jackson, M. }\end{array}$ & $\begin{array}{l}\text { The use of pesticides in French viticulture: a badly controlled } \\
\text { technology transfer! }\end{array}$ & 2012 & 4 & 0,723 & 44 \\
\hline Blad, S. & The impact of 'anthropotechnology' on human evolution & 2010 & 9 & & 29 \\
\hline Wisner, A. & $\begin{array}{c}\text { Towards an Anthropotechnology. x. a new activity for the United } \\
\text { Nations in the service of economic development: specifying } \\
\text { requirements for Technology Transfers in given geographical and } \\
\text { anthropological locations }\end{array}$ & 2004 & 3 & & -37 \\
\hline
\end{tabular}

Total $=7$

Fonte - Elaborado pela pesquisadora (2018) 
Tabela 5.b - Resultados obtidos na revisão de literatura** com o tema TKT. Author Title

Year InOrdinatio

Arvanitis, S., Kubli, U. and Woerter, M.

Edler, J., Fier, H. and Grimpe, C.

Landry, R., Amara, N.,

Cloutier, J.-S. and Halilem $\mathrm{N}$.

Morandi, V

Farinha, L., Ferreira, J. and Gouveia, B.

Gelijns, A. and Thier, S.

Grimpe, C. and Hussinger, $\mathrm{K}$.

Carayannis, E.G., Rozakis S. and Grigoroudis, E.

Huh, T. and Kim, H.-J.

Sinell, A., Ifflaender, V. and Muschner, A.

Sinell, A., Mueller-Wieland, R. and Muschner, A.

Meissner, D. and

Carayannis, E.G.

Van Horne, C. and Dutot, V.

Arvanitis, S., Sydow, N. and Woerter, M.

Bull, S.E., Ndunguru, J., Gruissem, W., Beeching,

J.R. and Vanderschuren, $H$.

Olaya Escobar, E.S.,

Berbegal- Mirabent, J.,

Alegre, I. and Duarte Velasco, O.G.

Calcagnini, G. and Favaretto, I.

Protogerou, A., Caloghirou, Twenty-five years of science-industry collaboration: the emergence Y. and Siokas, E.

Ndlovu, S.

Shirole, A.M.

University-industry knowledge and technology transfer in Switzerland: enterprises

International scientist mobility and the locus of knowledge and technology transfer

Technology transfer organizations: Services and business models 2013

The management of industry-university joint research projects: how do partners coordinate and control $R \& D$ activities?

Networks of Innovation and Competitiveness: A Triple Helix Case Study

Medical innovation and institutional interdependence - Rethinking university-industry connections

Formal and Informal Knowledge and Technology Transfer from Academia to Industry: Complementarity Effects and Innovation Performance

Agri-science to agri-business: the technology transfer dimension

Korean Experimentation of Knowledge and Technology Transfer to Address Climate Change in Developing Countries

Gender-Specific Constraints on Academic Entrepreneurship and Engagement in Knowledge and Technology Transfer

Value generation from industry-science linkages in light of targeted open innovation

Challenges in technology transfer: an actor perspective in a quadruple helix environment

Is there any impact of university-industry knowledge transfer on innovation and productivity? An empirical analysis based on swiss

$$
\text { firm }
$$$$
\text { data }
$$

Cassava: constraints to production and the transfer of biotechnology to African laboratories

Researchers' willingness to engage in knowledge and technology transfer activities: an exploration of the underlying motivations opportunity for the minerals industry during the economic downturn What university scientists think about co-operation with private $\quad 2008 \quad 276$

2011

165

126 
Tabela 5.c - Resultados obtidos na revisão de literatura ${ }^{\star \star \star}$ com o tema TKT + DMA.

Paton, D. and Johnston, D.

Spekman, R.E. and Davis, E.W.

Drabek, T.E. and McEntire, D.A.

Kapucu, N., Arslan, T. and Demiroz, $\mathrm{F}$

Alexander, D.

Heung, V.C.S., Kucukusta D. and Song, $\mathrm{H}$

Maon, F., Lindgreen, A. and Vanhamme, J.

Stewart, G.T., Kolluru, R. and Smith, M.

McEntire, D.A.

McEntire, D.A. and Myers, A.

McLachlin, R. and Larson, P.D.

Salmon, P., Stanton,

N., Jenkins, D. and Walker, G.

Every, D. and Richardson, $J$

Tantanee, S.,

Buranajarukorn

P. and Apichayakul, P

Vega, D. and Roussat, C.

Aliakbarlou, S., Wilkinson,

S., Costello, S.B. and Jang, $\mathrm{H}$.

Johnston, D., Becker, J. and Paton, D.

Nemakonde, L.D. and Niekerk,

D.V.

Asgary, A., Pantin, B., Saiiar,

B.E. and Wu, J.

Kasdan, D.O. and Kim, K.
Disasters and communities: vulnerability, resilience and preparedness

2001

Risky business: expanding the discussion on risk and the extended enterprise

2001

620

0,995

550

$2004 \quad 472 \quad 3,98 \quad 432$

Emergent phenomena and the sociology of disaster: lessons, trends and opportunities from the research literature

$2003 \quad 406$

0,995

Collaborative emergency management

and national emergency management network

Towards the development of a standard in emergency planning

20

191

0,995

2005

0,995

Medical tourism development in Hong Kong: An assessment of the barriers

$\begin{array}{lll}2011 & 174 & 6,048\end{array}$

Developing supply chains in disaster relief operations through cross-sector socially oriented collaborations: a theoretical model

Leveraging public-private partnerships to improve community resilience in times of disaster

2009

Coordinating multi-organisational responses to disaster: lessons from the March 28, 2000 Fort Worth tornado

$2002 \quad 201$

0,995

Preparing communities for disasters: issues and processes for government readiness

Building humanitarian supply chain

relationships: lessons from leading practitioners

$2011 \quad 81$

Coordination during multi-agency emergency response: issues and solutions

201176

0,995

106

A framework for disaster resilience education with homeless communities

$2018 \quad 0 \quad 0,995$

University-Industry Linkages in the Disaster

Resilience Sector: A Case Study of Thailand

$2018 \quad 0$

Humanitarian logistics: the role of logistics service providers

$2015 \quad 28$

3,98

Client values within post-disaster reconstruction contracting services

$2017 \quad 4$

0,995

94

Multi-agency community engagement during disaster recovery: Lessons from two New Zealand earthquake events

$2012 \quad 54$

0,995

94

A normative model for integrating organisations for disaster risk reduction and climate change adaptation within SADC member states

Developing disaster mutual assistance decision criteria for electricity industry

$2017 \quad 2 \quad 0,995$

92

From K-Pop to K-Preparedness: Korea confronts disaster reduction 
Tabela 5.d - Resultados obtidos na revisão de literatura ${ }^{\star \star \star \star}$ com o tema Antropotecnologia.

\begin{tabular}{|c|c|c|c|c|c|}
\hline Author & Title & Year & Citations & JCR & InOrdinatio \\
\hline $\begin{array}{l}\text { Romeiro } \\
\text { Filho, E. }\end{array}$ & $\begin{array}{l}\text { Uma abordagem centrada no usuário para o projeto } \\
\text { de máquinas agrícolas de tração animal. }\end{array}$ & 2012 & 9 & 0.0081 & 49 \\
\hline $\begin{array}{c}\text { Sousa, A A; } \\
\text { Proença, } \\
\text { Rossana P. } \\
\text { C. }\end{array}$ & $\begin{array}{l}\text { Tecnologias de gestão dos cuidados nutricionais: } \\
\text { recomendações para qualificação do atendimento nas } \\
\text { unidades de alimentação e nutrição hospitalares. }\end{array}$ & 2004 & 35 & 0,333 & $-4,9$ \\
\hline Wisner, Alain. & A antropotecnologia & 1992 & 27 & 0.0874 & -132 \\
\hline
\end{tabular}

Fonte - Elaborado pela pesquisadora (2018) 


\section{APÊNDICE B}

Quadro 11 - Relação de dados dos principais autores relacionados ao tema pesquisado

\begin{tabular}{|c|c|c|c|c|c|c|}
\hline Título & Autor & JCR & Ano & $\begin{array}{l}\text { Total de } \\
\text { Citações }\end{array}$ & $\begin{array}{l}\text { Local } \\
\text { (país) }\end{array}$ & Área \\
\hline \multicolumn{7}{|l|}{ Livros } \\
\hline Quant Voyagent Les Usines & Wisner, A & & 1975 & 1 & França & Engenharia \\
\hline $\begin{array}{l}\text { Anthropotechnology or adaptation of technology } \\
\text { to population - does it exist }\end{array}$ & Wisner, A & 0,3 & 1980 & 152 & França & Engenharia \\
\hline $\begin{array}{l}\text { Towards an anthropotechnology } X \text { a new activity } \\
\text { for the united nations in the service of economic } \\
\text { development: specifying requirements for } \\
\text { technology transfers in given geographical and } \\
\text { anthropological locations. }\end{array}$ & Wisner, A & & 2004 & 4 & USA & Engenharia Livro \\
\hline \multicolumn{7}{|l|}{ Conferência } \\
\hline $\begin{array}{l}\text { Innovative representation of normative support in } \\
\text { high-rise construction }\end{array}$ & Volkov, A. A., et al. & & 2014 & & Alemanha & $\begin{array}{l}\text { Engenharia } \\
\text { Seminário }\end{array}$ \\
\hline \multicolumn{7}{|l|}{ Boletins } \\
\hline $\begin{array}{l}\text { Anthropotechnological and industrial aspects of } \\
\text { coding and organization of information on color } \\
\text { displays }\end{array}$ & Geiser, G. et. al. & 0,348 & 1978 & 1 & Holanda & Engenharia \\
\hline Ergonomics in industrially developing countries. & Wisner, A & 1,713 & 1985 & 44 & França & Engenharia \\
\hline
\end{tabular}


APÊNDICES

\begin{tabular}{|c|c|c|c|c|c|c|}
\hline $\begin{array}{l}\text { When the factories travel - essay of } \\
\text { anthropotechnology }\end{array}$ & Leplat, A & 0,3 & 1986 & 49 & França & Engenharia \\
\hline $\begin{array}{l}\text { Anthropotechnology, autopoiesis and the work of } \\
\text { Piaget, Jean }\end{array}$ & Dossantos, N. et al & & 1994 & 43 & Holanda & Educação \\
\hline $\begin{array}{l}\text { The design of organization - contribuition of the } \\
\text { anthropotechnological approach }\end{array}$ & Langa, M. et al & & 1994 & 2 & Holanda & Engenharia \\
\hline $\begin{array}{l}\text { Organization anthropotechnological } \\
\text { contingencies - an analytical approach }\end{array}$ & Wisner, A & & 1994 & & Holanda & Engenharia \\
\hline $\begin{array}{l}\text { The Etienne-Grandjean-Memorial-Lecture- } \\
\text { Situated cognition and action - implications for } \\
\text { ergonomic work analisys and } \\
\text { anthropotechnology }\end{array}$ & Wisner, A & 1,713 & 1995 & 73 & França & Engenharia \\
\hline Psychological aspects of anthropotechnology & Wisner, A & 0,3 & 1997 & 11 & França & Engenharia \\
\hline $\begin{array}{l}\text { Macroergonomics: A proposed approach for use } \\
\text { ith anthropotechnology and ergonomic work } \\
\text { analysis in effecting technology transfer }\end{array}$ & Hendrick, H. W. & 0,3 & 1997 & 7 & França & Engenharia \\
\hline $\begin{array}{l}\text { Secret kinship: The ethnographer and the } \\
\text { antropotechnologist }\end{array}$ & Geslin, P & 0,3 & 1997 & & França & Engenharia \\
\hline Anthropotechnology - Introduction & Laville, A & 0,3 & 1997 & 1 & França & Engenharia \\
\hline $\begin{array}{l}\text { An anthropotechnological approach: The social } \\
\text { and the industrial fabric in technology transfer }\end{array}$ & Rubio, C & 0,3 & 1997 & 3 & França & Engenharia \\
\hline $\begin{array}{l}\text { Anthropotechnology: the ergonomics of the } \\
\text { production systems }\end{array}$ & Dossantos, N. et. al. & & 1998 & 2 & Holanda & Engenharia \\
\hline $\begin{array}{l}\text { The anthropotechnological aspects of the } \\
\text { management of building sites in Brazilian } \\
\text { constructions. }\end{array}$ & Franco, E. M., et al. & & 1998 & & Holanda & Engenharia \\
\hline
\end{tabular}


APÊNDICES

\begin{tabular}{|c|c|c|c|c|c|c|}
\hline $\begin{array}{l}\text { Anthropotechnology - For a multicentered } \\
\text { industrial world. }\end{array}$ & Bare, J. F. & 0,044 & 1999 & & França & Engenharia \\
\hline $\begin{array}{l}\text { Anthropotechnological analysis of industrial } \\
\text { accidents in Brazil }\end{array}$ & Binder, M. C. P., et al. & 4,939 & 1999 & 3 & EUA & Educação \\
\hline $\begin{array}{l}\text { Technology of management of nutritional care: } \\
\text { Recommendations to qualifying the attendance } \\
\text { in hospital food and nutrition services }\end{array}$ & De Sousa, A. A. et. al. & & 2004 & 3 & Brasil & Alimentação \\
\hline $\begin{array}{l}\text { How can anthropology contribute to the } \\
\text { expansion of saffron production? }\end{array}$ & Helfer, S. & & 2004 & 2 & USA & Agricultura \\
\hline $\begin{array}{l}\text { Review of the knowledge of microbial } \\
\text { contamination of the Russian manned spacecraft }\end{array}$ & Novikova, N. D. & 3,63 & 2004 & 107 & USA & Ecologia \\
\hline $\begin{array}{l}\text { The management of nutritional care in hospitals: } \\
\text { comparative study Brazil-France }\end{array}$ & Sousa, A. A. & & 2005 & 2 & França & Enfermagem \\
\hline Alain Wisner: A disputed heritage & Clot, Y. & & 2006 & & França & Engenharia \\
\hline $\begin{array}{l}\text { I would wonder what society expects from us » } \\
\text { On Alain Wisner's epistemological stances }\end{array}$ & Daniellou, F. & & 2006 & & França & Engenharia \\
\hline $\begin{array}{l}\text { Alain wisner and sociology: Between proximity } \\
\text { and distance }\end{array}$ & Dwyer, $\mathrm{T}$. & & 2006 & & França & Engenharia \\
\hline $\begin{array}{l}\text { The Political and the Scientific in the Practice of } \\
\text { Anthropotechnology. }\end{array}$ & Geslin, P. & & 2006 & & França & Engenharia \\
\hline $\begin{array}{l}\text { Genomics and identity: The bioinformatisation of } \\
\text { human life. }\end{array}$ & Zwart, $\mathrm{H}$. & 1,067 & 2009 & 18 & USA & Interdisciplinar \\
\hline $\begin{array}{l}\text { Housebreaking the human animal: Humanism } \\
\text { and the problem of sustainability in Margaret } \\
\text { Atwood's Oryx and Crake and the year of the } \\
\text { flood }\end{array}$ & Bergthaller, $\mathrm{H}$. & 0,048 & 2010 & 61 & USA & Letras \\
\hline
\end{tabular}


APÊNDICES

\begin{tabular}{|c|c|c|c|c|c|c|}
\hline $\begin{array}{l}\text { The impact of 'anthropotechnology' on human } \\
\text { evolution }\end{array}$ & Blad, S. & & 2010 & 8 & França & Ecologia \\
\hline $\begin{array}{l}\text { Ergopolis: An ergonomics approach applied to a } \\
\text { city. }\end{array}$ & De Carvalho, R. J. M. & 3,4 & 2012 & 3 & USA & Engenharia \\
\hline $\begin{array}{l}\text { The use of pesticides in French viticulture: } A \\
\text { badly controlled technology transfer }\end{array}$ & Garrigou, A., et al. & 3,4 & 2012 & 2 & USA & Engenharia \\
\hline $\begin{array}{l}\text { Situated modelling in the drawing workshop for } \\
\text { bobbin lace }\end{array}$ & Saldanhar, M. C. W. et. al. & 3,4 & 2012 & 1 & USA & Engenharia \\
\hline $\begin{array}{l}\text { The Néopassaction platform: Product and } \\
\text { witness of an anthropotechnologicalaproach in } \\
\text { education }\end{array}$ & Durand, M. & & 2014 & 2 & França & Educação \\
\hline $\begin{array}{l}\text { An approach antropotecnológica in formation } \\
\text { of Spin-offs }\end{array}$ & da Luz, A. A., et al. & & 2016 & & Venezuela & Engenharia \\
\hline $\begin{array}{l}\text { Anthropotechnology: Sloterdijk on environmental } \\
\text { design and the FoamWorlds of co-isolation }\end{array}$ & Mugerauer, R. & & 2016 & & França & Arquitetura \\
\hline $\begin{array}{l}\text { Política de ciência e tecnologia na América } \\
\text { Latina: A atividade política e a antropotecnologia } \\
\text { em processos de transferência de tecnologia }\end{array}$ & Gomes, M. A. S. et. al. & & 2017 & & Venezuela & Engenharia \\
\hline $\begin{array}{l}\text { Introduction: Critiquing technologies of the mind: } \\
\text { enhancement, alteration, and } \\
\text { anthropotechnology. }\end{array}$ & Meacham, D. & & 2017 & & USA & Engenharia \\
\hline
\end{tabular}




\section{APÊNDICE C}

Tabela 6 - Palavras-chave para pesquisa nas bases de dados e resultados brutos obtidos

\begin{tabular}{|c|c|c|c|c|c|c|c|c|}
\hline & \multirow{2}{*}{$\begin{array}{l}\text { Key words and } \\
\text { combinations }\end{array}$} & A & B & C & D & E & $F$ & \multirow[b]{2}{*}{ Total } \\
\hline & & Science Direct & Scopus & Web of Knowledge & Emerald Insight & PubMed & Scielo & \\
\hline 1 & Anthropotechnology & $\begin{array}{c}\text { Search results: } 4 \text { results found } \\
\text { for pub-date > } 2006 \text { and TITLE- } \\
\text { ABSTR-KEY } \\
\text { (-Anthropotechnologyll). }\end{array}$ & $\begin{array}{l}4 \text { document results TITLE- } \\
\text { ABS-KEY } \\
\text { ("Anthropotechnology") AND } \\
\text { DOCTYPE (ar) AND } \\
\text { PUBYEAR > 2006 }\end{array}$ & $\begin{array}{l}\text { Results: } 7 \text { search for: Topic: } \\
\text { ("Anthropotechnology") }\end{array}$ & $\begin{array}{c}\text { Anywhere: } \\
\text {-anthropotechnologyl } \\
\text { (Articles/Chapters - 4) }\end{array}$ & $\begin{array}{l}\text { Search results Items: } 4 \\
\text { "Anthropotechnology"[All Fields] }\end{array}$ & $\begin{array}{c}\text { Resultados: } 1 \text {-utilizando a } \\
\text { palavra } \\
\text {-Anthropotechnologyll em } \\
\text { todos os índices }\end{array}$ & 23 \\
\hline 2 & $\begin{array}{l}\text { Knowledge and } \\
\text { technology transfer" }\end{array}$ & $\begin{array}{l}\text { Search results: } 321 \text { pub-date > } \\
2006 \text { and TITLE-ABSTR- } \\
\text { KEY ("knowledge and } \\
\text { technology transfer") }\end{array}$ & $\begin{array}{l}79 \text { resultados de documentos } \\
\text { TITLE-ABS-KEY } \\
\text { ("conhecimento e transferência } \\
\text { de tecnologia") E DOCTYPE } \\
\text { (ar) E PUBYEAR > 2006 }\end{array}$ & $\begin{array}{l}\text { Results: } 110 \text { search for: } \\
\text { (from Principal Web of Science } \\
\text { Collection) ("knowledge and } \\
\text { technology transfer") }\end{array}$ & $\begin{array}{l}\text { Anywhere: "knowledge and } \\
\text { technology transfer" } \\
\text { (Articles/Chapters - 130) }\end{array}$ & $\begin{array}{l}\text { Search results Items: } 1 \text { to } 20 \text { of } \\
\qquad 145\end{array}$ & $\begin{array}{l}\text { Resultados: } 0 \text {-utilizando a } \\
\text { palavra -Knowledge and } \\
\text { technology transfer" em } \\
\text { todos os índices }\end{array}$ & 785 \\
\hline \multirow{2}{*}{3} & $\begin{array}{c}\text { Anthropotechnology AND } \\
\text { knowledge and } \\
\text { technology transfer" }\end{array}$ & $\begin{array}{l}\text { No results found. Your search } \\
\text { was:-Anthropotechnology\|l AND } \\
\text {-knowledge and technology } \\
\text { transfer" date: } 2007-2018 \text { article } \\
\text { Types: Review articles, } \\
\text { Research articles }\end{array}$ & $\begin{array}{l}\text { 0 Document search results } \\
\text { TITLE-ABS-KEY } \\
\text { ("Anthropotechnology" AND } \\
\text { "knowledge and technology } \\
\text { transfer") AND DOCTYPE (ar) } \\
\text { AND PUBYEAR > 2006 }\end{array}$ & $\begin{array}{l}\text { Results: } 0 \text { search for: Topic: } \\
\text { (-Anthropotechnologyll) AND } \\
\text { (-knowledge and technology } \\
\quad \text { transfer") } \\
\text { Time stipulated: } 2007-2018 .\end{array}$ & $\begin{array}{c}\text { Anywhere: } \\
\text {-anthropotechnologyll] AND } \\
\text { [Anywhere: } \\
\text {-knowledge] AND... } \\
\text { (Articles/Chapters - 0) }\end{array}$ & $\begin{array}{l}\text { Search results Items: } 0 \\
\text { "Anthropotechnology"[AAl Fields] } \\
\text { AND (("knowledge"[MeSH } \\
\text { Terms] OR "knowledge"[All } \\
\text { Fields]) AND ("technology } \\
\text { transfer") }\end{array}$ & $\begin{array}{c}\text { Resultados: } 0 \text {-utilizando a } \\
\text { palavra } \\
\text {-Anthropotechnologyll AND } \\
\text {-knowledge and technology } \\
\text { transfer" em todos os } \\
\text { índices }\end{array}$ & 0 \\
\hline & $\begin{array}{l}\text { Anthropotechnology AND } \\
\text { Disaster Mutual } \\
\text { Assistancell }\end{array}$ & $\begin{array}{c}\text { Search results: } 0 \text { results found } \\
\text { for pub-date > } 2006 \text { and TITLE- } \\
\text { ABSTR-KEY } \\
\text { ("Anthropotechnology" and } \\
\text { TITEE-ABSTR-KEY } \\
\text { (-Disaster Mutual Assistancel) }\end{array}$ & $\begin{array}{c}0 \text { Document search results } \\
\text { (TITLE-ABS-KEY } \\
\text { ("Anthropotechnology") AND } \\
\text { TITLE-ABS-KEY ("Disaster } \\
\text { Mutual Assistance")) AND } \\
\text { DOCTYPE (ar) AND } \\
\text { PUBYEAR > 2006 }\end{array}$ & $\begin{array}{c}\text { Results: } 0 \text { search for: } \\
\text { Topic:("Anthropotechnology") } \\
\text { AND Topic: (-Disaster Mutual } \\
\text { Assistancell). } \\
\text { Time stipulated: } 2007-2018 .\end{array}$ & $\begin{array}{c}\text { [Anywhere: } \\
\text { "anthropotechnology"] AND } \\
\text { [Anywhere: "Disaster Mutual } \\
\text { Assistance"] (Articles - 0) }\end{array}$ & $\begin{array}{l}\text { Search results Items: } 0 \\
\text { ("anthropotechnology"[All } \\
\text { Fields]) AND -Disaster Mutual } \\
\text { Assistance"[All Fields]) }\end{array}$ & $\begin{array}{c}\text { Resultados: } 0 \text {-utilizando a } \\
\text { palavra } \\
\text {-Anthropotechnologyll AND } \\
\text {-Disaster Mutual } \\
\text { Assistancell em todos os } \\
\text { índices }\end{array}$ & 0 \\
\hline
\end{tabular}




\begin{tabular}{|c|c|c|c|c|c|c|c|c|}
\hline \multirow[t]{2}{*}{4} & $\begin{array}{l}\text {-knowledge and } \\
\text { technology transfer" } \\
\text { AND -Disaster } \\
\text { Mutual Assistancell }\end{array}$ & $\begin{array}{l}\text { Search results: } 0 \text { No results } \\
\text { found. Your search was: } \\
\text {-knowledge and technology } \\
\text { transfer" AND -Disaster } \\
\text { Mutual Assistancell date: } \\
2007-2018 \text { article Types: } \\
\text { Review articles, Research } \\
\text { articles }\end{array}$ & $\begin{array}{l}\text { 0 Document search } \\
\text { results TITLE-ABS-KEY } \\
\text { ("knowledge and } \\
\text { technology transfer" AND } \\
\text { "Disaster Mutual } \\
\text { Assistance") AND } \\
\text { DOCTYPE (ar) AND } \\
\text { PUBYEAR > 2006 }\end{array}$ & $\begin{array}{l}\text { Results: } 0 \\
\text { search for: Topic:( -knowledge } \\
\text { and technology transfer" AND } \\
\text {-Disaster Mutual Assistancel) } \\
\text { Time stipulated: } 2007-2018 .\end{array}$ & $\begin{array}{c}\text { [Anywhere: } \\
\text {-knowledge and } \\
\text { technology transfer] } \\
\text { AND [Anywhere: "... } \\
\text { (Articles/Chapters - } \\
\text { 0) }\end{array}$ & $\begin{array}{l}\text { Search results Items: } 0 \\
\text { knowledge and technology } \\
\text { transfer" AND "Disaster } \\
\text { Mutual Assistance" }\end{array}$ & $\begin{array}{l}\text { Resultados: } 0 \text {-utilizando } \\
\text { a palavra -knowledge } \\
\text { and technology transfer" } \\
\text { AND } \\
\text {-Disaster Mutual } \\
\text { Assistancell em todos } \\
\text { osíndices }\end{array}$ & 0 \\
\hline & $\begin{array}{l}\text {-Disaster } \\
\quad \text { Mutual } \\
\text { Assistancell }\end{array}$ & $\begin{array}{l}1 \text { result found. Your search } \\
\text { was: "disaster mutual } \\
\text { assistance" }\end{array}$ & $\begin{array}{l}1 \text { document result TITLE- } \\
\text { ABS-KEY ("Disaster Mutual } \\
\text { Assistance") AND } \\
\text { DOCTYPE (ar) AND } \\
\text { PUBYEAR > 2006 }\end{array}$ & $\begin{array}{c}\text { Results: } 1 \\
\text { search for: } \\
\text { (from Principal Web of Science } \\
\text { Collection) (-Disaster Mutual } \\
\text { Assistancell) }\end{array}$ & $\begin{array}{c}\text { [Anywhere: -disaster } \\
\text { mutual assistancell] } \\
\text { AND [Publication: Di... } \\
\text { (Articles/Chapters - } \\
\text { 102) }\end{array}$ & $\begin{array}{c}\text { Search results Items: } 1 \text { to } 20 \\
\text { of } 22 \text {-Disaster Mutual } \\
\text { Assistancell }\end{array}$ & $\begin{array}{l}\text { Resultados: } 0 \text {-utilizando } \\
\text { a palavra -Disaster } \\
\text { Mutual Assistancell em } \\
\text { todos os índices }\end{array}$ & 127 \\
\hline 5 & $\begin{array}{c}\text {-Disaster } \\
\text { Mutual } \\
\text { Assistancell AND } \\
\text {-Mutual Disaster } \\
\text { Assistancell }\end{array}$ & $\begin{array}{c}1 \text { result found -Disaster } \\
\text { Mutual Assistancell AND } \\
\text {-Mutual Disaster Assistancell }\end{array}$ & $\begin{array}{c}0 \text { Document search results } \\
\text { TITLE-ABS-KEY ("Disaster } \\
\text { Mutual Assistance" AND } \\
\text { "Mutual Disaster } \\
\text { Assistance") AND } \\
\text { DOCTYPE (ar OR re) AND } \\
\text { PUBYEAR > 2006 }\end{array}$ & $\begin{array}{c}\text { Results: } 0 \\
\text { search for: Topic:( -Disaster } \\
\text { Mutual Assistancell AND } \\
\text {-Mutual Disaster Assistancel) } \\
\text { Time stipulated: } 2007-2018 .\end{array}$ & $\begin{array}{l}\text { [Anywhere: -disaster } \\
\text { mutual] AND } \\
\text { [Anywhere: } \\
\text { assistancell] AND [... } \\
\text { (Articles/Chapters - } \\
47 \text { ) }\end{array}$ & $\begin{array}{l}\text { Search results Items: } 1 \text { to } \\
20 \text { of } 22 \text { "Disaster Mutual } \\
\text { Assistance" AND mutual } \\
\text { disaster assistance }\end{array}$ & $\begin{array}{c}\text { Resultados: } 0 \text { - } \\
\text { utilizando a palavra } \\
\text {-Disaster Mutual } \\
\text { Assistancell AND } \\
\text {-Mutual Disaster } \\
\text { Assistancell em todos } \\
\text { os índices }\end{array}$ & 0 \\
\hline 6 & $\begin{array}{l}\text {-Mutual } \\
\text { Disaster } \\
\text { Assistancell AND } \\
\text {-knowledge and } \\
\text { technology } \\
\text { transfer" }\end{array}$ & $\begin{array}{l}\text { No results found. Your } \\
\text { search was: -Mutual } \\
\text { Disaster Assistance AND } \\
\text {-knowledge and } \\
\text { technology transfer" date: } \\
2007-2018\end{array}$ & $\begin{array}{c}0 \text { Document search } \\
\text { results TITLE-ABS-KEY } \\
\text { ("Assistência a Desastres } \\
\text { Mútuos" E "transferência de } \\
\text { conhecimento e } \\
\text { tecnologia") E DOCTYPE } \\
\text { (ar) E } \\
\text { PUBYEAR > } 2006\end{array}$ & $\begin{array}{c}\text { Results: } 0 \\
\text { search for: Topic:( - Mutual } \\
\text { Disaster Assistancell AND } \\
\text {-knowledge and technology } \\
\text { transfer") } \\
\text { Time stipulated: 2007-2018. }\end{array}$ & $\begin{array}{l}\text { [Anywhere: -mutual } \\
\text { disaster] AND } \\
\text { [Anywhere: } \\
\text { assistancell] AND } \\
\text {-knowledge and } \\
\text { technology transfer" } \\
\text { (Articles/Chapters - } \\
\text { 13) }\end{array}$ & $\begin{array}{l}\text { Search results Items } \\
\text { "Mutual Disaster } \\
\text { Assistance" AND } \\
\text { "knowledge and } \\
\text { technology transf... (0) }\end{array}$ & $\begin{array}{l}\text { Resultados: } 0 \text {-utilizando } \\
\text { a palavra -Mutual } \\
\text { Disaster Assistancell } \\
\text { AND } \\
\text {-knowledge and } \\
\text { technology transfer" } \\
\text { em todos os índices }\end{array}$ & 0 \\
\hline 7 & $\begin{array}{l}\text {-Mutual Disaster } \\
\text { Assistancell AND } \\
\text {-Anthropotechnology\| }\end{array}$ & $\begin{array}{c}\text { No results found. Your } \\
\text { search was: -Mutual Disaster } \\
\text { Assistance AND } \\
\text {-Anthropotechnologyll } \\
\text { date: } 2007-2018\end{array}$ & $\begin{array}{c}\text { 0 Document search } \\
\text { results TITLE-ABS-KEY (" } \\
\text { Mutual } \\
\text { Disaster Assistance" AND } \\
\text { "Anthropotechnology") } \\
\text { AND DOCTYPE (ar) AND } \\
\text { PUBYEAR > 2006 }\end{array}$ & $\begin{array}{c}\text { Results: } 0 \\
\text { search for: Topic: (-Mutual } \\
\text { Disaster Assistancell AND } \\
\text {-Anthropotechnologyll) Time } \\
\text { stipulated: } 2007-2018 .\end{array}$ & $\begin{array}{l}\text { [Anywhere: -mutual } \\
\text { disaster] AND } \\
\text { [Anywhere: } \\
\text { assistancell] } \\
\text { (Articles/Chapters - 0) }\end{array}$ & $\begin{array}{l}\text { Search results Items: } 0 \\
\text { "Mutual Disaster } \\
\text { Assistance" AND } \\
\text { "Anthropotechnology" (0) }\end{array}$ & $\begin{array}{l}\text { Resultados: } 0 \text {-utilizando } \\
\text { a palavra -Mutual } \\
\text { Disaster Assistancell } \\
\text { AND } \\
\text {-Anthropotechnologyll em } \\
\text { todos os índices }\end{array}$ & 0 \\
\hline 8 & -Antropotecnologiall & $\begin{array}{l}\text { No results found. Your } \\
\text { search was: } \\
\text {-Antropotecnologiall date: } \\
2007-2018\end{array}$ & $\begin{array}{l}0 \text { Document search } \\
\text { results TITLE-ABS-KEY } \\
\text { ("Antropotecnologia") } \\
\text { AND DOCTYPE (ar) AND } \\
\text { PUBYEAR > 2006 }\end{array}$ & $\begin{array}{c}\text { Results: } 0 \\
\text { search for: Topic: } \\
\text { (--Antropotecnologiall) Time } \\
\text { stipulated: } 2007-2018 .\end{array}$ & $\begin{array}{l}\text { [Anywhere: } \\
\text {-antropotecnologia } \\
\text { I] } \\
\text { (Articles/Chapters } \\
\text { - 0) }\end{array}$ & $\begin{array}{l}\text { Search results } \\
\text { Items: } \\
\text { "Antropotecnolgia" } \\
(0)\end{array}$ & Resultados: 3 & 3 \\
\hline \multirow[t]{2}{*}{9} & $\begin{array}{l}\text {-Plano de } \\
\text { Auxílio } \\
\text { Mútuoll }\end{array}$ & $\begin{array}{l}\text { No results found. Your } \\
\text { search was: -Plano de } \\
\text { Auxílio Mútuo" date: 2007- } \\
2018\end{array}$ & $\begin{array}{c}\text { 0 Document search } \\
\text { results TITLE-ABS-KEY (" } \\
\text { Plano de Auxílio Mútuo" } \\
\text { AND DOCTYPE (ar) AND } \\
\text { PUBYEAR > 2006 }\end{array}$ & $\begin{array}{c}\text { Results: } 0 \\
\text { search for: Topic: ("Plano de } \\
\text { Auxílio Mútuo") Time stipulated: } \\
\text { 2007-2018. }\end{array}$ & $\begin{array}{l}\text { [Anywhere: "Plano } \\
\text { de Auxílio Mútuo" } \\
\text { (Articles/Chapters - } \\
\text { 0) }\end{array}$ & $\begin{array}{l}\text { Search results Items: "Plano } \\
\text { de Auxílio Mútuo" (0) }\end{array}$ & Sem resulados & 0 \\
\hline & & & & Total & & & & 940 \\
\hline
\end{tabular}




\section{APÊNDICE D}

\section{Cidades do Paraná que possuem o PAM:}

\section{a) Município de Toledo}

O PAM de Toledo foi implantado em 29 de julho de 2014, contando com 14 empresas e a Guarda Municipal. Promove, portanto, reuniões mensais envolvendo todos os participantes. Devido ao tempo de formação e qualificação dos componentes, em 2017, adquiriram um contêiner para treinamentos de espaço confinado, combate a incêndio, melhorando cada vez mais a capacitação dos integrantes.

Foi estabelecido e criado um centro de treinamentos, onde pudesse trazer em tempo real, os ensinamentos entre a teoria e a prática dos treinamentos de resgate.

Foi o primeiro dos PAMs no Estado a conseguir um simulador (contêiner casa de fumaça), o que trouxe maior veracidade nos treinamentos oferecidos, aprimorando as técnicas de progressão realizadas no Corpo de Bombeiros, junto à comunidade do projeto. Havendo também investimentos nos -kit mínimosll, com roupas antifogo aprimoradas, e rádios de comunicação com melhor alcance.

As empresas a cada três meses, recebem a equipe do PAM (sem avisar), para realizar o check-list de todos os equipamentos como: mangueiras, kits, acionadores, EPIs, etc.

\section{b) Município de Araucária}

Um dos PAMs mais antigos do Estado, visto se mostrar extremamente necessário, após o evento ocorrido em 2002, com a REPAR (Refinaria de Petróleo da Petrobras) na região. Evento esse de grande monta, que envolveu riscos à vida para os colaboradores, terceiros, moradores da comunidade e destruição do meio ambiente.

Implantado em 18 de março de 2004, tendo como coordenador Ismael Pires, acompanhado pelo Tenente Bortolassi, e demais componentes. Possui 36 empresas 


\section{APÊNDICES}

parceiras, muitas delas do ramo petrolífero (refinarias), além do apoio da Polícia Rodoviária Federal, SAMU e agentes comunitários do município.

Conforme relatos das lideranças desse PAM, devido à situação econômica do país, houve muitas demissões, inclusive de participantes do projeto, no qual houve um desfalque de pessoal, sendo que os novos deverão passar por todos os processos iniciais para atingirem assim, o nível de conhecimento de todos.

$O$ atendimento emergencial é agregado a 1 grupo, que é composto por: Coordenação Geral, Corpo de Bombeiros, Defesa Civil, Grupos de Combustíveis, Grupos de Gás, e 3 subgrupos compostos por Empresas Transportadoras de Derivados de Petróleo.

$\mathrm{Na}$ busca de alinhar os conhecimentos entre todos os participantes citados acima, houve a necessidade de trazê-los à sala de aula, para fornecer capacitação em todos os aspectos, iniciando processos de conscientização sobre riscos humanos e ambientais que envolvem o polo industrial. Dentre os treinamentos, estão o de Instruções sobre Sistema de Comando de Incidente SCI e PSCIP (Plano de segurança contra incêndio e pânico). Os conceitos do Sistema de Comando de Incidentes são tão conectados, interligados, que pode ser difícil destacá-los e apresentá-los separadamente.

Profissionais com um bom nível de treinamento, conhecimento e experiência acharão este manual útil para todos os aspectos da resposta a emergência. Este manual foi produzido para subsidiar a confecção dos planos de contingências, planos de operações, protocolos, como ferramentas de treinamentos durante os exercícios e, mais importante, quando utilizado para responder a um incidente. (BIBLIOTECA MILITAR, 2017).

Devido ao grau de riscos oferecidos pelas empresas envolvidas, são ensinados e respeitados todos os principais protocolos de atendimentos emergenciais. Realizando simulados de combate a incêndio, simulado de acidente na rodovia PR-423 - (colisão ônibus com caminhão de produto químico) nas Distribuidoras de Combustíveis - treinando para possíveis incêndios nos tranques de óleo diesel. Reforçam, também, sobre a interação e debate entre os PAMs de todo o Estado, na busca de trocar experiências, dificuldades e possíveis ações na busca de uma melhoria continuada. 


\section{c) Município de São José dos Pinhais}

Formado em 25 de novembro de 2009, o PAM de São José dos Pinhais conta atualmente com 21 empresas atuantes, que para ser considerado membro, deve além de possuir o kit mínimo, participar de todos os treinamentos como: primeiros socorros; combate a incêndio; resgate em altura; simulados diversos; sistema de comando de incidentes.

O PAM está composto por Coordenadoria Estadual de Proteção e Defesa Civil (6ํㅡㄹ CORPDE); 60 Grupamento de Bombeiros do Paraná; Coordenadoria Municipal de Proteção e Defesa Civil (COMPDEC SJP) de São José dos Pinhais; Forças auxiliares (Instituições públicas prestadoras de apoio), e; Plano de Auxílio Mútuo (Empresas Signatárias PAM SJP), tendo como principais objetivos:

i) Contribuir e dar suporte ao PPDC - Plano Preventivo de Defesa Civil;

ii) Incentivar melhorias no grau de segurança das empresas;

iii) Promover a integração entre as empresas diante de possíveis sinistros;

iv) Alavancar desenvolvimento técnico e operacional das equipes;

v) Assegurar maior potencial de recursos materiais e humanos nas emergências;

vi) Reduzir o tempo-resposta dos recursos externos, e;

vii) Demonstrar compromisso social.

De acordo com 2º Seminário Técnico Científico De Prevenção E Proteção A Desastres (2017), as ações foram distribuídas por grupos de trabalho, tornando mais precisas e pontuais, envolvendo para tanto, controle documental sobre todos os protocolos necessários, também se torna de extrema necessidade, contatar novas empresas na busca de conscientiza-las e sobre a importância de sua participação, reintegrando aqueles que, por fatores adversos, deixaram de participar. Para tanto, existe um trabalho de divulgação implantado, utilizando os principais veículos de mídia digital, na busca de atualizar informações, e tornar conhecido de forma prática o projeto. 


\section{d) Município de Maringá}

O PAM de Maringá foi estabelecido e implantado em março de 2016, contando com 18 empresas atuantes, onde foram realizados, até esse momento, 5 simulados, tendo como principais objetivos:

— Integração entre o Corpo de Bombeiros e a Defesa Civil;

- Empresas participantes, conselhos municipais, associação comercial e industrial;

— Oferecer treinamentos contínuos;

- Valorização profissional;

— Respeito pela segurança, e;

- Fortalecimento das redes de voluntariado.

As atuações e treinamentos são fundamentados dentro do código de ética e conduta, de forma a valorizar todas as ações determinadas pelo grupo. O Corpo de Bombeiros atua como facilitador interagindo no primeiro contato entre as empresas e o PAM e, nos simulados, juntamente com a Coordenação da Defesa Civil.

Dentre as empresas participantes, estão: empresas de biodiesel (sucos, óleos e derivados), armazenadora de álcool, shoppings e outras. As reuniões e treinamentos acontecem bimestralmente. O PAM Maringá tem como objetivo aprovar o Projeto de Lei que regulamenta a necessidade do PAM no município, posteriormente, trazendo como pauta a aprovação do projeto em todo o Estado.

Missão: promover o investimento e cooperação, visando suplementar recursos humanos necessários para o atendimento de riscos a pessoas, patrimônio e ao meio ambiente; buscando mitigar os principais riscos.

Visão: reconhecimento junto à comunidade civil, atuando como fator público de credibilidade, profissionalismo e empreendedorismo. 


\section{e) Município de Cascavel}

Foi a cidade que sediou o 2ำ Seminário Técnico Científico de Prevenção e Proteção a Desastres, que aconteceu dia 30 e 31 de agosto de 2017. O PAM CASCAVEL (Plano de Auxílio Mútuo de Cascavel). Surgiu do impulso Institucional e Oficial do Comando do 4- Grupamento do Corpo de Bombeiros de Cascavel, tendo sua primeira reunião de esclarecimento e acolhimento das empresas, realizada em 24 de agosto de 2016, sendo comandado pelo Coronel Fábio.

Missão: promover a integração e cooperação das empresas de Cascavel no desenvolvimento de ações, visando suplementar recursos humanos e materiais necessários para apoiar com eficiência o atendimento de situações emergenciais com risco às pessoas, patrimônio e ao meio ambiente nas empresas integrantes e respectivas áreas de atuação.

Visão: ser reconhecido junto à sociedade civil e organismos públicos, como instituição de excelência, credibilidade, profissionalismo e empreendedorismo na atuação da Segurança Empresarial e Defesa Civil no município de Cascavel.

O PAM Cascavel conta com reuniões mensais envolvendo todos os participantes, seguindo calendário pré-estabelecido. São realizados conforme planejamento e calendário anual e tem como objetivo, a integração das empresas participantes com os demais órgãos nas situações de sinistros e emergências. Tem como objetivos:

- Integração entre os participantes;

- Troca de experiências e expertises;

- Capacitação e aprendizagem, tanto nos aspectos teóricos e conceituais quanto àqueles relacionados à efetiva prática frente às emergências e ou sinistros;

- Apoio referencial para adequação das empresas, e;

- Desenvolvimento de iniciativas direcionadas à atuação sustentável das empresas. 


\section{APÊNDICES}

Além dos treinamentos necessários sobre socorros e resgate, simulações de combate a incêndios, entre outros, foram executadas ações ambientais, visando à proteção do maior rio que corta e abastece toda a cidade.

O PAM de Cascavel esteve presente com as empresas participantes da $2^{\mathrm{a}}$ Ação de Conservação da Bacia do Rio Cascavel, realizada em 16/12/2016, na Bacia do Rio Cascavel. Além dos trabalhos junto à comunidade, participou da Semana do Meio Ambiente prestigiando e apoiando o Simulado do Atendimento a Produtos Perigosos, em 05 de junho de 2017.

O diferencial estratégico criado visa: a participação da comunidade acadêmica pública local, como membros participantes e efetivos do PAM; empresas integrantes do PAM participando do CEPED (Centro de Estudos e Pesquisas sobre Desastres da UNIOESTE). Visão e aplicação de conceitos de desenvolvimento sustentável no município e comunidades, sem perda do foco de proteção e mitigação do risco patrimonial e de segurança empresarial.

Como projetos futuros, buscam adquirir:

- Contêiner de fogo (casa de fumaça), concepção de mobiliário preparado de forma específica para o treinamento e capacitação das brigadas e equipes de combate a incêndio das empresas do PAMCascavel, e;

- Silo (confinamento) com intuito de simular eventos e treinar o resgate de trabalhadores, em espaços confinados, considerando que estas estruturas são de utilização frequente na região oeste e apresentam riscos de eventos de emergência.

Ações essas, que buscam oferecer suporte avançado em ações emergenciais que venham a ocorrer a qualquer um dos participantes, colaboradores, pessoas moradoras no entorno e subjacências das empresas.

Uma das participantes do PAM de Cascavel é uma Concessionária de Rodovias, a qual tem uma das filiais na cidade. Além da participação efetiva no PAM, ela possui participações junto à comunidade local, com inúmeras ações de cidadania, meio ambiente, saúde e segurança. 


\section{APÊNDICES}

As ações junto às comunidades existem em todas as demais filiais da concessionária, eventos como: o combate à exploração sexual infantil (nos postos de gasolina e portos), orientando os motoristas, turistas e demais pessoas, sobre as leis e rigores, além do principal: o cuidado e respeito às crianças. Inúmeros outros projetos têm ocorrido junto à comunidade abrangendo: escolas, creches, incentivo aos esportes, a eco cidadania, a sustentabilidade e a educação no trânsito.

\section{f) Município de Paranaguá}

Cidade portuária do Paraná, responsável por grande parte do escoamento da safra agrícola do país, importante complexo logístico de importação e exportação. A cidade comporta vários modais de transporte, sendo que também abriga as refinarias de petróleo, contando com terminais dutoviários, grandes tanques de combustíveis, sendo que a cidade fica cercada por essas empresas, além de grandes silos e armazéns, aumentando, dessa forma, o potencial de riscos à população.

A cidade já participou de vários eventos extraordinários envolvendo mortes, destruição, perigos e contaminação ao meio ambiente. Para tanto, o PAM Paranaguá conta com a participação de várias empresas, sendo destaque as ligadas ao setor petrolífero.

Liderado pelo Major Emmanuel (Especialista em Produtos Perigosos), o PAM de Paranaguá conta com uma visão aprimorada de treinamentos focados em desastres e ocorrências voltadas aos produtos químicos e inflamáveis. A atuação do PAM é de suma importância, visto que a população local (ex: Vila Becker, é rodeada por tanques das refinarias, não tendo área de escape, somente uma estrada que leva à saída da cidade). Segundo informações do Major responsável, a população, passa por estresse contínuo sempre que é acionada alguma sirene de emergência das empresas portuárias.

Foram organizadas as principais diretrizes das ações a serem tomadas em caso de eventos extraordinários, conforme a Figura 5. 
Figura 5 - Tomada de decisão em eventos adversos do PAM em Paranaguá

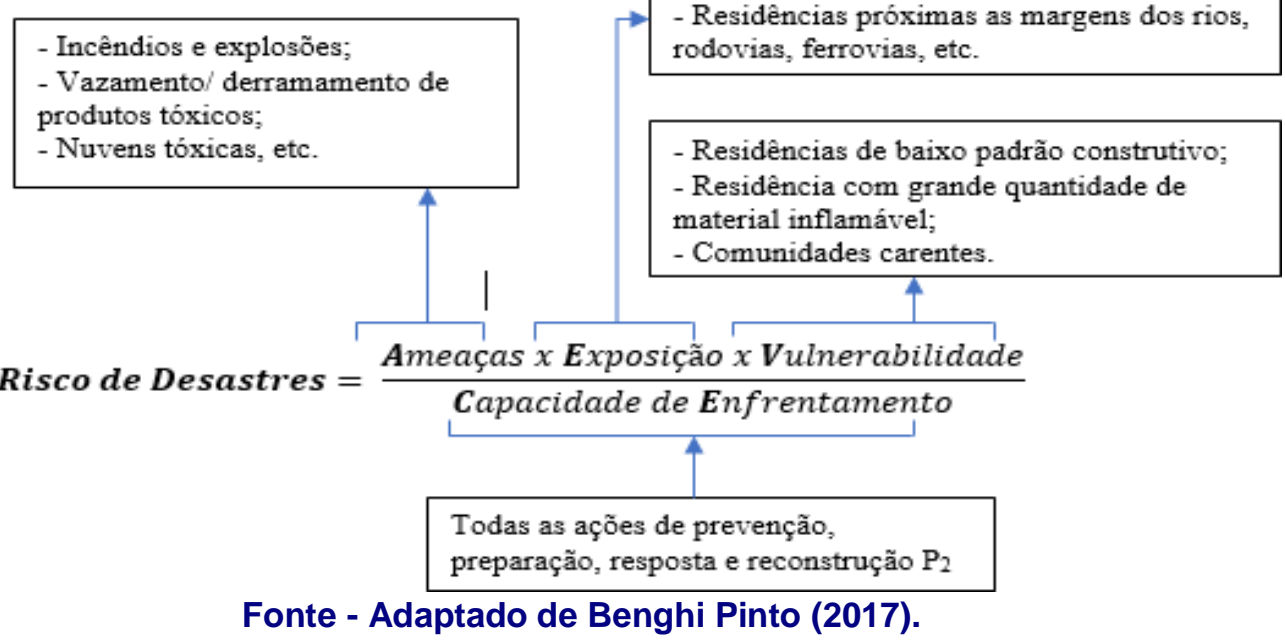

Tais ações têm como prioridade salvaguardar vidas, minimizando erros em possíveis vazamentos, contaminações e degradação do meio ambiente, e eventos que, anteriormente, aconteciam com maior frequência.

Segundo Benghi Pinto (2017) foram criados atualmente, zonas de controle de incidentes nas empresas, criando dois modelos, constituindo os seguintes objetivos:

- Sistema de Comando de Incidentes (SCI): busca implementar ferramenta de gestão emergencial (operacional e administrativa) de forma organizada, racional, modular, integrada e padronizada, e;

- Posto de Comando (PC) constituir o local de referência onde o Comando do Incidente exerce a gestão central, organizada e padronizada das ações, não permitindo confusões e conflitos.

Todas essas inovações buscam estabelecer mecanismos e formas mais ágeis oferecendo serviços de socorro e resgate com qualidade, de forma a primar pela vida, contando com a colaboração de empresas, colaboradores envolvidos no PAM e órgãos públicos, principalmente. 


\section{AUTORES}

\section{ROSÂNGELA DE FRANÇA BAIL}

Doutoranda em Engenharia de Produção UTFPR (externo), Mestre em Engenharia de Produção pela Universidade Tecnológica Federal do Paraná Campus Ponta Grossa; Pesquisadora e Antropotecnóloga em estudos voltados ao Homem, a Transferência do Conhecimento e Tecnologia e o Trabalho; Presidente do Projeto Plano de Auxílio Mútuo (PAM- PG) - Gestão em Desastres envolvendo o Corpo de Bombeiros, Multinacionais e colaboradores da área de prevenção, saúde e segurança do trabalho; Proprietária da empresa Kanija - Consultoria, Treinamento e Capacitação (envolvendo formação e capacitação nas áreas de: CIPA, SIPAT, NRs, Combate à Incêndio, Primeiros Socorros, Saúde e Segurança, Gestão e Desenvolvimento Humano); Especialista em Docência na Educação Profissional pelo Instituto de Desenvolvimento Federal do Paraná - Curitiba; Especialista em Gestão em Saúde pela Universidade Estadual de Ponta Grossa - PR; Especialista em Ciência e Tecnologia do Ensino Aprendizagem pela Universidade Tecnológica Federal do Paraná Campus - PR; Graduada em Administração Geral pela Faculdade Secal -;Santa Amélia Ponta Grossa - PR; Graduada em Educação Física pela Universidade Uniandrade de Ponta Grossa - PR; Docente da Pós-Graduação em Engenharia de Segurança do Trabalho CESCAGE - Ponta Grossa - PR; Docente da Pós-Graduação MBA em Gestão Estratégica de Pessoas - Faculdade Sagrada Família - Ponta Grossa - PR; Docente das Faculdades FATIFAJAR nas áreas de: Administração e Ciências Contábeis - Arapoti - PR; Docente em Administração, Contabilidade e Engenharias nas áreas: TGA, Logística, Gestão de Pessoas, Gestão de Processos, Economia Geral, Negociação e Negócios Internacionais, Custos de Produção, Saúde e Segurança no Trabalho e Ergonomia; Curso Técnico em Enfermagem e Socorrista/Resgatista atuando em acidentes em rodovias, hospitais e palestras 


\section{JOÃO LUIZ KOVALESKI}

\section{Bolsista de Produtividade Desen. Tec. e Extensão Inovadora do CNPq - Nível 1D}

Possui graduação em Engenharia Industrial Eletrônica pela Universidade Tecnológica Federal do Paraná (1986), graduação em Técnologo em Automação Industrial - Universite de Grenoble I (Scientifique Et Medicale - Joseph Fourier) (1985), mestrado em Informática Industrial pela Universidade Tecnológica Federal do Paraná (1988), DEA em Sistemas Eletrônicos no Institut Polithnique de Grenoble (INPG) e doutorado em Instrumentação Industrial - Universite de Grenoble I (Scientifique Et Medicale - Joseph Fourier) (1992). Atualmente é professor Titular da Universidade Tecnológica Federal do Parana - campus Ponta Grossa, editor das Revistas Gestão Industrial (Online) e Revista Innovare, e revisor das revistas RAI da PGT/USP. Tem experiência na área de Engenharia de Produção, com ênfase em Gestão Industrial, atuando principalmente nos seguintes temas: transferência de tecnologia, gestão industrial, agente de inovação, gestão do conhecimento e inovação tecnológica. Foi Diretor Geral do Campus Ponta Grossa da UTFPR por 8 anos. Vice-reitor por 4 anos da UTFPR. Foi Membro do Conselho Universitário da UTFPR por 12 anos. Atualmente 1- Presidente da APREPRO - Associação Paranaense de Engenharia de Produção. 2- Diretor de Relações Empresariais e Comunitárias da UTFPR. 3- Professor e Fundador do Mestrado/Doutorado em Engenharia de Produção.

\section{REGINA NEGRI PAGANI}

Doutora em Engenharia de Produção (UTFPR) com período sanduíche na UTC - Sorbonne Universités; Mestre em Engenharia de Produção (UTFPR); Especialista em Gestão Industrial (CEFET); Bacharel em Administração de Empresas (UEM); proficiente na Língua Inglesa pela Universidade de Miami (EUA). Foi Diretora Administrativa e Pedagógica na unidade do CCAA de Ponta Grossa; Professora Visitante na Universidade Estadual de Ponta Grossa (UEPG); Professora Visitante na Université de Tecnologie de Troyes (UTT), França; Professora na Faculdade União, Ponta Grossa; Professora de Pós-graduação na Faculdade de Telêmaco Borba (FATEB); Professora de Sociologia, Filosofia e Ética na Escola de Ministros Espírito e Verdade; é Professora Adjunta do Magistério Superior na Universidade Tecnológica Federal do Paraná, (UTFPR) e Chefe do Departamento Acadêmico de Engenharia de Produção (DAENP). Possui diversos artigos científicos publicados em eventos nacionais e internacionais, em periódicos nacionais e internacionais, e capítulos de livros no Brasil e no exterior. 


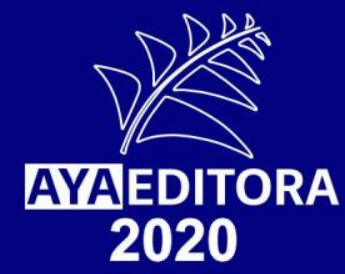

